\title{
ANÁLISE DE CORRESPONDÊNCIA NA IDENTIFICAÇÃO DE VARIÁVEIS ASSOCIADAS COM INTERVALO ENTRE PARTOS EM BOVINOS LEITEIROS
}

\author{
ARLEI COLDEBELLA \\ Médico Veterinário \\ Orientador: Prof. Dr. Décio Barbin \\ Dissertação apresentada à Escola Superior de \\ Agricultura "Luiz de Queiroz", Universidade de São \\ Paulo, para obtenção do título de Mestre em \\ Agronomia, Área de Concentração: Estatística e \\ Experimentação Agronômica.
}

P I R A C I C A B A

Estado de São Paulo - Brasil

Maio - 2000 
Dados Internacionais de Catalogaçāo na Publicação (CIP)

DIVISĀO DE BIBLIOTECA E DOCUMENTAÇĀO - Campus "Luiz de Oueiroz"/USP

\section{Coldebella, Arlei}

Análise de correspondência na identificação de variáveis associadas com intervalo entre partos em bovinos leiteiros / Arlei Coldebella. - Piracicaba, 2000.

104 p. : il.

Dissertação (mestrado) - - Escola Superior de Agricultura Luiz de Queiroz, 2000. Bibliografia.

1. Análise multivariada 2. Bovino leiteiro 3. Dados categóricos 4. Pós-parto animal Titulo

CDD 519.53

Termitida a cópia total ou parcial deste documento, desde que citada a fonte - 0 autor" 


\section{Agradecimentos}

Em pximeixa lugax, à Deus, pax pexmitix a fenalixaça de mais uma tarefa, passibilitando-me estax aqui, vivenda mais este momento impartante da minha vida, com muita alegria e satisfaçãa pax vex mais este txabatho finalizada, e pax tudo de bam que ele tem me xesexuada.

QHa $\mathscr{D}_{x}$. Décia Maxbin, pela oxientacãa sábia, segusxa e amiga, sempine disponivel, e cuja a expexiência e conhecimentos foxam de fundamental impoxtancia paxa a conclusão deste trabalho.

Dta professax Pauto Gustiniano Ribeixa Giniax, pela sua oxientação e amixade duxante a graduaçãa, hax sex a frimeixa pessoa que me incentivou a buscax um cuxsa de phs-gxaduação, e poxque, sem a ajuda dele, eu provarselmente não estaxia aqui conduindo este cuxso.

Qto Dx. Dabxiel Paxxies, pela sugestão do tema, acompanhamento no txabatho realizado e na busca de dados paxa estudo, e principalmente pela amizade a mim confexida.

DHa Dx. Paula Fexnando OMachado, pela prestera e amirade com que me recebueu, e pela disponibilixaçãa dos dadas do Laboxataxio de Fisiologia da Lactação (LAFLA), da Escola Olupexiax de exlgricultuxa "Luiz de Pueinax" (ESALQ), paxa estuda.

of'Dra. Regina Telia Caxvatho Pinto OHoxan, pelas sugestoes prestadas ao trabalho, na momenta opraxtuna, pexmitinda-me a conclusãa do meama.

OAlos colegas e amigos, pox todos os momentos vividas aqui em Pixacicaba, pois a tempo pode ate passax, mas as amixades de vexdade sempre poxmanecom.

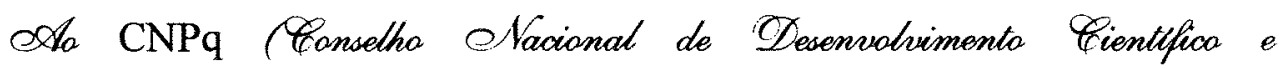
OFonolagioa), pela ajuda monetixia a mim conodida. 
A Ifamilia etthes, pax tex me recebida de bxacas abextos desde a primeixa instante, não medindo esfoxcos paxa que eu me sentisse sempre em casa de amigas, nessa jaxnada que agoxa se finda.

QA todos as professaxes da cusso, pela esmena e dedicaçãa em sempre ensinax, buscando a aprondixado conjunto, deisando aqui mencionada a Dra. Tlaxice Boxges Demétrio, eapureasãa de dedicação e conhecimento.

OHas funcionáxios do depaxtamento de Ciencias Exatas, que possibilitam a pexfeito

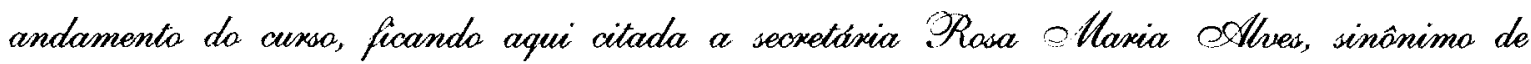
efuciência e dedicaçãa ao trabalha, que desde de a inicia mostrou-se uma amiga sincexa.

ef minha amiga, wizinha e colega, Laxa Hoffmann Maviex, hela amisade sincera, trabalho estudo conjuntos, desde as pximeinas dias do mestrado.

of professaxa Tra, pelo aprendirado prática a mim propaxcionado, e primaxdialmente, pela amizade e prestexa.

A minha DXtuxinha, meu amoxinha, eterna namoxada, pax tex me consolado nas hoxas mais diflecis, pax estax presente em todas as momentos, mesmo estando a $800 \mathrm{~km}$ de distancia, dedicanda todo seu amox e caxinha, e buscando entendex e campreendex todos os meus problemas.

OI minha familia, pxincipalmente meus pais, Dhomando e Louxdes, pela educaçãa a mim confexida com muito amox, e pax tex sempixe me incentivado nesta caminhada da vida, meito alsxigado.

Enfim, agradeca a todos, que dixeta ou indixetamente propiciaxam a realização deste txabatho, muithsima olexigado. 


\section{SUMÁRIO}

Página

RESUMO

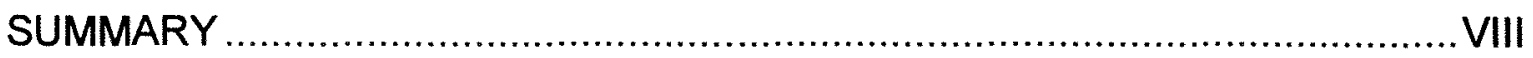

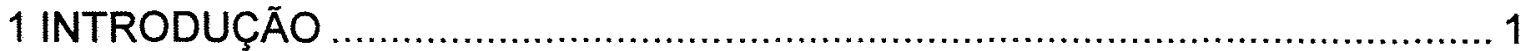

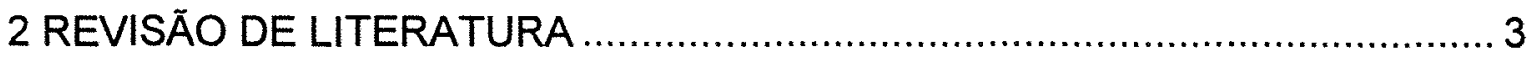

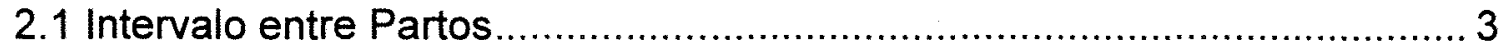

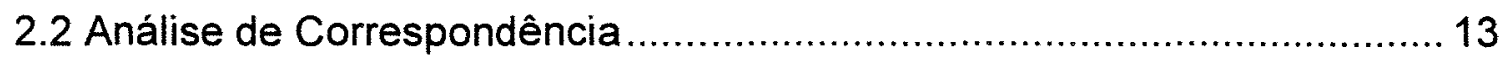

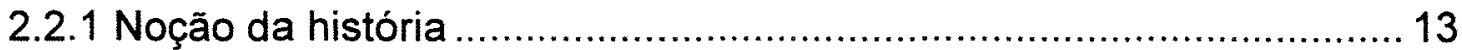

2.2.2 Objetivo da Análise de Correspondência ........................................ 14

2.2.3 Fundamentos teórico e algébrico do método .................................. 15

2.2.3.1 Tabela de contingência......................................................... 15

2.2.3.2 Matriz de freqüências relativas .............................................. 16

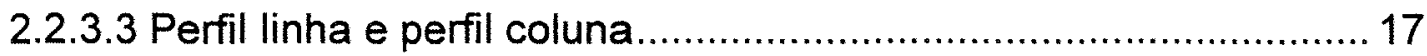

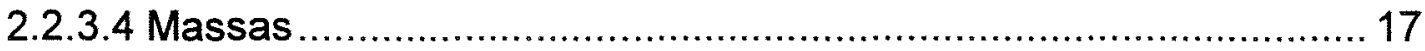

2.2.3.5 Centróide (ou Baricentro) ..................................................... 18

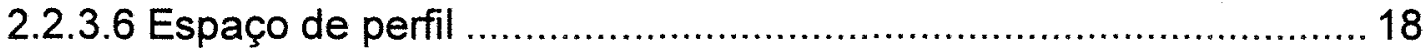

2.2.3.7 Estatística $X^{2}$, Distância $X^{2}$ e Inércia......................................... 19

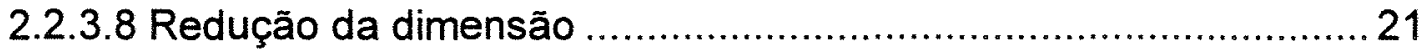

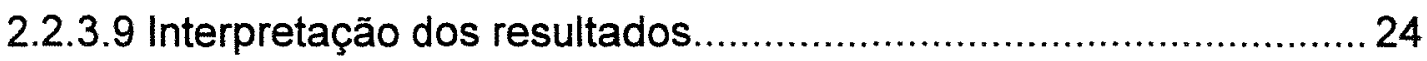

2.2.3.10 Reconstrução da tabela de contingência ................................... 28

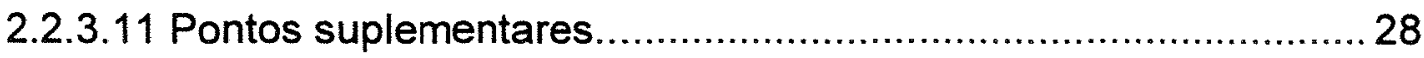

2.2.4 Análise de Correspondência de tabelas sobrepostas.......................29

2.2.5 Análise de Correspondência Múltipla ............................................. 29

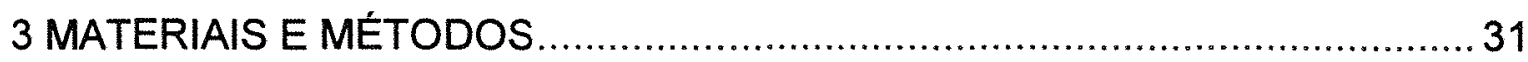

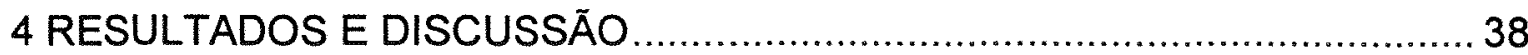


4.1 Categorização em 8 classes de igual amplitude .................................. 38

4.2 Categorização em 4 classes de igual freqüência ................................... 61

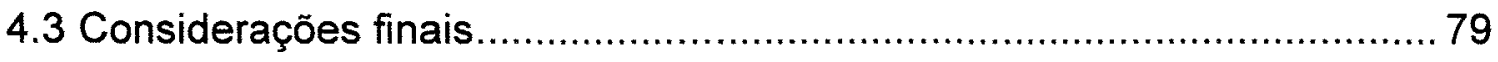

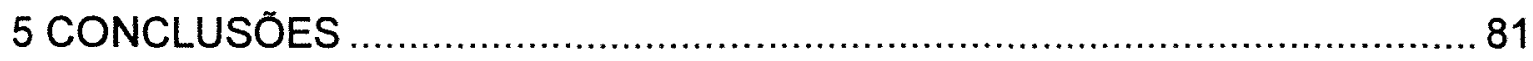

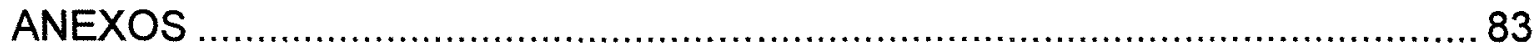

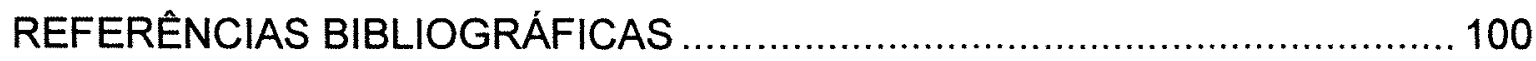




\title{
ANÁLISE DE CORRESPONDÊNCIA NA IDENTIFICAÇÃO DE VARIÁVEIS ASSOCIADAS COM INTERVALO ENTRE PARTOS EM BOVINOS LEITEIROS
}

\author{
Autor: ARLEI COLDEBELLA \\ Orientador: Prof. Dr. DÉCIO BARBIN
}

\section{RESUMO}

Este trabalho tem por objetivo fazer uma revisão de literatura buscando as técnicas e modelos utilizados na identificação de variáveis ou fatores associados com o intervalo entre partos (número de meses que separam as datas entre dois partos consecutivos), em bovinos leiteiros, bem como o de verificar a possibilidade de utilização da Análise de Correspondência para esse tema. Pela revisão bibliográfica, verificou-se que os autores utilizaram-se, na sua maioria, da análise de regressão múltipla, da análise de variância ou da análise de covariância com vistas a identificar quais os fatores que estão associados a essa variável. Para verificar a possibilidade de utilização da Análise de Correspondência, disponibilizaram-se informaç̃es através de parceria entre 0 Departamento de Ciências Exatas (DCE) e o Laboratório de Fisiologia da Lactação (LAFLA), ambos da Escola Superior de Agricultura "Luiz de Queiroz", Universidade de São Paulo, sendo que o primeiro proveu suporte técnico para a análise dos dados e o segundo forneceu os dados para estudo. Foram analisadas 2102 observações e 12 variáveis, incluindo o intervalo entre partos. A Análise de Correspondência foi aplicada para duas formas de categorização das variáveis quantitativas contínuas (variáveis categorizadas em 8 classes de igual amplitude e variáveis categorizadas em 4 classes de igual freqüência), e de três maneiras diferentes: 1) Análise de Correspondência de tabelas sobrepostas considerando a variável Intervalo entre Partos como "variável resposta" e as demais como "variáveis explicativas", exceção feita à variável Reprodutor, que foi considerada como suplementar; 2) Análise de Correspondência Múltipla, considerando as 
"variáveis explicativas" (todas as variáveis, exceto Reprodutor) como ativas na análise e a variável Intervalo entre Partos como suplementar ou ilustrativa; 3) Análise de Correspondência Simples, para o cruzamento da variável Reprodutor com a variável Intervalo entre Partos. As principais conclusões obtidas foram que: a) A análise de correspondência, principalmente de tabelas sobrepostas, mostrou-se uma ferramenta eficiente quando se trata de analisar dados observacionais, onde o interesse é verificar as associações entre "variáveis resposta" e "variáveis explicativas", como no presente caso; b) A categorização em 8 classes de igual amplitude para as variáveis quantitativas contínuas mostrou-se mais discriminatória na análise de tabelas sobrepostas, isto é, discriminou mais variáveis como associadas com o intervalo entre partos do que a categorização em 4 classes de igual freqüência; c) A análise de correspondência múltipla não foi suficientemente discriminatória para o fenômeno em estudo; d) As variáveis Dias em Lactação, Número de Inseminações, Produção de Leite por Dia de Intervalo entre Partos e Reprodutor (efeito genético), estão associadas com o intervalo entre partos, e que outras variáveis como Ano do Parto Anterior e Estação do Ano ao Parto Anterior estão mais fracamente associadas ao intervalo entre partos; e) Pelos resultados obtidos, o Intervalo entre Partos menor ou igual a 13 meses é o desejável nas condições do presente trabalho; 


\section{CORRESPONDENCE ANALYSIS IN THE IDENTIFICATION OF VARIABLES ASSOCIATED WITH CALVING INTERVAL IN DAIRY CATTLE}

Author: ARLEI COLDEBELA Adviser: Prof. Dr. DÉCIO BARBIN

\section{SUMMARY}

The objective of this dissertation is to review the literature about techniques and models used in the identification of variables or factors associated with the Calving Interval (number of months between two consecutive calvings), in dairy cattle, and to verify the possibility of the using correspondence analysis. Through the literature review it was found that the majority of the authors had used multiple analysis of regression, analysis of variance or analysis of covariance to identify those factors directly associated with this variable. To demonstrate (verify) the possibility of using correspondence analysis, information was available through a partnership between the Departamento de Ciências Exatas (DCE) and the Laboratório de Fisiologia da Lactação (LAFLA), of the Escola Superior de Agricultura "Luiz de Queiroz", Universidade de São Paulo, the first being responsible for the technical support of the data analysis, and the second providing the data for the study. In all 2102 observations and 12 variables, including the calving intervals, were analyzed. The correspondence analysis was applied in two ways to categorize the continuous quantitative variables (variables categorized into 8 classes of the same amplitude and variables categorized into 4 classes with equal frequency), and in three different ways: 1) Correspondence analysis of tables superimposed, considering the Calving Interval as a "dependent variable" and the rest as "explanatory variables", except the variable "Sire", considered as a supplementary variable; 2) Multiple Correspondence Analysis, considering the "explanatory variables" (all the variables, except "Sire") as active in the analysis and the variable "Calving 
Interval" as a supplementary or elucidative; 3) Simple Correspondence Analysis, for the cross between the variables Sire and Calving Interval. The main conclusions obtained were: A) the Correspondence Analysis, principally using the superimposed tables, is demonstrated to be an efficient instrument to analyze data from observations, where the objective is to verify the associations between the dependent and explanatory variables, as it was in the present study; b) the categorization into 8 classes with the same amplitude for the continuous quantitative variables was more discriminatory in the analysis of superimposed tables, that is, discriminates more variables associated with Calving Intervals than the categorization in 4 classes with equal frequency; c) the multiple correspondence analysis didn't discriminate enough in relation to the phenomenon we were studying; d) the variables Breastfeeding Days, Number of inseminations, Milk Production per Day during Calving Intervals and Sire (genetic effect), are associated with the Calving Interval, and other variables like Year of the Previous Calving and Season of the Year of the Previous Calving are associated more weakly with Calving Interval; e) observing the results obtained, Calving Interval less than or equal to 13 months is desirable under the conditions of the present study. 


\section{INTRODUÇÃO}

Com o advento da globalização, as informações são geradas e difundidas rapidamente pelo mundo todo, levando as pessoas e empresas a serem mais competitivas em praticamente todos os níveis. A busca de conhecimentos tornou-se algo indispensável a todos, seja para gerenciar negócios, ou simplesmente gerenciar a própria vida como um todo.

No contexto da globalização, uma variável muito importante em bovinocultura leiteira, o intervalo entre partos, merece especial atenção, pois pode significar a sobrevivência, ou não, do agropecuarista na atividade, porque além de influenciar o número de crias por ano, pode também ter influência na produção leiteira, sendo essas as principais variáveis na determinação do resultado econômico da atividade. Por isso, tem importância o estudo das variáveis associadas com o intervalo entre partos, com o intuito de identificá-las e efetuar, posteriormente, as devidas correções na busca de uma melhor performance do rebanho.

Este trabalho tem por objetivo fazer uma revisão de literatura buscando as técnicas e modelos utilizados na identificação de variáveis ou fatores associados com o intervalo entre partos em bovinos leiteiros, bem como o de verificar a possibilidade de uso de uma nova metodologia para esse tema, a Análise de Correspondência.

A Análise de Correspondência é uma técnica multivariada de análise gráfica, onde se busca encontrar a relação existente entre as categorias de linhas e colunas de uma tabela de contingência, tornando-se aqui uma importante ferramenta, pois, apesar de as observações da variável intervalo entre partos serem dados contínuos, 
muitas das variáveis que podem estar associadas a ela são de origem discreta ou qualitativa.

A Análise de Correspondência é utilizada nas mais variadas áreas, tais como sociologia, ecologia, paleontologia, arqueologia, geologia, educação, medicina, lingüística, pesquisa de mercado, ciências agrárias, estudos religiosos, arte, música, epidemiologia e outras segundo Barioni Júnior (1995), e pode ser uma metodologia interessante a ser aplicada nessa área com o intuito de identificar variáveis associadas com o intervalo entre partos.

Este trabalho, além de dar outra ênfase ao estudo da variável Intervalo entre partos, poderá gerar informações importantes no que tange à Análise de Correspondência em aplicações em ciências agrárias. 


\section{REVISÃO DE LITERATURA}

Dividiu-se a revisão de literatura em duas partes para melhor compreensão do problema. Na primeira parte discutiram-se sucintamente alguns artigos relacionados ao tema intervalo entre partos', enquanto que na segunda parte apresentou-se resumidamente a metodologia de Análise de Correspondência.

\subsection{Intervalo entre Partos}

$\mathrm{Na}$ prática, vários foram os autores que se ativeram ao tema intervalo entre partos em bovinos leiteiros, porém, esses utilizaram-se, na sua maioria, da análise de variância, análise de regressão múltipla ou análise de covariância no intuito de verificar quais os fatores que estão associados a essa variável, deixando de lado a metodologia de Análise de Correspondência. Neste item, far-se-á, portanto, uma descrição e discussão de alguns artigos relacionados ao tema, com a finalidade de mostrar como é procedido o estudo dessa variável.

Em 1976, Slama et al., analisando dados de 696 intervalos entre partos de 370 vacas de quatro raças (Ayrshire, Holandês, Jersey e Guernsey), do rebanho leiteiro da Universidade do Estado de Oklahoma, utilizaram a análise de variância de mínimos quadrados dentro de cada raça para estimar os efeitos relativos das seguintes variáveis sobre o intervalo entre partos: 1) dias entre o parto e o primeiro serviço; 2) dias entre o primeiro serviço e a concepção; 3) serviços por concepção; 4) mês do primeiro serviço;

${ }^{1}$ Define-se intervalo entre partos como o período de tempo, geralmente em meses, entre dois partos consecutivos. 
5) mês da concepção; 6) mês do parto; 7) ano do parto (1968 a 1974); 8) idade ao parto e 9) pico de lactação. O modelo geral utilizado é como segue:

$$
Y_{i j}=\mu+C_{i}+L_{j}+\beta_{1} X_{i j}+\ldots+\beta_{9} X_{9 i j}+e_{i j},
$$

onde: $\mu$ representa a média geral, $C_{i}$ é o efeito da i-ésima vaca, $L_{j}$ é o efeito da j-ésima lactação, $\beta_{1}$ até $\beta_{9}$ são os coeficientes de regressão parcial do intervalo entre partos sobre as variáveis independentes, e $\mathrm{e}_{\mathrm{ij}}$ representa o erro aleatório.

Para maior eficiência no tratamento dos dados, as estimativas de mínimos quadrados de $\mathrm{C}_{\mathrm{i}}$ e $\mathrm{L}_{j}$ para esse modelo, foram primeiro calculadas da forma como segue:

$$
Y_{i j}=\mu+C_{i}+L_{j}+Z_{i j} \text {, }
$$

onde $Z_{i j}=\beta_{1} X_{1 i j}+\ldots+\beta_{9} X_{9 i j}+e_{i j}$. Assim, os efeitos fixos de $C_{i}$ e $L_{j}$ foram obtidos e $Y_{i j}-\hat{Y}_{i j}=Z_{i j}$ foi gerado. Essa nova variável, $Z_{i j}$, foi utilizada para estimar os valores de $\beta$ nesta última equação. Este procedimento computacional não estimou a duração do intervalo entre partos; no entanto, estimou o efeito de uma mudança em uma das variáveis sobre a mudança no intervalo entre partos. A regressão múltipla "stepwise" foi, então, utilizada para examinar e avaliar a significância $(\mathrm{P}<0,10)$ de todas as variáveis em explicar a variação no intervalo entre partos. Os coeficientes de correlação parcial, ajustados para vaca e lactação, foram calculados para estudar a relação entre as variáveis.

Pela análise das constantes ajustadas, Slama et al.(1976), concluíram que os intervalos do parto ao primeiro serviço, do primeiro serviço até a concepção e o número de serviços por concepção foram os fatores que mais afetaram o intervalo entre partos, o que na realidade seria esperado, pois esses estão intimamente ligados ao tempo de intervalo entre partos. Observaram, também, que mês de parto, mês de concepção, ano de parto, idade ao parto e pico de lactação não tiveram efeito significativo sobre a média do intervalo entre partos. Note-se, porém, que nessa época a dificuldade no cálculo computacional fazia com que os pesquisadores buscassem formas variadas e inteligentes de analisar os dados, o que não garante a validade dos resultados, pois como qualquer modelo de análise de variância, certas suposições devem ser atendidas para garantir a validez da análise. 
Posteriormente, Viana et al. (1980), estudando a influência de alguns fatores de meio no intervalo entre partos de um rebanho da raça Gir, na Fazenda da Mata, município de Ipameri, no Estado de Goiás, analisaram dados de 1033 intervalos entre partos, utilizando análise de regressão múltipla, método "stepwise", e o seguinte modelo:

$$
\begin{aligned}
Y_{i j k l m p q}= & \beta_{0}+\beta_{1} M_{i}+\beta_{2} A_{j}+\beta_{3} S_{k}+\beta_{4} I_{1}+\beta_{5} C_{m}+\beta_{6} \Phi_{p}+\beta_{7} M_{i}^{2}+\beta_{8} A_{j}^{2}+\beta_{9} \Phi_{p}^{2}+ \\
& +\beta_{10} M_{i}^{3}+\beta_{11} M_{i} \Phi_{p}+\beta_{12} M_{i}^{2} \Phi_{p}+\beta_{13} M_{i} \Phi_{p}^{2}+\beta_{14} M_{i}^{2} \Phi_{p}^{2}+\varepsilon_{i j k l m p q}
\end{aligned}
$$

onde:

$\mathrm{Y}_{\mathrm{ijklmpq}}$ : intervalo entre partos do animal q sob as condições ijklmp;

$\beta_{0} \quad$ : intersecção;

$\beta_{1}$ a $\beta_{14}$ : coeficiente de regressão relativo a cada variável;

$\mathrm{M}_{\mathrm{i}} \quad$ : mês do parto anterior, $\mathrm{i}$ variando de 1 a 12;

$\mathrm{A}_{\mathrm{j}} \quad$ : ano do parto anterior, $\mathrm{j}$ variando de 1961 a 1978;

$\mathrm{S}_{\mathrm{k}} \quad$ : sexo da cria, $\mathrm{k}$ igual a 1 e 2: 1 para masculino e 2 para feminino;

$\mathrm{I}_{\mathrm{l}} \quad$ : idade ao primeiro parto, 1 variando de 24 a 60 meses;

$\mathrm{C}_{\mathrm{m}} \quad$ : manejo de cobrição, $\mathrm{m}$ igual a 1 e 2: 1 para manejo anterior a 1970 (touros eram soltos com as fềmeas) e 2 para período posterior (monta controlada);

$\Phi_{\mathrm{p}} \quad$ : ordem de parição, p variando de 1 a 12;

$\varepsilon_{\mathrm{ijklmpq}}:$ erro experimental do animal $q$, sob as condições ijklmp.

Obtiveram efeitos significativos para as seguintes variáveis:

a) Ano do parto anterior, determinando uma curva quadrática, com o ponto de máximo correspondendo ao ano de 1970, sendo a curva quadrática explicada, provavelmente, pelas mudanças no manejo reprodutivo e no nível alimentar das vacas durante o período de estudo;

b) Mês de parto anterior, determinando uma curva cúbica, com o menor intervalo correspondendo ao mês de abril e o maior ao mês de setembro, 
sendo essa configuração devida, possivelmente, ao nível nutricional das vacas no pré-parto;

c) Ordem de parto, com efeito quadrático e ponto de mínimo correspondendo à sétima ordem;

Nesse artigo, não se sabe se as pressuposições do modelo de análise de regressão para a realização dos testes são atendidas, o que pode por em dúvida os resultados obtidos.

Empregando a análise de variância para a estudo dos dados, Costa et al. (1982), utilizaram informações relativas ao período de 1968 a 1979, obtidas de fichas individuais de vacas Holandesas, variedade preta e branca, puras de origem e puras por cruzamento, da Fazenda São Judas Tadeu, localizada em Betim, Minas Gerais, e o seguinte modelo:

$$
Y_{i j k l m}=\mu+A_{i}+E_{j}+O_{k}+R_{l i}+e_{i j k l m},
$$

onde:

$Y_{\mathrm{ijlkm}}$ : intervalo entre partos observado na vaca $\mathrm{m}$, filha do reprodutor 1 , na ordem de parto k, na estação j e no ano i;

$\mu \quad$ : efeito comum a todas as observações;

$A_{i} \quad$ : efeito do ano de parto prévio, sendo $\mathrm{i}=68,69, \ldots, 79$;

$E_{j} \quad$ : efeito da estação de parto prévio, sendo $\mathrm{j}=1,2,3,4$;

$\mathrm{O}_{\mathrm{k}} \quad$ : efeito da ordem de parto, sendo $\mathrm{k}=1,2, \ldots, 7$;

$\mathrm{R}_{\mathrm{li}} \quad$ : efeito de reprodutor 1 , dentro do ano $\mathrm{i}$, sendo $\mathrm{l}=1,2, \ldots, 10$;

$\mathrm{e}_{\mathrm{ijklm}}$ : erro aleatório associado a cada observação.

Observaram efeito significativo apenas para ano de parto.

Para este artigo também ficam as perguntas: as suposições do modelo de análise de variância para a realização dos testes foram atendidas? Será que o efeito do erro está bem estimado? E se mais fatores estivessem disponíveis para estudo, será que outros efeitos não seriam significativos?

Outros autores, tais como Mejía et al. (1982), Madalena et al. (1983), Ribas et al. (1983), Nobre et al. (1984), Queiroz et al. (1986), Basile et al. (1989) e 
Teixeira et al. (1994), utilizaram a análise da variância para o estudo da variável intervalo entre partos, considerando diversos fatores no modelo, bem como interação desses fatores, obtendo resultados variáveis. Boa parte desses autores utilizaram o método de mínimos quadrados descrito por Harvey (1975) para análise da variância. A herdabilidade do intervalo entre partos também foi estimada por alguns desses autores, incluindo o efeito de reprodutor no modelo. Obtiveram herdabilidades variando de 0,12 a 0,24 (Mejía et al. (1982) e Queiroz et al. (1986), respectivamente). A repetibilidade da variável foi estimada por alguns desses autores, incluindo o efeito de vaca no modelo de análise da variância.

Exemplificando um caso de análise de covariância, tem-se Ribas et al. (1996), analisando dados obtidos junto à Associação Paranaense de Criadores de Bovinos da Raça Holandesa, provenientes de vacas dos rebanhos associados à Cooperativa Agropecuária Witmarsum Ltda., com sede no município de Palmeiras, Estado do Paraná. Empregaram para as análises estatísticas dos dados, o método de mínimos quadrados, utilizando o "General Linear Model" (GLM), do programa SAS (Statistical Analysis System), e o seguinte modelo matemático:

$$
\begin{gathered}
Y_{i j k l m n o p}=m+R_{i}+A_{j}+E_{k}+G_{1}+L_{m}+O_{n}+T_{n o}+v_{i l m n o p}+b_{1}\left(I_{i j k l m n o p}-\bar{I}\right)+ \\
+b_{2}\left(I_{i j k l m n o p}-\bar{I}\right)^{2}+e_{i j k l m n o p},
\end{gathered}
$$

onde:

$\mathrm{Y}_{\mathrm{ijklmnop}}$ : intervalo entre partos observado;

m : constante geral;

$R_{i} \quad$ : efeito fixo do rebanho $i$, sendo $i=1,2, \ldots, 48$;

$A_{j} \quad$ : efeito fixo do ano de parto $\mathrm{j}$, sendo $\mathrm{j}=1983,1984, \ldots, 1992$;

$E_{k}$ : efeito fixo da estação de parto $k$, sendo $k=1$ (dez-jan-fev), 2(mar-abr-maio), 3(jun-jul-ago) e 4(set-out-nov);

$\mathrm{G}_{\mathrm{l}} \quad$ : efeito fixo do grupo genético $\mathrm{l}$, sendo $\mathrm{l}=1(\mathrm{PO}), 2(\mathrm{GHB}), 3(31 / 32), 4(\mathrm{GC} / 1)$, 5(GC/2), 6(GC/3), 7(GC/4), 8(GC/5) e $9(\geq \mathrm{GC} / 6)$;

$L_{m} \quad$ : efeito da ordem de lactação $m$, sendo $m=1,2, \ldots, \geq 7$; 
$\mathrm{O}_{\mathrm{n}}$ : efeito da origem do reprodutor $\mathrm{n}$, sendo $\mathrm{n}=1(\mathrm{BRA} / \mathrm{IA}), 2(\mathrm{BRA} / \mathrm{MN})$, 3(EUA/IA), 4(CAN/IA) e 5(ALE/IA);

$\mathrm{T}_{\mathrm{no}} \quad$ : efeito do reprodutor $\mathrm{o}$, dentro da origem do reprodutor $\mathrm{n}$, sendo $\mathrm{o}=1,2, \ldots$, 232 ;

$V_{\text {ilmnop }}$ : efeito da vaca $p$, dentro do rebanho $i$, do grupo genético 1 , da ordem de lactação $\mathrm{m}$, da origem do reprodutor $\mathrm{n}$ e do reprodutor $\mathrm{o}$, sendo $\mathrm{p}=1,2, \ldots, 993$;

$b_{1}$ e $b_{2}$ : coeficientes de regressão linear e quadrático da característica $Y_{i j k l m n o p}$, considerando o período de lactação, em dias;

$\mathrm{I}_{\mathrm{ijklmnop}}$ : periodo de lactação, em dias, usado como covariável;

I : : média do período de lactação, em dias;

$\mathrm{e}_{\mathrm{ijk} k \mathrm{mnop}}$ : erro aleatório associado a cada observação $\mathrm{Y}_{\mathrm{ijk} \text { mnop. }}$

Observaram que os efeitos do rebanho, do ano de parto, da ordem de lactação, do reprodutor dentro de origem e da vaca dentro de rebanho influenciaram significativamente o intervalo entre partos, assim como, o efeito quadrático do período de lactação.

Para esse artigo, ficam as mesmas perguntas do artigo relacionado à análise da variância.

Autores como: Freitas et al. (1980), Ramos (1986), Polastre et al. (1987), Cardoso et al. (1987), Milagres et al. (1988), Ribas et al. (1988), Souza et al. (1995) e Pimpão et al. (1995), utilizaram também a análise de covariância para o estudo dos dados, considerando diversos fatores no modelo, bem como interação desses fatores, obtendo resultados variáveis. O método de mínimos quadrados descrito por Harvey (1975) para análise da variância foi utilizado por vários desses autores. A herdabilidade do intervalo entre partos também foi estimada por alguns desses autores, incluindo o efeito de reprodutor no modelo. Obtiveram herdabilidades variando de 0,05 a 0,20 (Cardoso et al. (1987) e Ramos (1986), respectivamente). Incluindo o efeito de vaca no modelo de análise de covariância, alguns desses autores estimaram a repetibilidade para a variável. 
Tem-se ainda, que de todos os artigos pesquisados, o único em que um experimento foi instalado para estudar o intervalo entre partos é de Mcgowan et al. (1996), onde os mesmos averiguaram os fatores potenciais que influenciam o desempenho reprodutivo num rebanho leiteiro de alta produção da raça Holandesa. Para tal, utilizaram dois grupos genéticos: uma linha de seleção (S) consistindo de novilhas e vacas com o mérito genético superior para $\mathrm{kg}$ de gordura e proteína, e uma linha de controle (C) consistindo de novilhas e vacas com mérito genético médio para $\mathrm{kg}$ de gordura e proteína. Dentro de cada grupo, as novilhas e vacas foram aleatoriamente designadas para uma dieta completa de alto concentrado (HC: quantidade média anual de aproximadamente 2,5 toneladas por vaca) ou baixo concentrado (LC: quantidade média anual de aproximadamente 1,0 tonelada por vaca), baseada em silagem de capim, grãos fermentados e concentrados.

Os pesos corporais e escores para a condição corporal foram selecionados para vários estágios chaves da lactação para cada animal, incluindo o peso vivo médio durante as 26 primeiras semanas de lactação ( $\mathrm{LW}$ ), peso vivo ao parto (CLW), peso vivo 10 semanas após o parto (PLW), escore médio para condição corporal durante as primeiras 26 semanas de lactação (CS), escore para condição corporal ao parto (CCS) e escore para condição corporal 10 semanas após o parto (PCS). Calcularam também as mudanças no peso ou no escore para condição corporal durante as 10 primeiras semanas de lactação ( $\triangle \mathrm{LW}$ e $\Delta \mathrm{CS}$, respectivamente). Para suavizar algum erro na medida de peso vivo, estimaram o peso às 10 semanas de uma equação polinomial cúbica ajustada através de todas as 26 medidas de peso semanais para cada animal separadamente. A produção de leite $(\mathrm{MY}, \mathrm{kg})$ foi a produção somada durante as primeiras 26 semanas, extrapolada dos registros de 2 a 26 semanas após o parto.

Utilizaram o método da Máxima Verossimilhança Restrita (REML) para estimar os efeitos médios para dieta e linha genética. Para tal criaram dois conjuntos de dados para estimar os efeitos nas novilhas separadamente dos efeitos nas vacas. Testaram os efeitos dos fatores utilizando a Estatística de Wald para calcular os níveis de 
significância, ajustando o último efeito de interesse no modelo. Utilizaram os modelos que se seguem:

Modelo 1:

$Y_{\mathrm{ijklm}}=\mathrm{U}+\mathrm{Y}_{\mathrm{i}}+\mathrm{M}_{\mathrm{j}}+\mathrm{DIET}_{1}+\mathrm{LINE}_{\mathrm{m}}+\mathrm{DIET}_{1} \times \mathrm{LINE}_{\mathrm{m}}+\mathrm{b}_{1} \mathrm{AC}_{\mathrm{ijklm}}+\mathrm{C}_{\mathrm{ijklm}}+\mathrm{E}_{\mathrm{ijklm}}$,

Modelo 2:

$$
\begin{aligned}
\mathrm{Y}_{\mathrm{ijklm}}= & \mathrm{U}+\mathrm{Y}_{\mathrm{i}}+\mathrm{M}_{\mathrm{j}}+\mathrm{DIET}_{1}+\mathrm{LINE}_{\mathrm{m}}+\mathrm{DIET}_{1} \times \mathrm{LINE}_{\mathrm{m}}+ \\
& +\mathrm{b}_{1} \mathrm{AC}_{\mathrm{ijklm}}+\mathrm{b}_{2} \mathrm{X}_{\mathrm{ijklm}}+\mathrm{C}_{\mathrm{ijk \textrm {j } m}}+\mathrm{E}_{\mathrm{ijklm}},
\end{aligned}
$$

onde:

$\mathrm{Y}_{\mathrm{ijklm}} \quad$ : intervalo entre partos;

$\mathrm{U} \quad$ : média geral;

$Y_{i} \quad$ : ano de parto $(1988,1989,1990,1991) ;$

$\mathrm{M}_{\mathrm{j}} \quad$ : mês de parto (Set, Out, Nov, Dez);

$\mathrm{b}_{1} \mathrm{AC}_{\mathrm{ijk} k \mathrm{~m}}$ : regressão linear sobre a idade ao parto em dias;

DIET $_{1}$ : efeito da dieta (concentrado e forragem);

$\operatorname{LINE}_{\mathrm{m}}$ : efeito da linha genética (seleção ou controle);

$\mathrm{C}_{\mathrm{ijk} / \mathrm{m}} \quad$ : efeito aleatório de vaca;

$\mathrm{E}_{\mathrm{ijklm}} \quad$ : efeitos residuais;

$\mathrm{b}_{2} \mathrm{X}_{\mathrm{ijklm}}$ : regressão sobre $\mathrm{X}(\mathrm{MY}, \mathrm{CLW}, \Delta \mathrm{LW}, \mathrm{LW}, \mathrm{CCS}, \Delta \mathrm{CS}$ e CS).

Concluiram que somente o efeito de dietas foi significativo para as novilhas, sendo que as alimentadas com dieta de alto concentrado tiveram intervalos entre partos significativamente mais longos do que aquelas alimentadas com dieta de baixo concentrado. Os outros efeitos não foram significativos nem para novilhas e nem para vacas. Nas vacas, a produção de leite foi positivamente correlacionada com o intervalo entre partos e, o escore médio para condição corporal das vacas durante as primeiras 26 semanas de lactação foi negativamente correlacionado ao intervalo entre partos.

Mesmo para este artigo, onde um experimento foi instalado, podem-se fazer as mesmas perguntas referentes aos artigos anteriores, pois devido ao longo período 
que separa um parto do outro, fica dificultado qualquer controle de ambiente que se possa fazer em relação às vacas, e portanto, outras variáveis não disponíveis para estudo podem estar associadas ao intervalo entre partos ficando assim o efeito do erro superestimado, dificultando, portanto, a detecção de efeitos significativos.

Tomando-se por base os artigos aqui relatados e para melhor visualização dos fatores estudados, bem como, da influência, ou não, destes fatores no intervalo entre partos, montou-se um quadro resumo, o qual se encontra na Tabela 1.

Verifica-se que o fator que mereceu maior atenção pelos pesquisadores da área foi o ano do parto, o que na realidade é uma incoerência, pois qual o sentido de saber que o ano do parto teve influência no intervalo entre partos? $\mathrm{O}$ ano já passou e não volta mais e, além disso, o efeito do ano pode estar confundido com efeito de outros fatores. Logo, o que interessaria mais, seria identificar o que aconteceu dentro de cada ano: manejo, alimentação, doenças, entre outros. Outras variáveis também estudadas com grande ênfase, foram: estação do ano ao parto, ordem de lactação ou ordem de parto, grupo genético e reprodutor; e dentre estas, a que mais teve influência no intervalo entre partos foi o efeito de reprodutor, seguida por ordem de lactação e estação do ano.

Tem-se, outrossim, pela Tabela 1 que o fator rebanho foi estudado seis vezes, sendo cinco vezes significativo, então também é uma importante causa de variação no intervalo entre partos, porém, da forma como foi estudado, não se podem identificar as variáveis dentro de cada rebanho que realmente influenciam a variável de interesse, não tendo esse estudo uma conclusão prática, mostrando somente que existe influência de rebanho, sem identificar a causa real dessa influência. 
Tabela 1. Resumo das variáveis estudadas.

\begin{tabular}{|c|c|c|c|c|c|}
\hline \multirow{3}{*}{ Variável } & \multirow{3}{*}{ Freqüência } & \multicolumn{4}{|c|}{ Influência } \\
\hline & & \multicolumn{2}{|c|}{ Sim } & \multicolumn{2}{|c|}{ Não } \\
\hline & & Freq. & $(\%)$ & Freq. & $(\%)$ \\
\hline 1) Ano do parto & 19 & 13 & $68,4 \%$ & 6 & $31,6 \%$ \\
\hline 2) Estação do ano ao parto & 14 & 5 & $35,7 \%$ & 9 & $64,3 \%$ \\
\hline 3) Ordem de lactação ou ordem de parto & 13 & 5 & $38,5 \%$ & 8 & $61,5 \%$ \\
\hline 4) Reprodutor & 12 & 7 & $58,3 \%$ & 5 & $41,7 \%$ \\
\hline 5) Grupo genético & 12 & 1 & $8,3 \%$ & 11 & $91,7 \%$ \\
\hline 6) Vaca & 8 & 1 & $12,5 \%$ & 7 & $87,5 \%$ \\
\hline 7) Idade da vaca ao parto & 7 & 2 & $28,6 \%$ & 5 & $71,4 \%$ \\
\hline 8) Rebanho & 6 & 5 & $83,3 \%$ & 1 & $16,7 \%$ \\
\hline 9) Mês do parto & 5 & 3 & $60,0 \%$ & 2 & $40,0 \%$ \\
\hline 10) Origem do reprodutor & 2 & 0 & $0,0 \%$ & 2 & $100,0 \%$ \\
\hline 11) Período de lactação (em dias) & 2 & 2 & $100,0 \%$ & 0 & $0,0 \%$ \\
\hline 12) Variedades da raça Holandesa & 2 & 1 & $50,0 \%$ & 1 & $50,0 \%$ \\
\hline 13) Forma de cobertura & 2 & 0 & $0,0 \%$ & 2 & $100,0 \%$ \\
\hline 14) Interação entre mês e ordem de parto & 2 & 1 & $50,0 \%$ & 1 & $50,0 \%$ \\
\hline 15) Outras variáveis ${ }^{l}$ & 31 & 11 & $35,5 \%$ & 20 & $64,5 \%$ \\
\hline
\end{tabular}

${ }^{1}$ Variáveis estudadas apenas uma vez, sendo significativas às seguintes: 1) Interação entre ano de parto e grupo genético; 2) Ano-estação de início de lactação; 3) Região geográfica; 4) Interação de rebanho e grupo genético; 5) Dieta alimentar; 6) Produção de leite; 7) Escore médio para a condição corporal durante as 26 primeiras semanas de lactação; 8) Dias entre o parto e o primeiro serviço; 9) Dias entre o primeiro serviço e a concepção; 10) Serviços por concepção; 11) Interação entre rebanho e estação do ano ao parto: 


\subsection{Análise de Correspondência}

\subsubsection{Noção da história}

Segundo Barioni Júnior (1995), a preocupação com a análise exploratória de dados categorizados, particularmente para tabelas de contingência, teve início em 1933 com Richardson \& $\operatorname{Kuder}^{2}$ e, a partir daí, vários autores tais como Hirshfield ${ }^{3}$, 1935; Fisher ${ }^{4}$, 1940; Guttman ${ }^{5}$, 1941; Burt ${ }^{6}$, 1950; Hayashi ${ }^{7}, 1950$, dentre outros, escreveram, de forma independente, trabalhos referentes ao assunto com diferentes denominações como: Optimal scalling, Reciprocal averages, Optimal scoring, Homogeneity analysis, Dual scaling, Scalogram analysis.

Também, segundo o mesmo autor, o assunto foi retomado na década de 60 , por intermédio de um grupo francês, liderado pelo pesquisador Jean-Paul Benzécri, que definiu um método, mostrando suas propriedades algébricas e geométricas. Este método foi denominado de "Analyse Factorialle des Correspondences", e mais tarde, apenas de "Analyse des Correspondences".

${ }^{2}$ RICHARDSON, L. \& KUDER, G.F. Marking a rating scale that measures. Personnel Journal, Costa Mesa, CA, vol.2, p.36-40, 1933.

${ }^{3}$ HIRSHFIELD, H.O. A connection between correlation and contingency. Philosophical Society Proceedings, Cambridge, vol.31, p.520-524, 1935

${ }^{4}$ FISHER, R.A. The precision of discriminant function. Annals of Eugenics, Cambridge, vol.10, p.422$429,1940$.

${ }^{5}$ GUTTMAN, L. The quantification of a class of attributes: a theory and method of scale construction, in the prediction of personal adjustment. Eds. P. Horst, et al., New York: Social Science Research Council. 1941.

${ }^{6}$ BURT, C. The factorial analysis of qualitative data. British Journal of Psychology, Leicester, England, vol.3, p.166-185, 1950.

${ }^{7}$ HAYASHI, C. On the quantification of qualitative data from the mathematico-statistical point of view. Annals of the Institute of Statistical Mathematics, vol.2, n.1, p.35-47, 1950. 


\subsubsection{Objetivo da Análise de Correspondência}

A Análise de Correspondência é um método que tem por objetivo analisar toda a informação contida em uma tabela de contingência, representando, graficamente, a estrutura dessa tabela e produzindo estatísticas complementares de controle (não havendo necessidade de assumir modelos e nem distribuições fundamentais). Isso é obtido através da representação simultânea das categorias (linhas e colunas) de uma tabela de contingência sobre um gráfico, em dimensão reduzida, na forma de pontos.

Segundo Aguayo (1993), o método poderia ser comparado ao uso de um aparelho radiográfico, que fornece imagens a partir de uma realidade não observável. $\mathrm{O}$ uso de tal aparelho para um diagnóstico, supõe uma certa preparação, por um lado, do doente que deve, por exemplo, absorver um produto, e pelo outro, de buscar a posição e a direção mais convenientes para que, ao tirar a radiografia, possam ser captadas as formas dos órgãos ou ossos de interesse distribuídos no interior do corpo. A interpretação dos resultados está ligada ao conhecimento dos princípios de funcionamento do aparelho e a opacidade aos raios $\mathrm{X}$, que depende da densidade, do volume e da composição química dos órgãos, inclusive quando o paciente absorve o produto.

A Análise de Correspondência pode ser considerada como um caso particular da Análise de Componentes Principais, por ambas buscarem o mesmo objetivo: Redução de Dimensão; o que as diferencia é o tipo de matriz de dados a ser analisada, e por conseqüência, a métrica utilizada.

No próximo item serão apresentados os procedimentos essenciais para a execução de uma Análise de Correspondência Simples sobre uma tabela de contingência de dupla entrada, porém o mesmo procedimento pode ser utilizado em outras tabelas, obtendo-se excelentes resultados, como por exemplo: a Análise de Correspondência Múltipla, a qual está relacionada com a representação das categorias de mais de duas variáveis discretas ("Tabela de Burt"). Além disso, a Análise de Correspondência pode 
ser integrada aos Modelos Log-lineares, à Análise Longitudinal de Dados Categorizados, etc.

\subsubsection{Fundamentos teórico e algébrico do método}

Neste item, buscar-se-á definir, resumidamente, através de alguns conceitos básicos, as etapas para se chegar aos resultados da Análise de Correspondência.

Foram tomadas como base as seguintes publicações: Mandel (1982); Greenacre (1984); Greenacre \& Hastie (1987); Aguayo (1993); Crivisqui (1993); Greenacre (1993), Krzanowski (1993) e Barioni Júnior (1995).

\subsubsection{Tabela de contingência}

Seja $\mathbf{N}$ uma tabela de contingência, com I categorias de linhas e $\mathbf{J}$ categorias de colunas, contendo elementos não negativos, de modo que, a soma de cada linha ou coluna seja não nula. A tabela é a seguinte:

Tabela 2. Tabela de contingência.

\begin{tabular}{|c|c|c|c|c|c|}
\hline $\mathbf{A} \backslash \mathbf{B}$ & 1 & 2 & ... & $\mathbf{J}$ & $\begin{array}{c}\text { Total de } \\
\text { linha }\end{array}$ \\
\hline 1 & $\mathbf{n}_{11}$ & $n_{12}$ & $\ldots$ & $n_{1 J}$ & $\mathbf{n}_{1 .}$ \\
\hline 2 & $\mathbf{n}_{21}$ & $\mathbf{n}_{22}$ & ... & $\mathbf{n}_{2 J}$ & $\mathbf{n}_{2}$ \\
\hline$\cdots$ & $\ldots$ & $\ldots$ & $\cdots$ & $\cdots$ & $\cdots$ \\
\hline I & $\mathbf{n}_{11}$ & $\mathbf{n}_{12}$ & $\ldots$ & $\mathbf{n}_{\mathrm{IJ}}$ & $\mathbf{n}_{\mathbf{l}}$ \\
\hline Total de coluna & $\mathrm{n}_{.1}$ & $\mathbf{n}_{.2}$ & $\ldots$ & $\mathbf{n}_{. J}$ & $\mathbf{n}$ \\
\hline
\end{tabular}

onde: 
$\mathbf{n}_{\mathbf{i j}}$ é o número de freqüências observadas para a interseção da i-ésima linha com a j-ésima coluna;

$\mathbf{n}_{\mathbf{i}}=\sum_{\mathbf{j}} \mathbf{n}_{\mathbf{i j}}$ é o total de freqüências observadas na i-ésima linha;

$\mathbf{n}_{\mathrm{j}}=\sum_{\mathbf{i}} \mathbf{n}_{\mathrm{ij}}$ é o total de freqüências observadas na j-ésima coluna;

$\mathbf{n}=\sum_{\mathbf{i j}} \mathbf{n}_{\mathbf{i j}}$ é o total geral de freqüências observadas;

$\mathbf{N}=\left[\mathbf{n}_{\mathbf{i j}}\right]_{\mathbf{I} \times \mathbf{J}}$ é uma matriz de freqüências absolutas.

\subsubsection{Matriz de freqüências relativas}

A matriz $\mathbf{N}$ pode ser transformada em uma matriz de freqüências relativas. expressa por:

$$
P=(1 / n) N,
$$

sendo também conhecida como Matriz de Correspondência. Cada linha ou coluna da matriz $\mathbf{P}$ pode ser vista como um vetor de proporções representado na Tabela 3.

Tabela 3. Freqüências relativas.

\begin{tabular}{|c|c|c|c|c|c|}
\hline$A \backslash B$ & 1 & 2 & $\ldots$ & $\mathbf{J}$ & $\begin{array}{c}\text { Total de } \\
\text { linha }\end{array}$ \\
\hline 1 & $p_{11}$ & $\mathbf{p}_{12}$ & $\ldots$ & $p_{1 J}$ & $\mathbf{p}_{1 .}$ \\
\hline 2 & $\mathbf{p}_{21}$ & $\mathbf{p}_{22}$ & $\ldots$ & $\mathbf{p}_{2 \mathrm{~J}}$ & $\mathbf{p}_{2 .}$ \\
\hline$\cdots$ & $\ldots$ & $\cdots$ & $\ldots$ & $\cdots$ & ... \\
\hline I & $\mathbf{p}_{\mathbf{1}}$ & $\mathbf{p}_{12}$ & $\ldots$ & $\mathbf{p}_{\mathrm{IJ}}$ & pi. \\
\hline Total de coluna & P.1 & p.2 & $\ldots$ & p.s & 1 \\
\hline
\end{tabular}

onde:

$\mathbf{p}_{i j}=n_{i j} / \mathbf{n} ; p_{i .}=\sum_{j} p_{i j}=\sum_{j} n_{i j} / n ; p_{. j}=\sum_{i} p_{i j}=\sum_{i} n_{i j} / n$.

Então, definem-se os seguintes vetores: 
r: vetor de freqüências relativas de linhas;

$r=\left(p_{1}, p_{2}, \ldots, p_{1} .\right)^{\prime}=P 1 \in R^{1}$;

c: vetor de freqüências relativas de colunas;

$\mathrm{c}=\left(\mathbf{p}_{.1}, \mathbf{p}_{.2}, \ldots, \mathbf{p}_{.1}\right)^{\prime}=\mathrm{P}^{\prime} 1 \in \mathrm{R}^{\mathrm{J}}$.

Definem-se também, as matrizes diagonais de frequêencias relativas de cada linha e de cada coluna, por:

$$
\mathbf{D}_{\mathbf{r}}=\operatorname{diag}(\mathbf{r})=\left[\begin{array}{lll}
\mathbf{p}_{\mathrm{l}} & & 0 \\
& \ddots & \\
0 & & \mathbf{p}_{\mathbf{I} .}
\end{array}\right] ; \mathbf{D}_{\mathbf{c}}=\operatorname{diag}(\mathbf{c})=\left[\begin{array}{lll}
\mathbf{p}_{.1} & & 0 \\
& \ddots & \\
0 & & \mathbf{p}_{. J}
\end{array}\right] \text {. }
$$

\subsubsection{Perfil linha e perfil coluna}

Em função da matriz de correspondência $\mathbf{P}$, define-se o i-ésimo perfil linha como o vetor:

$$
\mathbf{a}_{\mathbf{i}}=\left(\mathbf{p}_{\mathrm{i} 1} / \mathbf{p}_{\mathrm{i}}, \mathbf{p}_{\mathrm{i} 2} / \mathbf{p}_{\mathrm{i}}, \ldots, \mathbf{p}_{\mathrm{i}} / \mathbf{p}_{\mathrm{i}}\right)^{\prime} ; \mathrm{i}=1,2, \ldots, \mathrm{I},
$$

onde cada vetor $\mathbf{a}_{\mathbf{i}}$ representa uma distribuição multinomial, condicionada à i-ésima categoria da variável $\mathbf{A}$.

Logo, a Matriz de perfis linha é dada por:

$$
R=D_{r}^{-1} \mathbf{P}=\left[a_{1}\left|a_{2}\right| \ldots \mid a_{1}\right] \text {. }
$$

Analogamente, o j-ésimo perfil coluna será:

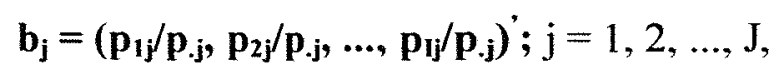

e a Matriz de perfis coluna é dada por:

$$
C=D_{c}^{-1} P^{\prime}=\left[b_{1}\left|b_{2}\right| \ldots \mid b_{J}\right]^{\prime} .
$$

\subsubsection{Massas}

Definem-se massas de linha ou de coluna de tabela de contingência por:

- Massa da i-ésima linha:

$$
r_{i}=p_{i}=n_{i} / n,
$$


sendo, o vetor de massa das linhas representado por:

$$
r=\left(r_{1}, r_{2}, \ldots, r_{1}\right),
$$

que é o vetor de freqüências relativas de linhas.

\section{- Massa da j-ésima coluna:}

$$
\mathbf{c}_{\mathbf{j}}=\mathbf{p}_{\mathbf{j}}=\mathbf{n}_{\mathbf{j}} / \mathbf{n},
$$

sendo, o vetor de massa das colunas representado por:

$$
c=\left(c_{1}, c_{2}, \ldots, c_{1}\right)^{\prime},
$$

que é o vetor de freqüências relativas de colunas.

\subsubsection{Centróide (ou Baricentro)}

O centróide (linha ou coluna) de uma tabela de contingência indica geometricamente a posição média dos perfis (linha ou coluna), como se fosse o centro de gravidade ou o ponto de equilíbrio da matriz de dados.

Como cada perfil (linha ou coluna) está associado a uma massa $\left(\mathbf{r}_{\mathbf{i}}\right.$ ou $\left.\mathbf{c}_{\mathbf{j}}\right)$, define-se como centróide (linha ou coluna) a média ponderada dos perfis (linha ou coluna). Então:

- Centróide dos perfis linha:

Centróide $_{(\mathbf{r})}=\sum_{\mathbf{i}} \mathbf{r}_{\mathbf{i}} \mathbf{a}_{\mathbf{i}}=\mathbf{R}^{\prime} \mathbf{r}=\mathbf{c}$ (vetor de massa das colunas).

- Centróide dos perfis coluna:

Centróide $_{(\mathbf{c})}=\sum_{\mathbf{j}} \mathbf{c}_{\mathbf{j}} \mathbf{b}_{\mathbf{j}}=\mathbf{C}^{\prime} \mathbf{c}=\mathbf{r}$ (vetor de massa das linhas).

Reduzindo-se, portanto, às freqüências relativas marginais.

\subsubsection{Espaço de perfil}

Cada perfil linha $\mathbf{a}_{\mathbf{i}}$ define um ponto em $\mathrm{R}^{\mathrm{J}}$, logo, este espaço acomoda uma nuvem de pontos representando os $I$ perfis linha. $O$ fato de os elementos de cada 
perfil linha somarem 1 , pois $\sum_{\mathrm{j}=1}^{\mathrm{J}} \mathrm{p}_{\mathrm{ij}} / \mathrm{p}_{\mathrm{i} .}=1, \mathrm{i}=1,2, \ldots, \mathrm{I}$, significa que a nuvem de pontos está restrita a uma região, num subespaço de dimensão $(\mathbf{J}-\mathbf{1})$ do espaço das colunas $\left(\mathrm{R}^{J}\right)$, conhecida como: "Simplex". Este simplex ou espaço dos perfis linha está limitado por segmentos de retas que unem os vértices unitários $\left(\mathbf{e}_{1}, \mathbf{e}_{2}, \ldots, \mathbf{e}_{\mathbf{J}}\right)$ sobre os $\mathbf{J}$ eixos perpendiculares, que representam as categorias de coluna. O sistema de coordenadas gerado dentro do simplex é definido como: "Sistema de coordenadas baricêntricas".

A interpretação do espaço dos perfis coluna é feita da mesma forma que a descrita para perfis linha, porém utilizando-se a matriz transposta ( $\left.\mathbf{P}^{\prime}\right)$.

\subsubsection{Estatística $\mathrm{X}^{2}$, Distância $\mathrm{X}^{2}$ e Inércia}

Quando o interesse é testar a hipótese de independência entre linhas e colunas $\left(\mathbf{p}_{\mathrm{ij}}=\mathbf{p}_{\mathrm{i}} \mathbf{p}_{\mathrm{j}}\right)$, que é equivalente à hipótese de homogeneidade entre linhas $\left(\mathbf{p}_{1 \mathrm{j}} / \mathbf{p}_{\mathbf{1}}=\mathbf{p}_{\mathbf{2}} / \mathbf{p}_{\mathbf{2}}=\ldots=\mathbf{p}_{1 \mathrm{j}} / \mathbf{p}_{\mathbf{1}}\right)$ de uma tabela de contingência recorre-se, na maioria das vezes, à Estatística $\mathrm{X}^{2}$ de Pearson, expressa pela fórmula a seguir:

$$
X^{2}=\sum_{i j} \frac{\left(\mathbf{n}_{i j}-\mathbf{e}_{i j}\right)^{2}}{\mathbf{e}_{i j}},
$$

onde: $\mathbf{X}^{2}$ tem distribuição de $\chi^{2}$, com $(I-1)(J-1)$ graus de liberdade e $\mathbf{e}_{\mathrm{ij}}=\mathbf{n}_{\mathrm{i}} \mathbf{n}_{\mathrm{j}} / \mathbf{n}$ é o valor esperado na interseção da i-ésima categoria de linha com a j-ésima categoria de coluna, na amostra, se as variáveis cruzadas forem independentes.

Da expressão (1), chega-se facilmente a:

$$
X^{2}=n \sum_{i j} \frac{\left(p_{i j}-p_{i . p_{. j}}\right)^{2}}{\mathbf{p}_{i .} \mathbf{p}_{. j}}
$$

Sob a hipótese de homogeneidade, a Estatística $X^{2}$ pode ser interpretada geometricamente como sendo a diferença dos perfis (linha ou coluna) aos seus respectivos centróides (c ou r). 
Tem-se também que a Inércia Total de uma tabela de contingência é a Estatística $\mathrm{X}^{2}$ dividida pelo total geral (n), que é dada por:

$$
\text { Inércia }_{(\text {total })}=\sum_{i j} \frac{\left(p_{i j}-r_{i} c_{j}\right)^{2}}{r_{i} c_{j}}=\frac{X^{2}}{n} .
$$

A Inércia Total dos perfis linha é igual a dos perfis coluna, sendo ambas iguais à Inércia Total. Então, temos que:

$$
\begin{aligned}
& \operatorname{Inércia~}_{\text {(linha) }}=\frac{X^{2}}{n}=\sum_{i} p_{i .} \sum_{j}\left(p_{i j} / p_{i .}-p_{. j}\right)^{2} / p_{. j}=I_{\text {Inércia }}(\text { total); } \\
& \text { Inércia }_{\text {(coluna) }}=\frac{X^{2}}{n}=\sum_{j} p_{. j} \sum_{i}\left(p_{i j} / p_{. j}-p_{i .}\right)^{2} / p_{i .}=\text { Inércia }_{(\text {total). }}
\end{aligned}
$$

A diferença ao quadrado da expressão: $\sum_{\mathbf{j}}\left(1 / \mathbf{p}_{\mathbf{j}}\right)\left(\mathbf{p}_{\mathbf{i j}} / \mathbf{p}_{\mathbf{i}}-\mathbf{p}_{\mathbf{. j}}\right)^{2}$, em (2), representa a distância entre o i-ésimo perfil linha $\left(\mathbf{a}_{\mathbf{i}}\right)$ e o perfil linha médio $\left(\right.$ Centróide $\left._{(\mathrm{c})}\right)$. Note que para cada termo da diferença, existe um fator extra $\left(\mathbf{p}_{\mathbf{j}}: \mathrm{j}=1,2\right.$, ..., J) que pondera estas diferenças. Por essa razão, em Análise de Correspondência não se define a distância dos perfis linha ao centróide pela Métrica Euclideana Clássica, mas sim, pela Métrica Euclideana Ponderada.

A inércia é, portanto uma medida de dispersão, similar à variância. Uma inércia alta pode ser interpretada como uma forte associação entre linhas e colunas, sendo representada geometricamente pela ampla dispersão dos pontos no espaço de perfis. Além disso, o valor máximo que pode ser atingido pela inércia é igual ao mínimo entre $(\mathrm{I}-1)$ e $(\mathrm{J}-1)$, dependente, portanto, do número de linhas e de colunas da tabela de contingência.

A distância $\mathrm{X}^{2}$ entre os perfis linha e o centróide (c) é definida como sendo a distância euclideana ponderada por $\mathbf{D}_{\mathbf{c}}{ }^{-1}$, que é representada pela seguinte expressão:

$$
D_{X_{c}^{2}}^{2}\left\{a_{i}, c\right\}=\left(a_{i}-c\right)^{\prime} D_{c}^{-1}\left(a_{i}-c\right)=\left(R-c^{\prime} 1\right)^{\prime} D_{c}^{-1}\left(R-c^{\prime} 1\right)
$$


Da mesma forma, a distância $X^{2}$, entre os perfis coluna e o centróide (r) é definida como sendo a distância euclideana ponderada por $\mathbf{D}_{\mathbf{r}}^{-1}$, que é representada pela seguinte expressão:

$$
D_{X_{r}^{2}}^{2}\left\{b_{j}, r\right\}=\left(b_{j}-r\right)^{\prime} D_{r}^{-1}\left(b_{j}-r\right)=\left(C-r^{\prime} 1\right)^{\prime} D_{c}^{-1}\left(C-r^{\prime} 1\right)
$$

Portanto, realizar uma análise considerando a Distância $X^{2}$ é o mesmo que realizar uma análise com a Distância Euclideana aplicada aos novos pontos linha, com suas respectivas massas, da matriz:

$$
\mathrm{RD}_{\mathrm{c}}^{-1 / 2} \text {. }
$$

Analogamente, para os perfis coluna, realizar uma análise considerando a Distância $\mathrm{X}^{2}$ é o mesmo que realizar uma análise com a Distância Euclideana aplicada aos novos pontos coluna, com suas respectivas massas, da matriz:

$$
\mathrm{RD}_{\mathrm{r}}^{-1 / 2} \text {. }
$$

\subsubsection{Redução da dimensão}

Geralmente, quando se aplica Análise de Correspondência, a tabela de contingência tem um grande número de linhas e colunas, de modo que os perfis (linhas ou colunas) encontram-se num espaço de dimensão muito grande, tornando-se difícil observá-los diretamente. Por esse motivo, na Análise de Correspondência, como em outras técnicas multivariadas, a preocupação é identificar um subespaço de dimensão reduzida, preferencialmente, não mais do que duas ou três dimensões e que estejam o mais próximo possível de todos os pontos perfis. Então, neste subespaço não se têm mais as posições originais e sim, suas projeções. As posições dos perfis neste subespaço podem ser vistas como uma aproximação das suas verdadeiras posições no espaço de origem. Neste contexto, as distâncias entre os perfis projetados passam a ser Distâncias $\mathrm{X}^{2}$ aproximadas.

$\mathrm{Na}$ Análise de Correspondência tem-se o problema Dual, pois ora se faz análise em linha, ora em coluna, ambas na busca da redução de dimensão. $\mathrm{Na}$ análise em 
$\mathbf{R}^{\mathbf{J}}$ tem-se uma nuvem de pontos representando os $\mathbf{I}$ perfis linha, que se acomodam exatamente num simplex de dimensão ( $\mathbf{J}-\mathbf{1})$, enquanto que na análise em $\mathbf{R}^{\mathbf{I}}$ tem-se uma nuvem de pontos representando os $\mathbf{J}$ perfis coluna, que se acomodam exatamente num simplex de dimensão $(\mathbf{I}-\mathbf{1})$.

Portanto, diante do problema dual, busca-se um subespaço de dimensão reduzida que melhor represente os perfis linha, quando se trabalha em coluna, e um subespaço de dimensão reduzida que melhor represente os perfis coluna, quando se trabalha em linha.

Além disso, para o ajuste do respectivo subespaço de linha ou coluna, a Análise de Correspondência utiliza um critério denominado de "Soma Ponderada das Distâncias ao Quadrado".

Neste item não estaremos preocupados em demonstrar a solução para o problema, da análise em linha, e em coluna, mas sim mostrar o resultado final. Deve-se, no entanto, ter em mente que a resposta para o problema está ligada à Técnica de Decomposição por Valores Singulares (DVS), ora sobre uma matriz que representa o espaço das colunas, ora sobre uma matriz que representa o espaço das linhas.

O problema reduz-se em buscar uma nova base ortogonal, isto é, ajustar um subespaço de dimensão reduzida no sentido de Mínimos Quadrados Ponderados, de modo que a representação dos I (ou $\mathbf{J}$ ) perfis linha (ou coluna) sofra o mínimo de deformação ao ser projetado neste subespaço.

A idéia fundamental da Análise de Correspondência é obter as coordenadas principais dos perfis linha e coluna para este subespaço de dimensão reduzida e representá-las simultaneamente. Esta representação justifica-se devido às Relações Baricêntricas e à ortogonalidade existente entre os espaços.

Logo, as coordenadas principais dos perfis linha e coluna nesta representação são obtidas da Decomposição por Valores Singulares (DVS) da matriz X, isto é:

$$
\mathrm{X}=\mathrm{USV}^{\prime} \text {, }
$$

onde: 
i. $\mathbf{X}$ é a matriz definida por $\mathbf{D}_{\mathrm{r}}^{-1 / 2}\left(\mathbf{P}-\mathbf{r} \mathbf{c}^{\prime}\right) \mathbf{D}_{\mathbf{c}^{-1 / 2}}$

ii. $\mathbf{S}$ é uma matriz diagonal de valores singulares $s_{k}=\sqrt{\lambda_{k}}: k=1,2, \ldots, K$, onde $\lambda_{k}$ são os autovalores de $\mathbf{X}^{\prime} \mathbf{X}$ ou de $\mathbf{X X}^{\prime}$, tal que $\lambda_{1} \geq \lambda_{2} \geq \cdots \geq \lambda_{\mathbf{K}} \geq 0$;

iii. $U^{\prime} \mathbf{U}=\mathbf{I}$ e $V^{\prime} \mathbf{V}=\mathbf{I}$, ou seja, $\mathbf{U}$ e $\mathbf{V}$ têm colunas ortonormais;

iv. As colunas de $\mathbf{U}$ são vetores característicos normalizados, associados às raízes não nulas de $\mathbf{X X}$ ' e as linhas de $\mathbf{V}^{\prime}$ são vetores característicos normalizados, associados às raízes não nulas de $\mathbf{X}^{\prime} \mathbf{X}$;

v. Existe uma relação entre as matrizes $\mathbf{U}$ e $\mathbf{V}$, sendo: $\mathbf{U}^{\prime}=\mathbf{X V S}^{\mathbf{1}}$ e $\mathbf{V}=\mathbf{X}^{\prime} \mathbf{U S}^{-\mathbf{1}}$.

Então, as matrizes de coordenadas principais, para as respectivas nuvens de pontos linha e coluna, considerando apenas as dimensões não nulas, são:

$$
\mathbf{F}=\left[\mathbf{F}_{(\mathbf{1})}\left|\mathbf{F}_{(\mathbf{2})}\right| \ldots \mid \mathbf{F}_{(\mathbf{K})}\right] \text { e } \mathbf{G}=\left[\mathbf{G}_{(\mathbf{1})}\left|\mathbf{G}_{(\mathbf{2})}\right| \ldots \mid \mathbf{G}_{(\mathbf{K})}\right]
$$

onde:

$$
\mathbf{F}=\mathbf{R D}_{\mathbf{c}}^{-1 / 2} \mathrm{~V} \text { e } \mathbf{G}=\mathbf{C D}_{\mathbf{r}}^{-1 / 2} \mathbf{U}
$$

Ainda, tem-se que as coordenadas principais de linhas e colunas satisfazem às seguintes Fórmulas de Transição ou Relações Baricêntricas, respectivamente:

$$
\mathbf{F}=\mathbf{R G S}^{-1} \text { e } \mathbf{G}=\mathbf{C F S}^{-1},
$$

possibilitando, portanto, transitar com as coordenadas de um espaço para outro, tornando possivel representar, simultaneamente, as projeções dos pontos linhas e colunas sobre um mesmo gráfico, facilitando e enriquecendo a interpretação.

Tem-se também, que as coordenadas do i-ésimo perfil linha e as coordenadas do j-ésimo perfil coluna, sobre o k-ésimo eixo principal, são respectivamente:

$$
\mathbf{f}_{i k}=\frac{1}{s_{k}} \sum_{j}\left(\frac{p_{i j}}{p_{i}}\right) g_{j k} \text { e } g_{j k}=\frac{1}{s_{k}} \sum_{i}\left(\frac{p_{i j}}{p_{. j}}\right) f_{i k} .
$$




\subsubsection{Interpretação dos resultados}

Como o interesse primordial da Análise de Correspondência é representar simultaneamente as linhas e colunas de uma tabela de contingência sobre um mesmo gráfico em termos de coordenadas principais, tendo como base as Fórmulas Transição em (3) e os resultados em (4), as posições das linhas em relação às posições das colunas podem ser interpretadas como:

a) Dada uma linha $i$, quanto maior for a proporção de uma coluna $j$ nesta linha, mais atraída esta será na direção de j, logo os pontos que as representam estarão próximos, pois o vetor resultante $\mathbf{F}_{\mathbf{i}}(\mathrm{i}=1,2, \ldots, \mathrm{I})$ contém uma proporção maior do vetor $\mathbf{S}^{-1} \mathbf{G}_{\mathbf{j}}(\mathrm{j}=1,2, \ldots, J)$;

b) A proximidade de uma linha i e uma coluna $\mathrm{j}$ só pode ser interpretada como uma associação entre estas, se ambos os pontos estiverem na periferia da nuvem, longe da origem; caso contrário, pode acontecer que: $1^{\circ}$ ) Quando uma linha tem um perfil próximo ao perfil médio, encontrar-se-á próxima à origem, de modo que a linha não desempenha um papel importante para nenhuma das colunas, já que se distribuem sem uma tendência particular, tal como faz a maioria do grupo observado; $2^{9}$ ) A proximidade entre $\mathrm{i}$ e $\mathrm{j}$ pode ser devida a outras colunas $j$ ' e $j$ " que se encontram muito longe de $j$ e em extremos opostos e, não à própria coluna $\mathrm{j}$;

c) Deve-se interpretar a posição de um ponto linha com relação às posições de todos os pontos coluna.

A interpretação das posições das colunas em relação às linhas, é realizada de modo análogo ao anterior.

Contudo, não se deve tentar interpretar os resultados da Análise de Correspondência sem antes verificar os resultados de algumas medidas de auxilio construídas a partir da decomposição da Inércia Total que serão dadas a seguir. 
Tem-se que a Inércia Total $\left(\mathbf{X}^{2} / \mathbf{n}\right)$ é decomposta através do conjunto de autovalores: $\lambda_{1}, \lambda_{2}, \cdots, \lambda_{K}$, os quais são denominados de Inércias Principais. Como cada eixo principal $\left(e_{k}: k=1,2, \ldots, K\right)$ corresponde a uma Inércia Principal $\left(\lambda_{k}\right)$, podese, então, obter uma "Porcentagem de Inércia" referente a cada eixo em relação à Inércia Total, isto é, quanto cada eixo principal explica da decomposição de cada nuvem de pontos. Tem-se então que:

$$
\text { Porcentagem de Inércia }=\frac{\lambda_{k}}{\sum_{k} \lambda_{k}}=\frac{\lambda_{k}}{X^{2} / n} .
$$

Do fato de as Inércias Principais estarem em ordem descendente, implica que os primeiros eixos contabilizam a maior porcentagem de explicação. Por exemplo, se $90 \%$ da inércia dos perfis está representada num subespaço bidimensional, então o erro, que se encontra fora deste subespaço é de $10 \%$. Logo a qualidade deste ajuste é de $90 \%$ e o erro cometido é de $10 \%$.

Consequentemente, cada Inércia Principal $\lambda_{\mathrm{k}}$ pode ser decomposta em componentes correspondentes a cada perfil linha e a cada perfil coluna ao longo dos eixos principais. Estes componentes estão ilustrados na Tabela 4. Esta tabela dispõe de informações numéricas de grande importância, pois além de serem úteis na interpretação dos resultados da Análise de Correspondência, darão também suporte para definir outras medidas auxiliares, como as contribuições absolutas e relativas.

As Contribuições Absolutas e as Contribuições Relativas fornecem um diagnóstico que permite identificar quais são os pontos que mais contribuem na formação dos eixos principais e, por conseguinte, quantificar quão bem um ponto individual está representado.

A contribuição absoluta é quanto um ponto expressa de contribuição na caracterização de um eixo. Logo a Contribuição Absoluta do i-ésimo perfil linha ao késimo eixo é definida por:

$$
\begin{aligned}
& \mathbf{C}_{\mathbf{i k}}{ }^{(\mathbf{a})}=\mathbf{r}_{\mathbf{i}} \mathbf{f}_{\mathbf{i k}}{ }^{\mathbf{2}} / \boldsymbol{\lambda}_{\mathbf{k}} \mathrm{e} \\
& \sum_{\mathbf{i}} \mathbf{C}_{\mathbf{i k}}^{(\mathbf{a})}=1 .
\end{aligned}
$$


Tabela 4. Decomposição da inércia

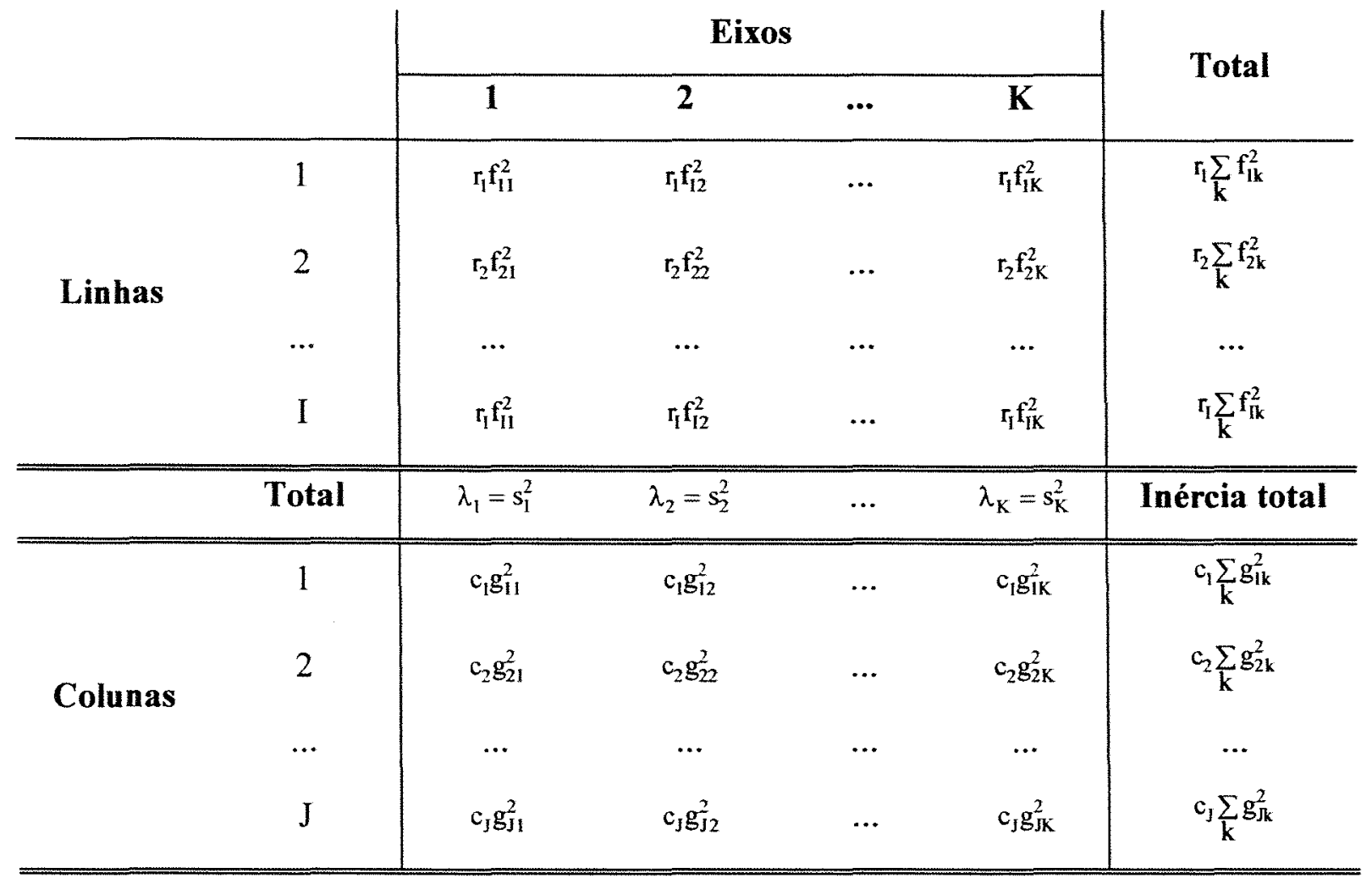

Analogamente, a Contribuição Absoluta do j-ésimo perfil coluna ao késimo eixo é definida por:

$$
\begin{aligned}
& \mathbf{C}_{\mathbf{j k}}{ }^{(a)}=\mathbf{c}_{\mathbf{j}} \mathbf{g}_{\mathbf{j} \mathbf{k}}{ }^{2} / \lambda_{\mathbf{k}} \quad \mathrm{e} \\
& \sum_{\mathbf{j}} \mathbf{C}_{\mathbf{j k}}^{(\mathbf{a})}=1 .
\end{aligned}
$$

A Contribuição Relativa é quanto um eixo contribui na caracterização de um ponto. Então, a contribuição relativa do k-ésimo eixo ao i-ésimo perfil linha é definida por:

$$
\mathbf{C}_{\mathbf{i k}}^{\left({ }^{(r)}\right.}=\frac{\mathbf{f}_{\mathbf{i k}}^{2}}{\sum_{\mathbf{k}} \mathbf{f}_{\mathbf{i k}}^{2}} .
$$

Analogamente, a contribuição relativa do k-ésimo eixo ao j-ésimo perfil coluna é definida por: 


$$
\mathrm{C}_{\mathbf{j k}}^{\left({ }^{(r)}\right.}=\frac{\mathbf{g}_{\mathbf{j k}}^{2}}{\sum_{\mathbf{k}} \mathbf{g}_{\mathbf{j k}}^{2}} .
$$

Alternativamente, a Contribuição relativa pode ainda ser vista como o co-seno ao quadrado de um ângulo. Considere a situação descrita na Figura 1, onde: $\mathbf{r}_{\mathbf{i}}$ é a massa do i-ésimo perfil linha $\mathbf{a}_{\mathbf{i}} ; \mathbf{c}$ é o centróide; $\mathbf{d}_{\mathbf{i}}$ é a distância $X^{2}$ de $\mathbf{a}_{\mathbf{i}}$ até $\mathbf{c} ; \tilde{\mathbf{a}}_{\mathbf{i}}$ é a projeção de $\mathbf{a}_{\mathbf{i}}$ sobre o k-ésimo eixo principal; $\mathbf{f}_{\mathrm{ik}}$ é a coordenada principal de $\mathbf{a}_{\mathbf{i}}$ em relação ao k-ésimo eixo principal; $\lambda_{\mathrm{k}}$ é a k-ésima inércia principal; e $\theta_{\mathrm{ik}}$ é o ângulo formado entre o vetor $\mathbf{a}_{\mathrm{i}} \mathrm{e}$ o k-ésimo eixo principal em relação ao centróide c.

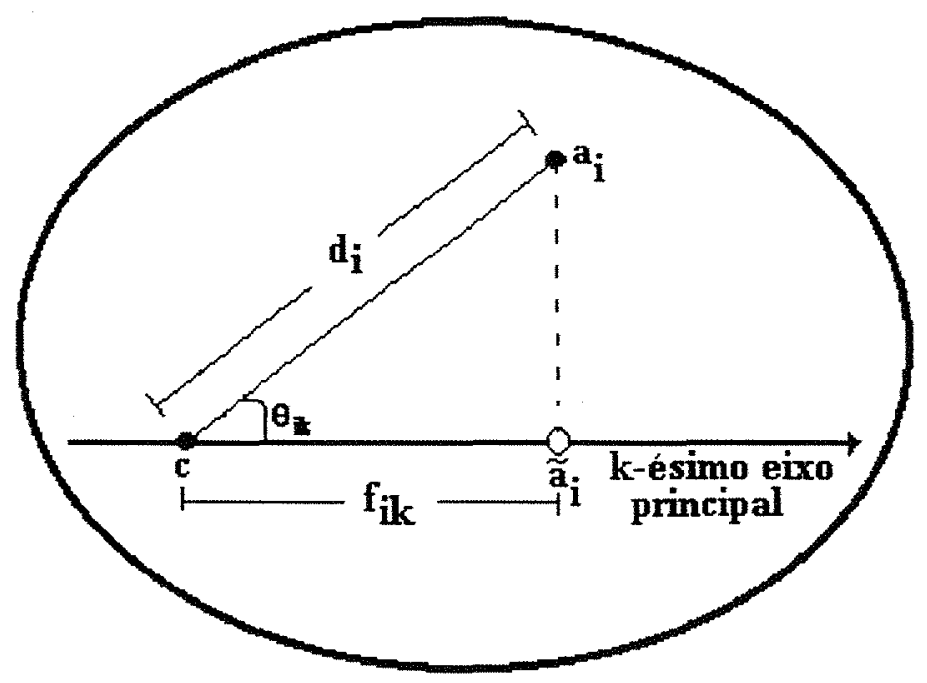

Figura 1. Contribuição relativa como co-seno ao quadrado de um ângulo: $\mathrm{C}_{\mathrm{ik}}{ }^{(\mathrm{r})}=\cos ^{2}\left(\theta_{\mathrm{ik}}\right)$.

Sabe-se que: $\mathrm{C}_{\mathrm{ik}}^{(\mathrm{r})}=\cos ^{2}\left(\theta_{\mathrm{ik}}\right)=\mathrm{f}_{\mathrm{ik}}{ }^{2} / \mathrm{d}_{\mathrm{i}}{ }^{2}$, onde $\mathrm{d}_{\mathrm{i}}{ }^{2}=\mathrm{f}_{\mathrm{i} 1}{ }^{2}+\mathrm{f}_{\mathrm{i} 2}{ }^{2}+\ldots+\mathrm{f}_{\mathrm{iK}}{ }^{2}=$ $\sum_{\mathrm{k}} \mathrm{f}_{\mathrm{ik}}{ }^{2}$ (Teorema de Pitágoras). A Contribuição Relativa atinge um valor máximo de 1 , se o perfil linha se encontra sobre o eixo principal, e um valor mínimo de 0 , se o perfil linha é perpendicular ao eixo principal, uma vez que sua projeção tem comprimento zero. Portanto, a Contribuição relativa é um indicador da qualidade da representação de um ponto pelo eixo. 


\subsubsection{Reconstrução da tabela de contingência}

A tabela $\mathbf{P}$, pode ser reconstruída através da seguinte expressão:

$$
\mathbf{P}=\mathbf{r c} \mathbf{c}^{\prime}+\mathbf{D}_{\mathbf{r}} \mathrm{FS}^{-1} \mathbf{G}^{\prime} \mathbf{D}_{\mathbf{c}} \text {. }
$$

Ao visualizar essa expressão, percebe-se claramente que a Análise de Correspondência decompõe os resíduos da esperança de $\mathbf{P}$ sob hipótese de independência $\left(\mathbf{p}_{\mathrm{ij}}=\mathbf{p}_{\mathbf{i}} \mathbf{p}_{\mathrm{j} j}\right)$. Gera-se a partir dessa decomposição um modelo definido como modelo de independência para Análise de Correspondência, sendo então, os resíduos desse modelo decompostos e plotados, ficando assim explícita a interação entre linhas e colunas.

\subsubsection{Pontos suplementares}

A interpretação da análise pode ser facilitada ou enriquecida com a representação gráfica de pontos suplementares, que são linhas e/ou colunas adicionais de uma tabela de contingência. São pontos que não interferem na análise, não participam no ajuste dos eixos e não contribuem para o cálculo da inércia, mas podem ser projetados sobre os gráficos obtidos, de modo que sua localização seja um auxilio para a interpretação. As massas desses pontos são iguais a zero.

As projeções dos pontos suplementares, para linhas e colunas, são obtidas usando as expressões apresentadas em (3). Assim, a projeção de uma linha suplementar $\mathbf{m}$, com valores $\mathbf{n}_{\mathbf{m j}}$ sobre o k-ésimo eixo principal será:

$$
\mathbf{f}_{\mathrm{mk}}=\mathbf{a}_{\mathrm{m}} \mathbf{G S}^{-1} \text {. }
$$

onde: $a_{m}^{\prime}=1 / n_{m}\left(n_{m 1}, n_{m 2}, \ldots, n_{m u}\right)$.

Analogamente, a projeção de uma coluna suplementar $\mathbf{m}$, com valores $\mathbf{n}_{\mathbf{i m}}$ sobre o mesmo eixo principal será:

$$
\mathrm{g}_{\mathrm{mk}}=\mathbf{b}_{\mathrm{m}}^{\prime} \mathrm{FS}^{-1} \text {. }
$$

onde: $b^{\prime}{ }_{m}=1 / n_{. m}\left(n_{1 m}, n_{2 m}, \ldots, n_{I m}\right)$. 


\subsubsection{Análise de Correspondência de tabelas sobrepostas}

Quando o interesse é verificar a relação entre "variáveis explicativas" e uma "variável resposta", como em análise de regressão múltipla, pode-se, em muitos casos, recorrer à Análise de Correspondência, utilizando-se a sobreposição de tabelas de contingência. Isto é, faz-se a Análise de Correspondência Simples de uma Tabela de Contingência, cujas colunas são compostas pelas categorias da "variável resposta" e as linhas pelas categorias das "variáveis explicativas" ou vice-versa.

Nessa análise não se pode verificar quais as relações existentes entre as categorias das "variáveis explicativas". Porém, através dela, verifica-se quais as relações das categorias das "variáveis explicativas" com as categorias da "variável resposta".

Para maiores detalhes, ver Greenacre (1984).

\subsubsection{Análise de Correspondência Múltipla}

A maneira mais convencional para analisar dados multivariados pela Análise de Correspondência, especialmente quando há um grande número de variáveis, é a chamada Análise de Correspondência Múltipla (ACM). Na ACM todas as associações entre pares de variáveis são analisadas, bem como cada associação entre a variável e ela mesma. Portanto, a ACM é a Análise de Correspondência de uma Tabela de Burt.

Da mesma forma, quando o interesse é verificar a relação entre "variáveis explicativas" e uma ou mais "variáveis resposta", pode-se, também, recorrer à Análise de Correspondência Múltipla. Nesse caso, a Análise de Correspondência Múltipla é feita considerando as "variáveis explicativas" como variáveis ativas na análise e as "variáveis resposta" como suplementares ou ilustrativas.

Assim, por essa análise, pode-se, além de verificar as relações entre as categorias das "variáveis explicativas" com as categorias das "variáveis resposta", 
também observar as associações existentes entre as categorias das "variáveis explicativas".

Os resultados da Análise de Correspondência Simples são facilmente extrapoláveis para a ACM. Para maiores detalhes ver Greenacre (1984), Greenacre (1993) e Crivisqui (1993). 


\section{MATERIAIS E MÉTODOS}

Para verificar a possibilidade de utilização da Análise de Correspondência na identificação de variáveis associadas com o Intervalo entre Partos, disponibilizaram-se informações através de parceria entre o Departamento de Ciências Exatas (DCE) e o Laboratório de Fisiologia da Lactação (LAFLA), ambos da Escola Superior de Agricultura "Luiz de Queiroz" - Universidade de São Paulo (ESALQ - USP), sendo que o primeiro proveu suporte técnico para a análise dos dados e o segundo forneceu os dados para estudo. Os dados são provenientes de quatro empresas agropecuárias situadas no estado de São Paulo, e foram registrados por essas empresas desde o início de 1994 até setembro de 1999.

Os dados brutos eram compostos por 9686 observações, e as seguintes variáveis:

1) Número do brinco da vaca;

2) Reprodutor (pai da vaca);

3) Data de nascimento da vaca;

4) Data do parto;

5) Intervalo entre partos;

6) Dias em lactação;

7) Idade ao parto;

8) Ordem de lactação;

9) Produção de leite por lactação $(\mathrm{kg})$;

10) Pico de produção (kg de leite);

11) Número de Inseminações; 
12) Rebanho.

No entanto, não se pôde analisar os dados na forma como se encontravam, pois muitas observações estavam incompletas, e além disso, no arquivo de dados havia também as datas ao primeiro parto, para as quais todas as observações deveriam ser excluidas, pois, sendo o primeiro parto, o intervalo entre partos é inexistente.

Portanto, primeiramente, utilizando-se o procedimento PROC SORT do SAS, ordenaram-se os dados por Número do brinco da vaca, Reprodutor, e Número de lactações, e posteriormente exportou-se esse arquivo de dados para o EXCEL, no intuito de criar novas variáveis a partir das variáveis existentes e eliminar as observações incompletas.

No EXCEL, utilizando-se as funções DATA.VALOR(), ANO(), MÊS() e outras funções, procedeu-se à criação de novas variáveis, como segue:

1) Ano do parto anterior;

2) Mês do parto anterior;

3) Idade ao parto anterior;

4) Produção de leite por lactação $(\mathrm{kg})$, durante o intervalo entre partos;

5) Pico de produção ( $\mathrm{kg}$ de leite), durante o intervalo entre partos;

6) Dias em lactação, durante o intervalo entre partos;

7) Ordem de lactação, correspondente ao intervalo entre partos;

8) Produção de leite por dia de intervalo entre partos.

Utilizando-se os comandos lógicos $\mathrm{SE}()$ e $\mathrm{E}($ ), bem como o autofiltro, eliminaram-se as observações incompletas, restando então, um arquivo de dados com 4222 observações.

$\mathrm{O}$ autofiltro permite identificar facilmente os maiores e menores valores de cada variável, observações faltantes e observações que se encontrem dentro de um limite especificado de valores, permitindo assim a eliminação dessas observações.

$\mathrm{O}$ arquivo com 4222 observações já poderia ser utilizado para análise, porém, como era de interesse verificar se o Intervalo entre partos está associado também com efeito de Reprodutor (genético), optou-se por eliminar do arquivo todos os dados 
cujos reprodutores tinham menos do que 15 observações. Isso foi realizado utilizando-se as tabelas dinâmicas, o comando lógico OU() e o autofiltro do EXCEL.

Assim, o arquivo final de dados a ser utilizado na análise de correspondência continha 2102 observações e 12 variáveis:

1) Reprodutor (pai da vaca);

2) Intervalo entre partos;

3) Número de Inseminações;

4) Rebanho;

5) Ano do parto anterior;

6) Mês do parto anterior:

7) Idade ao parto anterior;

8) Produção de leite por lactação $(\mathrm{kg})$, durante o intervalo entre partos;

9) Pico de produção ( $\mathrm{kg}$ de leite), durante o intervalo entre partos;

10) Dias em lactação, durante o intervalo entre partos;

11) Ordem de lactação, correspondente ao intervalo entre partos;

12) Produção de leite por dia de intervalo entre partos.

Contudo, as variáveis quantitativas contínuas, como o próprio intervalo entre partos, devem ser categorizadas para a aplicação da metodologia. Greenacre (1984), sugere que variáveis desse tipo sejam categorizadas em classes condizentes com as classes de freqüências para a construção de histogramas, enquanto Crivisqui (1993), sugere que as classes de cada variável tenham freqüências iguais.

Optou-se, então, para uma primeira análise, por agrupar cada uma das variáveis quantitativas contínuas em 8 classes distintas, observando-se para isso, a dispersão e distribuição dos dados como sugerido por Greenacre (1984). A Tabela 5 mostra as 12 variáveis utilizadas com a respectiva sigla, identificação das categorias e, categorias ou classes correspondentes para essa forma de categorizar. 
Tabela 5. Variáveis e respectivas categorias para a categorização em 8 classes de igual amplitude.

\begin{tabular}{|c|c|c|c|}
\hline Variáveis & Sigla & $\begin{array}{c}\text { Identificação } \\
\text { das Categorias }\end{array}$ & Categorias ou classes \\
\hline 1) Intervalo entre Partos (meses) & IEP & $\begin{array}{l}\text { IEP1 } \\
\text { IEP2 } \\
\text { IEP3 } \\
\text { IEP4 } \\
\text { IEP5 } \\
\text { IEP6 } \\
\text { IEP7 } \\
\text { IEP8 } \\
\end{array}$ & $\begin{array}{c}(9 ; 11] \\
(11 ; 13] \\
(13 ; 15] \\
(15 ; 17] \\
(17 ; 19] \\
(19 ; 21] \\
(21 ; 23] \\
>23 \\
\end{array}$ \\
\hline 2) Dias em Lactação & $\mathrm{DL}$ & $\begin{array}{l}\text { DL1 } \\
\text { DL2 } \\
\text { DL3 } \\
\text { DL4 } \\
\text { DL5 } \\
\text { DL6 } \\
\text { DL7 } \\
\text { DL8 }\end{array}$ & $\begin{array}{c}\leq 180 \\
(180 ; 255] \\
(255 ; 330] \\
(330 ; 405] \\
(405 ; 480] \\
(480 ; 555] \\
(555 ; 630] \\
>630 \\
\end{array}$ \\
\hline 3) Pico de Lactação (kg de leite) & PC & $\begin{array}{l}\text { PC1 } \\
\text { PC2 } \\
\text { PC3 } \\
\text { PC4 } \\
\text { PC5 } \\
\text { PC6 } \\
\text { PC7 } \\
\text { PC8 } \\
\end{array}$ & $\begin{array}{c}(8 ; 15] \\
(15 ; 22] \\
(22 ; 29] \\
(29 ; 36] \\
(36 ; 43] \\
(43 ; 50] \\
(50 ; 57] \\
>57 \\
\end{array}$ \\
\hline 4) Produção de leite por lactação $(\mathrm{kg})$ & PROD & $\begin{array}{l}\text { PROD1 } \\
\text { PROD2 } \\
\text { PROD3 } \\
\text { PROD4 } \\
\text { PROD5 } \\
\text { PROD6 } \\
\text { PROD7 } \\
\text { PROD8 } \\
\end{array}$ & $\begin{array}{c}\leq 2,5 \\
(2,5 ; 4,0] \\
(4,0 ; 5,5] \\
(5,5 ; 7,0] \\
(7,0 ; 8,5] \\
(8,5 ; 10,0] \\
(10,0 ; 11,5] \\
>11,5 \\
\end{array}$ \\
\hline $\begin{array}{l}\text { 5) Produção de Leite por Dia de Intervalo } \\
\text { entre partos (kg/dia) }\end{array}$ & PDI & $\begin{array}{l}\text { PDI1 } \\
\text { PDI2 } \\
\text { PDI3 } \\
\text { PDI4 } \\
\text { PDI5 } \\
\text { PDI6 } \\
\text { PDI7 } \\
\text { PDI8 } \\
\end{array}$ & $\begin{array}{c}\leq 7 \\
(7 ; 11] \\
(11 ; 15] \\
(15 ; 19] \\
(19 ; 23] \\
(23 ; 27] \\
(27 ; 31] \\
>31 \\
\end{array}$ \\
\hline 6) Idade ao Parto anterior & IDP & $\begin{array}{l}\text { IDP1 } \\
\text { IDP2 } \\
\text { IDP3 } \\
\text { IDP4 } \\
\text { IDP5 } \\
\text { IDP6 } \\
\text { IDP7 } \\
\text { IDP8 }\end{array}$ & $\begin{array}{c}\leq 28 \\
(28 ; 36] \\
(36 ; 44] \\
(44 ; 52] \\
(52 ; 60] \\
(60 ; 68] \\
(68 ; 76] \\
>76 \\
\end{array}$ \\
\hline
\end{tabular}


Tabela 5. Variáveis e respectivas categorias para a categorização em 8 classes de igual amplitude (continuação).

\begin{tabular}{|l|c|c|c|}
\hline \multicolumn{1}{|c|}{ Variáveis } & Sigla & $\begin{array}{c}\text { Identificação } \\
\text { das Categorias }\end{array}$ & Categorias ou classes \\
\hline 7) Ordem de Lactação & L & L1 & 1 \\
& & L2 & 2 \\
& & L3 & 3 \\
& & L4 & 4 \\
& NI & LI1 & $\geq 5$ \\
\hline 8) Número de Inseminações & & NI2 & 1 \\
& & NI3 & 2 \\
& & NI4 & 3 \\
& & NI5 & 4 \\
& & NI6 & 5 \\
& & NI7 & 7 \\
9)Ano do Parto anterior & NI8 & $\geq 8$ \\
\hline & ANOP & ANO94 & 1994 \\
& & ANO95 & 1995 \\
& & ANO96 & 1996 \\
& & ANO97 & 1997 \\
& & ANO98 & 1998 \\
\hline 10) Estação do Ano ao Parto anterior & ESTP & OUT & Março a maio \\
& & INV & Junho a agosto \\
& & PRI & Setembro a novembro \\
& & VER & Dezembro a fevereiro \\
\hline 11) Rebanho & & COL & Colorado \\
& & NAM & Nova América \\
& & SM & Santa Maria \\
& & TOURO & SI Reprodutores numerados de 1 a 61 \\
\hline
\end{tabular}

Para uma segunda análise, obtiveram-se as estimativas dos três valores que limitam os quartis (1. ${ }^{\circ}$ Quartil, Mediana e $3 .^{\circ}$ Quartil) e a partir desses valores agrupou-se cada uma das variáveis quantitativas contínuas em 4 classes distintas, limitadas por tais valores. Assim, cada classe apresentava aproximadamente $25 \%$ das observações de cada variável. A Tabela 6 mostra as 12 variáveis utilizadas com a respectiva sigla, identificação das categorias e, categorias ou classes correspondentes a tal categorização. 
Tabela 6. Variáveis e respectivas categorias considerando os quartis como limites de classe.

\begin{tabular}{|c|c|c|c|}
\hline Variáveis & Sigla & $\begin{array}{l}\text { Identificação } \\
\text { das Categorias }\end{array}$ & Categorias ou classes \\
\hline 1) Intervalo entre Partos (meses) & IEP & $\begin{array}{l}\text { IEP1 } \\
\text { IEP2 } \\
\text { IEP3 } \\
\text { IEP4 } \\
\end{array}$ & $\begin{array}{c}\leq 11,8 \\
(11,8 ; 13,2] \\
(13,2 ; 16,2] \\
>16,2 \\
\end{array}$ \\
\hline 2) Dias em Lactação & $\mathrm{DL}$ & $\begin{array}{l}\text { DL1 } \\
\text { DL2 } \\
\text { DL3 } \\
\text { DL4 } \\
\end{array}$ & $\begin{array}{c}\leq 293 \\
(293 ; 332] \\
(332 ; 395] \\
>395 \\
\end{array}$ \\
\hline 3) Pico de Lactação (kg de leite) & $\mathrm{PC}$ & $\begin{array}{l}\mathrm{PC} 1 \\
\mathrm{PC} 2 \\
\mathrm{PC} 3 \\
\mathrm{PC} 4 \\
\end{array}$ & $\begin{array}{c}\leq 29,7 \\
(29,7 ; 34,6] \\
(34,6 ; 40,2] \\
>40,2 \\
\end{array}$ \\
\hline 4) Produção de leite por lactação $(\mathrm{kg})$ & PROD & $\begin{array}{l}\text { PROD1 } \\
\text { PROD2 } \\
\text { PROD3 } \\
\text { PROD4 } \\
\end{array}$ & $\begin{array}{c}\leq 6873 \\
(6873 ; 8068] \\
(8068 ; 9261] \\
>9261 \\
\end{array}$ \\
\hline $\begin{array}{l}\text { 5) Produção de Leite por Dia de Intervalo } \\
\text { entre partos (kg/dia) }\end{array}$ & PDI & $\begin{array}{l}\text { PDI1 } \\
\text { PDI2 } \\
\text { PDI3 } \\
\text { PDI4 } \\
\end{array}$ & $\begin{array}{c}\leq 15,2 \\
(15,2 ; 19,5] \\
(19,5 ; 23,1] \\
>23,1 \\
\end{array}$ \\
\hline 6) Idade ao Parto anterior & IDP & $\begin{array}{l}\text { IDP1 } \\
\text { IDP2 } \\
\text { IDP3 } \\
\text { IDP4 } \\
\end{array}$ & $\begin{array}{c}\leq 26,7 \\
(26,7 ; 37,2] \\
(37,2 ; 48,2] \\
>48,2 \\
\end{array}$ \\
\hline 7) Ordem de Lactação & $\mathrm{L}$ & $\begin{array}{l}\text { L1 } \\
\text { L2 } \\
\text { L3 } \\
\text { L4 } \\
\text { L5 } \\
\end{array}$ & $\begin{array}{c}1 \\
2 \\
3 \\
4 \\
\geq 5 \\
\end{array}$ \\
\hline 8) Número de Inseminaçôes & NI & $\begin{array}{l}\text { NI1 } \\
\text { NI2 } \\
\text { NI3 } \\
\text { NI4 } \\
\text { NI5 } \\
\end{array}$ & $\begin{array}{c}1 \\
2 \\
3 \\
4 \\
\geq 5 \\
\end{array}$ \\
\hline 9) Ano ao Parto anterior & ANOP & $\begin{array}{l}\text { ANO94 } \\
\text { ANO95 } \\
\text { ANO96 } \\
\text { ANO97 } \\
\text { ANO98 } \\
\end{array}$ & $\begin{array}{l}1994 \\
1995 \\
1996 \\
1997 \\
1998 \\
\end{array}$ \\
\hline 10) Estação do Ano ao Parto anterior & ESTP & $\begin{array}{l}\text { OUT } \\
\text { INV } \\
\text { PRI } \\
\text { VER } \\
\end{array}$ & $\begin{array}{c}\text { Março a maio } \\
\text { Junho a agosto } \\
\text { Setembro a novembro } \\
\text { Dezembro a fevereiro }\end{array}$ \\
\hline 11) Rebanho & REBANHO & $\begin{array}{l}\text { COL } \\
\text { NAM } \\
\text { SM } \\
\text { SMP } \\
\end{array}$ & $\begin{array}{c}\text { Colorado } \\
\text { Nova América } \\
\text { Santa Maria } \\
\text { Santa Maria da Posse } \\
\end{array}$ \\
\hline 12) Reprodutor & TOURO & 61 Reproduto & numerados de 1 a 61 \\
\hline
\end{tabular}


Para efetuar a categorização, utilizou-se novamente o sistema SAS, importando-se o arquivo final do EXCEL, e acrescentando-se a esse arquivo, com o comando IF, novas variáveis com os nomes das categorias correspondentes às classes de cada variável (ver Anexo A e Anexo B).

Depois de categorizadas todas as variáveis, procedeu-se a uma análise descritiva das variáveis disponiveis, para as duas formas de categorizar, bem como uma ilustração de cada variável, utilizando histogramas ou gráficos de colunas, dependendo da origem da variável.

Buscando uma metodologia de análise de correspondência que se aplicasse ao fenômeno em estudo, efetuaram-se 3 análises para ambas as formas de categorizar, como segue:

1) Análise de Correspondência de tabelas sobrepostas: análise considerando a variável Intervalo entre Partos como "variável resposta" e as demais como "variáveis explicativas", exceção feita à variável Reprodutor, que foi considerada como suplementar, devido ao seu grande número de categorias (61 categorias) quando comparada com as demais, o que poderia distorcer a análise;

2) Análise de Correspondência Múltipla: análise considerando as "variáveis explicativas" (Número de Inseminações; Rebanho, Ano do parto anterior; Mês do parto anterior; Idade ao parto anterior; Produção de leite por lactação $(\mathrm{kg})$, durante o Intervalo entre partos; Pico de produção (kg de leite), durante o Intervalo entre partos; Dias em lactação, durante o Intervalo entre partos; Ordem de lactação, correspondente ao Intervalo entre partos e Produção de leite por dia de Intervalo entre partos) como ativas na análise e a variável Intervalo entre Partos como suplementar ou ilustrativa;

3) Análise de Correspondência Simples: Análise para o cruzamento da variável Reprodutor com a variável Intervalo entre Partos. 


\section{RESULTADOS E DISCUSSÃO}

Inicialmente, realizaram-se as 3 análises de correspondência referentes à categorização das variáveis quantitativas contínuas em 8 classes de igual amplitude $\left(1 .^{\mathrm{a}}\right.$ forma), e posteriormente, as 3 análises referentes à categorização em 4 classes de igual freqüência $\left(2 .^{\mathrm{a}}\right.$ forma).

\subsection{Categorização em 8 classes de igual amplitude}

Para melhor visualizar a composição da amostra, quanto a cada variável disponível, resumiram-se os dados em tabelas de freqüências e a partir dessas tabelas construíram-se histogramas ou gráficos de colunas de acordo com a natureza da variável.

A Tabela 7 ilustra os resultados preliminares para todas as variáveis para a $1 .^{\text {a }}$ forma de categorizar. Note-se que a variável Reprodutor não é mostrada, pois essa variável apresenta 61 indivíduos com freqüência observada maior ou igual a 15, por definição, para ambas as formas de categorizar e, portanto, torna-se difícil e desnecessário apresentá-la aqui.

Pela Tabela 7, observa-se que para a variável Intervalo entre Partos a classe mais freqüente foi a IEP2 (intervalo entre partos entre 11 e 13 meses), mas que, mesmo assim, mais de $30 \%$ dos intervalos encontram-se acima de 15 meses. Para a variável Dias em Lactação, nota-se a existência de apenas 19 vacas com lactações inferiores a 180 dias, e que a classe mais freqüente foi a DL3 (255 a 330 dias em lactação). 
Tabela 7. Freqüências observadas para as categorias de cada variável para a $1 .^{\text {a }}$ forma de categorizar.

\begin{tabular}{|c|c|c|c|c|c|}
\hline Variáveis & $\begin{array}{l}\text { Ident. das } \\
\text { Categorias } \\
\end{array}$ & $\begin{array}{l}\text { Categorias } \\
\text { ou classes }\end{array}$ & $\begin{array}{l}\text { Freq. } \\
\text { obs. }\end{array}$ & $\begin{array}{l}\text { Freq. esp. } \\
\text { Acum. }\end{array}$ & $\begin{array}{c}\text { Histogramas ou Gráficos de } \\
\text { Colunas }\end{array}$ \\
\hline 1) Intervalo entre & IEPI & $(9 ; 11]$ & 175 & 0,083 & \multirow{8}{*}{ 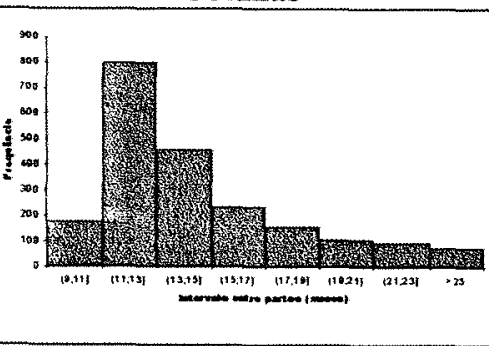 } \\
\hline \multirow{7}{*}{ Partos (meses) } & IEP2 & $(11 ; 13]$ & 801 & 0,464 & \\
\hline & IEP3 & $(13 ; 15]$ & 462 & 0,684 & \\
\hline & IEP4 & $(15 ; 17]$ & 234 & 0,795 & \\
\hline & IEP5 & $(17 ; 19]$ & 158 & 0,871 & \\
\hline & IEP6 & $(19 ; 21]$ & 107 & 0,922 & \\
\hline & IEP7 & $(21 ; 23]$ & 91 & 0,965 & \\
\hline & IEP8 & $>23$ & 74 & 1,000 & \\
\hline \multirow{8}{*}{$\begin{array}{ll}\text { 2) Dias } & \mathrm{em} \\
\text { Lactação } & \end{array}$} & DL1 & $\leq 180$ & 19 & 0,009 & \multirow{8}{*}{ 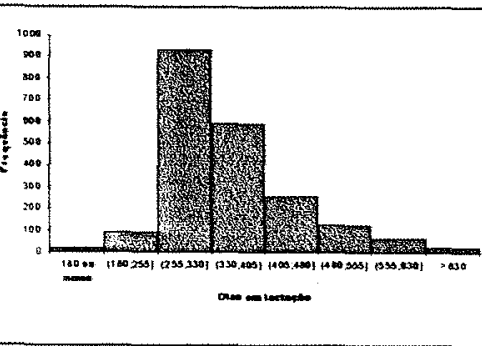 } \\
\hline & DL2 & $(180 ; 255]$ & 94 & 0,054 & \\
\hline & DL3 & $(255 ; 330]$ & 929 & 0,496 & \\
\hline & DL4 & $(330 ; 405]$ & 590 & 0,776 & \\
\hline & DL5 & $(405 ; 480]$ & 258 & 0,899 & \\
\hline & DL6 & $(480 ; 555]$ & 126 & 0,959 & \\
\hline & DL7 & $(555 ; 630]$ & 65 & 0,990 & \\
\hline & DL8 & $>630$ & 21 & 1,000 & \\
\hline \multirow{8}{*}{$\begin{array}{llll}\text { 3) Pico } & & \text { de } \\
\text { Lactação } & (\mathrm{kg} & \mathrm{de} \\
\text { leite) } & & \\
\end{array}$} & $\mathrm{PCl}$ & $(8 ; 15]$ & 19 & 0,009 & \multirow{8}{*}{ 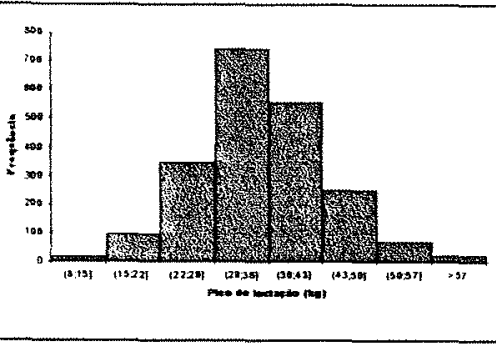 } \\
\hline & $\mathrm{PC} 2$ & $(15 ; 22]$ & 97 & 0,055 & \\
\hline & $\mathrm{PC} 3$ & $(22 ; 29]$ & 346 & 0,220 & \\
\hline & $\mathrm{PC} 4$ & $(29 ; 36]$ & 742 & 0,573 & \\
\hline & PC5 & $(36 ; 43]$ & 558 & 0,838 & \\
\hline & PC6 & $(43 ; 50]$ & 252 & 0,958 & \\
\hline & $\mathrm{PC} 7$ & $(50 ; 57]$ & 68 & 0,990 & \\
\hline & PC8 & $>57$ & 20 & 1,000 & \\
\hline \multirow{8}{*}{$\begin{array}{l}\text { 4) Produção de } \\
\text { leite por lactação } \\
\text { (mil kg) }\end{array}$} & PRODI & $\leq 2,5$ & 15 & 0,007 & \multirow{8}{*}{ 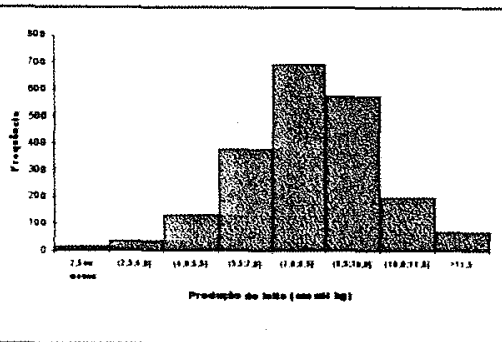 } \\
\hline & PROD2 & $(2,5 ; 4,0]$ & 37 & 0,025 & \\
\hline & PROD3 & $(4,0 ; 5,5]$ & 135 & 0,089 & \\
\hline & PROD4 & $(5,5 ; 7,0]$ & 377 & 0,268 & \\
\hline & PROD5 & $(7,0 ; 8,5]$ & 693 & 0,598 & \\
\hline & PROD6 & $(8,5 ; 10,0]$ & 577 & 0,873 & \\
\hline & PROD7 & $(10,0 ; 11,5]$ & 200 & 0,968 & \\
\hline & PROD8 & $>11,5$ & 68 & 1,000 & \\
\hline \multirow{8}{*}{$\begin{array}{l}\text { 5) Produção de } \\
\text { Leite por Dia de } \\
\text { Intervalo entre } \\
\text { partos }(\mathrm{kg} / \mathrm{dia})\end{array}$} & PDII & $\leq 7$ & 26 & 0,012 & \multirow{8}{*}{ 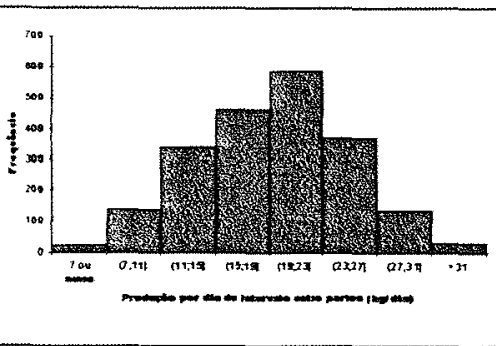 } \\
\hline & PDI2 & $(7 ; 11]$ & 140 & 0,079 & \\
\hline & PDI3 & $(11 ; 15]$ & 343 & 0,242 & \\
\hline & PDI4 & $(15 ; 19]$ & 463 & 0,462 & \\
\hline & PDI5 & $(19 ; 23]$ & 589 & 0,743 & \\
\hline & PDI6 & $(23 ; 27]$ & 372 & 0,920 & \\
\hline & PDI7 & $(27 ; 31]$ & 135 & 0,984 & \\
\hline & PDI8 & $>31$ & 34 & 1,000 & \\
\hline \multirow{8}{*}{$\begin{array}{l}\text { 6) Idade ao Parto } \\
\text { anterior }\end{array}$} & IDP1 & $\leq 28$ & 653 & 0,311 & \multirow{8}{*}{ : } \\
\hline & IDP2 & $(28 ; 36]$ & 319 & 0,462 & \\
\hline & IDP3 & $(36 ; 44]$ & 479 & 0,690 & \\
\hline & IDP4 & $(44 ; 52]$ & 264 & 0,816 & \\
\hline & IDP5 & $(52 ; 60]$ & 177 & 0,900 & \\
\hline & IDP6 & $(60 ; 68]$ & 116 & 0,955 & \\
\hline & IDP7 & $(68 ; 76]$ & 51 & 0,980 & \\
\hline & IDP8 & $>76$ & 43 & 1,000 & \\
\hline
\end{tabular}


Tabela 7. Freqüências observadas para as categorias de cada variável para a $1 .^{a}$ forma de categorizar (continuação).

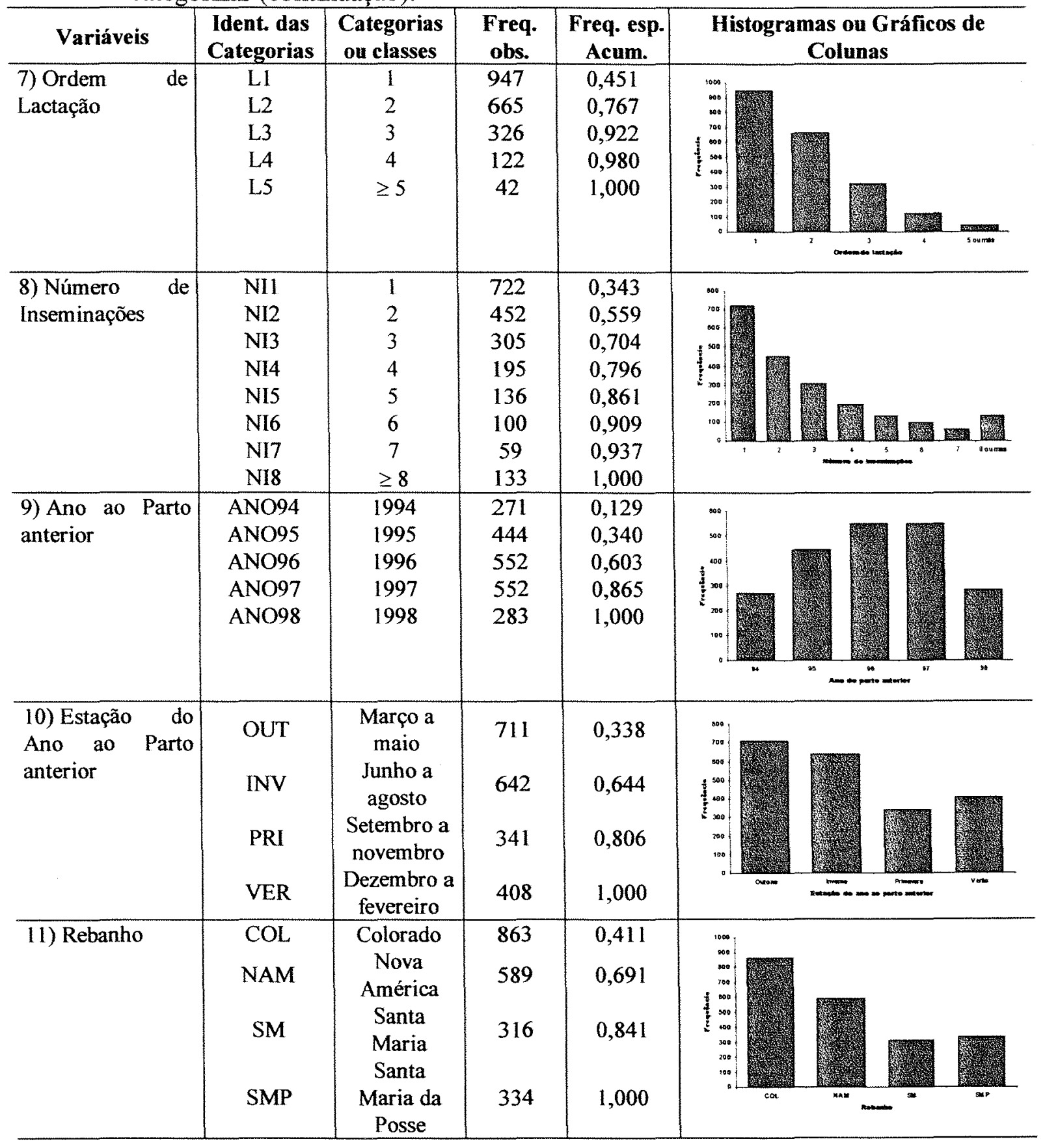

Levando-se em conta as variáveis ligadas à produção de leite, verifica-se que as vacas tiveram picos de lactação com produção variando desde 8 até mais de $57 \mathrm{~kg}$ de leite em um dia, e que a classe mais freqüente foi a PC4 (Pico de lactação entre 29 e 
$36 \mathrm{~kg}$ de leite). Quanto à Produção de Leite por Lactação, houve uma variação de desde menos de $2500 \mathrm{~kg}$ de leite a mais de $11500 \mathrm{~kg}$ de leite em uma lactação, sendo PROD5 (produção entre 7 a 8,5 mil kg de leite) a classe com maior número de observações. Para Produção de Leite por Dia de Intervalo entre Partos a classe PDI5 (19 a $23 \mathrm{~kg}$ de leite/dia) apresentou-se a mais freqüente.

Para as variáveis Idade ao Parto anterior e Ordem de Lactação, nota-se que a primeira classe de ambas foi a mais freqüente, o que era esperado, pois as vacas mais velhas e com maior número de lactações vão sendo descartadas com o passar do tempo.

O Número mais freqüente de Inseminações foi um (1), porém quase $30 \%$ das vacas necessitaram de 4 ou mais inseminações para emprenhar e chegar ao próximo parto, e além disso, 133 vacas foram inseminadas 8 ou mais vezes para o mesmo fim. Observa-se aqui, um problema econômico, pois quanto maior o número de inseminações necessárias para a vaca emprenhar e parir, maior é o custo de produção desta vaca.

Tratando-se de Estação do Ano ao parto anterior, verifica-se que as vacas apresentaram a maior parte dos partos entre os meses de março a agosto. Para Ano do Parto anterior, nota-se um aumento gradativo no número de vacas paridas de 1994 a 1997, enquanto em 1998 houve uma queda, devida provavelmente à data limite (setembro de 1999) da coleta dos dados. Observa-se também, que os rebanhos das fazendas Colorado e Nova América foram os que mais forneceram dados para este trabalho.

$\mathrm{Na}$ continuação da análise, como o interesse primordial está ligado em identificar variáveis associadas com o Intervalo entre Partos, procedeu-se ao cruzamento desta variável com as outras 11. A metodologia da análise de correspondência foi então aplicada, analisando-se conjuntamente todas as tabelas de contingência geradas a partir desse cruzamento (Análise de Correspondência de tabelas sobrepostas). Nessa análise a variável Reprodutor (efeito genético) foi considerada como suplementar, para separá-la das demais (ativas) e evitar possíveis distorções na análise ocasionadas devido ao seu grande número de categorias em relação às demais variáveis. Utilizou-se o PROC 
CORRESP do SAS para efetuar a análise (Anexo A), e o software STATISTICA para a confecção dos mapas de perfis.

No Anexo $\mathrm{C}$ têm-se as freqüências observadas para o cruzamento da variável Intervalo entre Partos com as variáveis ativas, enquanto no Anexo $\mathrm{D}$ são ilustrados os mesmos resultados do primeiro, porém considerando os perfis linha (em porcentagem) das categorias de cada variável ativa, no intuito de ajudar na interpretação do mapa de perfis.

$\mathrm{Na}$ análise de correspondência, a inércia total da tabela de contingência dos dados é decomposta em eixos ou fatores principais, e a cada eixo está associado um autovalor ou inércia principal e por conseguinte uma porcentagem de inércia. A Tabela 8 ilustra essa decomposição, cuja inércia total $(0,36368)$ foi decomposta em sete eixos principais.

Tabela 8. Histograma dos autovalores da análise de correspondência de tabelas sobrepostas na $1 .^{\text {a }}$ forma de categorizar.

\begin{tabular}{|c|c|c|c|c|}
\hline Eixos & Autovalores & Porcentagem & $\begin{array}{l}\text { Porcentagem } \\
\text { acumulada }\end{array}$ & $\begin{array}{ccccc}10 & 20 & 30 & 40 & 50 \\
- & -+-\end{array}$ \\
\hline 1 & 0,18661 & $51,31 \%$ & $51,31 \%$ & 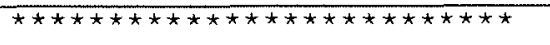 \\
\hline 2 & 0,08592 & $23,62 \%$ & $74,930^{\circ}$ & 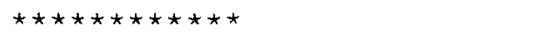 \\
\hline 3 & 0,04546 & $12,50 \%$ & $87,43 \%$ & $\star \star \star \star \star \star ~$ \\
\hline 4 & 0,02253 & 6,19 & $93,62 \%$ & $\star \star \star$ \\
\hline 5 & 0,01181 & $3,25 \%$ & $96,87 \%$ & $\star \star$ \\
\hline 6 & 0,00804 & $2,21 \%$ & $99,08 \%$ & $\star$ \\
\hline 7 & 0,00331 & $0,91 \%$ & $100,00 \%$ & \\
\hline
\end{tabular}

Inércia Total $=0,36368$

Note-se que os dois primeiros eixos explicaram $74,93 \%$ da inércia total da tabela, o que é razoável. Optou-se, então, por estudarem-se apenas os dois primeiros eixos principais.

Com propósito de facilitar a visualização do mapa de perfis, e por conseqüência a interpretação da análise, fizeram-se dois mapas de perfis: o primeiro para estudar a associação das variáveis ativas com o Intervalo entre Partos e o segundo para verificar a possível associação da variável suplementar (Reprodutor) com a "variável resposta" deste estudo. 
$\mathrm{Na}$ Tabela 9 são apresentados os resultados da análise de correspondência de tabelas sobrepostas referentes às variáveis ativas. Esses resultados possibilitam a geração e a interpretação de um gráfico bidimensional - mapa de perfis - definido pelas coordenadas principais de $1 .^{\mathrm{a}} \mathrm{e} 2 .^{\mathrm{a}}$ dimensão.

A partir desses resultados construiu-se o primeiro mapa de perfis, considerando-se apenas as variáveis ativas e a variável Intervalo entre Partos. Esse mapa é mostrado na Figura 2.

Nota-se que somente as variáveis mais contributivas para a análise foram plotadas no mapa para facilitar a visualização. Entenda-se por mais contributivas, as variáveis em que pelo menos uma categoria apresentou contribuição absoluta maior do que a média em um dos dois eixos.

Salienta-se que para interpretar o mapa de perfis, deve-se, além de observar a posição dos pontos no gráfico, averiguar os valores das medidas auxiliares, e também, se for o caso, recorrer à tabela de contingência e aos perfis linha.

Pela Figura 2, nota-se que as categorias das variáveis mais correlacionadas com ambos os eixos, configuram este plano apresentando uma figura clássica da Análise de Correspondência, denominada "Efeito Guttman". Esse efeito é caracterizado pela parábola formada pelas categorias de uma mesma variável.

No estudo do $1 .^{\circ}$ eixo, observa-se que para a variável objeto principal do estudo (IEP), existe uma oposição de intervalos entre partos menores do que 13 meses (IEP1 e IEP2), que se encontram no lado negativo do eixo, e intervalos maiores do que 17 meses (de IEP5 a IEP8), que se encontram no lado positivo do eixo. 


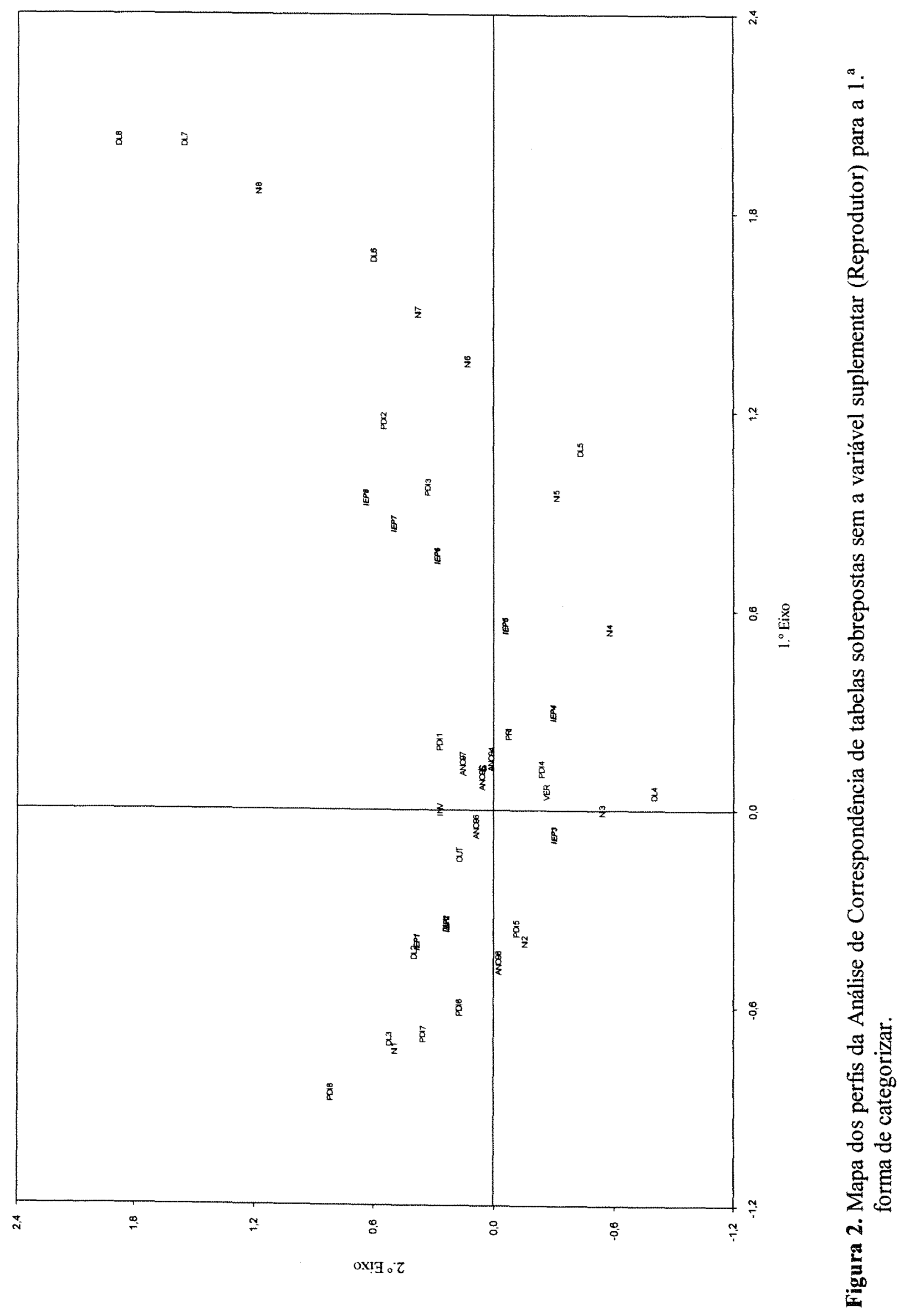


Tabela 9. Resultados da Análise de Correspondência de tabelas sobrepostas para as variáveis ativas para a $1 .^{a}$ forma de categorizar.

\begin{tabular}{|c|c|c|c|c|c|c|c|c|}
\hline \multirow{2}{*}{ Variáveis } & \multirow{2}{*}{ Categorias } & \multirow{2}{*}{ Inércia } & \multicolumn{2}{|c|}{ Coordenadas } & \multicolumn{2}{|c|}{ Contribuições } & \multicolumn{2}{|c|}{ Co-seno Quadrado } \\
\hline & & & 1. ${ }^{\mathrm{a}} \mathrm{Dim}$. & 2. ${ }^{\mathrm{a}} \mathrm{Dim}$. & 1. ${ }^{\mathrm{a}} \mathrm{Dim}$. & 2. ${ }^{\mathrm{a}} \mathrm{Dim}$. & $1 .^{\mathrm{a}} \mathrm{Dim}$. & 2. ${ }^{a}$ Dim. \\
\hline \multirow{8}{*}{$\begin{array}{l}\text { 1) Dias } \\
\text { Lactação }\end{array}$} & DL1 & 0,00057 & $-0,34995$ & 0,15982 & 0,00059 & 0,00027 & 0,53167 & 0,11089 \\
\hline & DL2 & 0,01122 & $-0,43527$ & 0,32245 & 0,00454 & 0,00541 & 0,20771 & 0,11399 \\
\hline & DL3 & 0,08730 & $-0,69620$ & 0,44472 & 0,11479 & 0,10173 & 0,67468 & 0,27529 \\
\hline & DL4 & 0,08451 & 0,04986 & $-0,87434$ & 0,00037 & 0,24975 & 0,00227 & 0,69815 \\
\hline & DL5 & 0,08394 & 1,08819 & $-0,50831$ & 0,07788 & 0,03691 & 0,47610 & 0,10388 \\
\hline & DL6 & 0,07956 & 1,67208 & 0,52550 & 0,08981 & 0,01927 & 0,57919 & 0,05721 \\
\hline & DL7 & 0,07898 & 2,01714 & 1,48068 & 0,06742 & 0,07891 & 0,43806 & 0,23604 \\
\hline & DL8 & 0,05517 & 2,01747 & 1,81233 & 0,02179 & 0,03819 & 0,20265 & 0,16353 \\
\hline \multirow{8}{*}{$\begin{array}{lll}\text { 2) Pico } & & \text { de } \\
\text { Lactação } & (\mathrm{kg} & \mathrm{de} \\
\text { leite) } & & \\
\end{array}$} & $\mathrm{PCl}$ & 0,00124 & $-0,57096$ & 0,12853 & 0,00158 & 0,00017 & 0,65160 & 0,03302 \\
\hline & $\mathrm{PC} 2$ & 00087 & $-0,08267$ & $-0,09141$ & 0,00017 & 0,00045 & 0,09971 & 0,12191 \\
\hline & PC3 & 0,00119 & $-0,13910$ & 0,02216 & 0,00171 & 0,00009 & 0,73499 & 0,01866 \\
\hline & PC4 & 0,00030 & 0,03241 & $-0,00285$ & 0,00020 & 0,00000 & 0,33518 & 0,00259 \\
\hline & PC5 & 0,00070 & $-0,05832$ & 0,00815 & 0,00048 & 0,00002 & 0,35439 & 0,00691 \\
\hline & PC6 & 0,00391 & 0,26927 & $-0,01863$ & 0,00466 & 0,00005 & 0,61125 & 0,00293 \\
\hline & PC7 & 0,00100 & 0,06976 & 0,03578 & 0,00008 & 0,00005 & 0,04313 & 0,01135 \\
\hline & PC8 & 0,00106 & 0,14463 & $-0,07066$ & 0,00011 & 0,00006 & 0,05154 & 0,01230 \\
\hline \multirow{8}{*}{$\begin{array}{l}\text { 3) Produção de } \\
\text { leite por lactação } \\
(\mathrm{mil} \mathrm{kg)}\end{array}$} & PROI & 0,00067 & $-0,51716$ & 0,05339 & 0,00102 & .00002 & 0,78054 & 0,00832 \\
\hline & PRO & 097 & $-0,24080$ & 0,04152 & 0,00055 &, 00004 & 0,28997 & 0,00862 \\
\hline & PROD & 0,00180 & $-0,08772$ & 0,06626 & 0,00026 & 0,00033 & 0,07547 & 0,04306 \\
\hline & PROD4 & 0,00335 & $-0,09848$ & 0,12544 & 0,00093 & 0,00328 & 0,14295 & 0,23192 \\
\hline & PROD5 & 0,00069 & $-0,05146$ & 0,05584 & 0,00047 & 0,00120 & 0,35040 & 0,41245 \\
\hline & PROD6 & 0,00230 & 0,07138 & $-0,08543$ & 0,00075 & 0,00233 & 0,16744 & 0,23981 \\
\hline & PROD7 & 0,00204 & 0,17451 & $-0,16997$ & 0,00155 & 0,00320 & 0,39083 & 0,37075 \\
\hline & PROD8 & 0,00369 & 0,37074 & $-0,20558$ & 0,00238 & 0,00159 & 0,33152 & 0,10194 \\
\hline \multirow{8}{*}{$\begin{array}{l}\text { 4) Produção } \quad \text { de } \\
\text { Leite por Dia } \\
\text { Intervalo entre } \\
\text { partos }(\mathrm{kg} / \mathrm{dia})\end{array}$} & PDII & 0,00156 & 0,20251 & 0,19028 & 0,00027 & 0,00052 & 0,08943 & 0,07896 \\
\hline & PDI2 & 0,03331 & 1,16979 & 0,47622 & 0,04884 & 0,01758 & 0,75229 & 0,12468 \\
\hline & PDI3 & 0,04738 & 0,97155 & 0,24943 & 0,08254 & 0,01182 & 0,89379 & 0,05891 \\
\hline & PDI4 & 0,00972 & 0,12147 & $-0,31421$ & 0,00174 & 0,02531 & 0,09197 & 0,61538 \\
\hline & PDI5 & 0,01353 & $-0,36173$ & $-0,18841$ & 0,01965 & 0,01158 & 0,74520 & 0,20216 \\
\hline & PDI6 & 01898 & $-0,60219$ & 0,10028 & 0,03439 & 0,00207 & 0,92979 & 0,02578 \\
\hline & PDI7 & 0,00968 & $-0,68293$ & 0,27148 & 0,01605 & 0,00551 & 0,85064 & 0,13442 \\
\hline & PDI8 & 0,00865 & $-0,86014$ & 0,74480 & 0,00641 & 0,01044 & 0,38046 & 0,28527 \\
\hline \multirow{8}{*}{$\begin{array}{l}\text { 5) Idade ao Parto } \\
\text { anterior }\end{array}$} & IDP1 & 0,00050 & $-0,03362$ & 0,03243 & 0,00019 & 0,00038 & 0,19484 & 0,18129 \\
\hline & IDP2 & 0,00112 & $-0,06503$ & 0,11477 & 0,00034 & 0,00233 & 0,15770 & 0,49122 \\
\hline & IDP3 & 0,00047 & 0,00194 & 0,00078 & 0,00000 & 0,00000 & 0,00050 & 0,00008 \\
\hline & IDP4 & 0,00061 & 0,02128 & $-0,04486$ & 0,00003 & 0,00029 & 0,02546 & 0,11312 \\
\hline & IDP5 & 0,00172 & 0,08855 & $-0,10626$ & 0,00035 & 0,00111 & 0,10560 & 0,15206 \\
\hline & IDP6 & 0,00133 & 0,10269 & $-0,23689$ & 0,00031 & 0,00360 & 0,12025 & 0,63984 \\
\hline & IDP7 & 0,00037 & $-0,06186$ & $-0,06868$ & 0,00005 & 0,00013 & 0,06828 & 0,08417 \\
\hline & IDP8 & 0,00198 & 0,27253 & 0,08078 & 0,00081 & 0,00016 & 0,21150 & 0,01858 \\
\hline \multirow{5}{*}{$\begin{array}{l}\text { 6) Ordem } \\
\text { Lactação }\end{array}$} & $\mathrm{Ll}$ & 0,00082 & $-0,03456$ & 0,06780 & 0,00029 & 0,00241 & 0,18079 & 0,69570 \\
\hline & $\mathrm{L} 2$ & 0,00049 & 0,02582 & $-0,03130$ & 0,00011 & 0,00036 & 0,11905 & 0,17506 \\
\hline & L3 & 0,00088 & 0,03165 & $-0,05385$ & 0,00008 & 0,00052 & 0,04833 & 0,13991 \\
\hline & L4 & 0,00126 & 0,00698 & $-0,22516$ & 0,00000 & 0,00342 & 0,00062 & 0,64346 \\
\hline & L5 & 0,00073 & 0,10460 & 0,03892 & 0,00012 & 0,00004 & 0,08235 & 0,01140 \\
\hline
\end{tabular}


Tabela 9. Resultados da Análise de Correspondência de tabelas sobrepostas para as variáveis ativas para a $1 .^{a}$ forma de categorizar (continuação).

\begin{tabular}{|c|c|c|c|c|c|c|c|c|}
\hline \multirow{2}{*}{ Variáveis } & \multirow{2}{*}{ Categorias } & \multirow{2}{*}{ Inércia } & \multicolumn{2}{|c|}{ Coordenadas } & \multicolumn{2}{|c|}{ Contribuições } & \multicolumn{2}{|c|}{ Co-seno Quadrado } \\
\hline & & & 1. ${ }^{\mathrm{a}} \mathrm{Dim}$ & 2. ${ }^{\mathrm{a}}$ Dim. & 1. ${ }^{\mathrm{a}} \mathrm{Dim}$. & 2. ${ }^{a}$ Dim. & 1. ${ }^{\mathrm{a}} \mathrm{Dim}$. & 2. ${ }^{a} \mathrm{Dim}$. \\
\hline \multirow{8}{*}{$\begin{array}{l}\text { 7) Número } \\
\text { Inseminações }\end{array}$} & NII & 0,06997 & $-0,72662$ & 0,41733 & 0,09718 & 0,06963 & 0,71265 & 0,23508 \\
\hline & NI2 & 0,01878 & $-0,40143$ & $-0,22963$ & 0,01857 & 0,01320 & 0,50745 & 0,16605 \\
\hline & NI3 & 0,01801 & $-0,00375$ & $-0,61769$ & 0,00000 & 0,06444 & 0,00003 & 0,84521 \\
\hline & NI4 & 0,01918 & 0,54247 & $-0,65218$ & 0,01463 & 0,04593 & 0,39139 & 0,56569 \\
\hline & NI5 & 0,02495 & 0,94852 & $-0,38981$ & 0,03119 & 0,01144 & 0,64154 & 0,10835 \\
\hline & NI6 & 0,02965 & 1,35119 & 0,05908 & 0,04654 & 0,00019 & 0,80556 & 0,00154 \\
\hline & NI7 & 0,01910 & 1,49942 & 0,30209 & 0,03382 & 0,00298 & 0,90862 & 0,03688 \\
\hline & NI8 & 0,09055 & 1,87101 & 1,10779 & 0,11869 & 0,09038 & 0,67263 & 0,23579 \\
\hline \multirow{5}{*}{$\begin{array}{l}\text { 8) Ano ao Parto } \\
\text { anterior }\end{array}$} & ANO94 & 0,00135 & 0,15330 & $-0,06163$ & 0,00162 & 0,00057 & 0,61911 & 0,10006 \\
\hline & ANO95 & 0,00140 & 0,09468 & $-0,01708$ & 0,00101 & 0,00007 & 0,37296 & 0,01214 \\
\hline & ANO96 & 0,00107 & $-0,05190$ & 0,01333 & 0,00038 & 0,00005 & 0,18097 & 0,01195 \\
\hline & ANO97 & 0,00374 & 0,13919 & 0,08194 & 0,00273 & 0,00205 & 0,37390 & 0,12959 \\
\hline & ANO98 & 0,00921 & $-0,46561$ & $-0,10003$ & 0,01564 & 0,00157 & 0,87110 & 0,04021 \\
\hline \multirow{4}{*}{$\begin{array}{l}\text { 9) Estação do Ano } \\
\text { ao Parto anterior }\end{array}$} & INV & 489 & $-0,00281$ & 0,18724 & 0,00000 & 0,01246 & 0,00014 & 0,60231 \\
\hline & OUT & 0,00453 & $-0,13753$ & 0,09678 & 0,00343 & 0,00369 & 0,38799 & 0,19212 \\
\hline & PRI & 0,00773 & 0,22884 & $-0,14893$ & 0,00455 & 0,00419 & 0,30214 & 0,12798 \\
\hline & VER & 0,00778 & 0,05283 & $-0,33880$ & 0,00029 & 0,02593 & 0,01915 & 0,78771 \\
\hline \multirow[t]{4}{*}{ 10) Rebanho } & $\mathrm{COL}$ & 0,00038 & 0,00003 & $-0,00776$ & 0,00000 & 0,00003 & 0,00000 & 0,01771 \\
\hline & NAM & 0,00132 & $-0,03626$ & 0,06769 & 0,00020 & 0,00149 & 0,07674 & 0,26742 \\
\hline & SM & 0,00153 & 0,16279 & 0,08025 & 0,00213 & 0,00113 & 0,71675 & 0,17418 \\
\hline & SMP & 0,00275 & $-0,09014$ & $-0,17523$ & 0,00069 & 0,00568 & 0,12914 & 0,48795 \\
\hline \multirow{8}{*}{$\begin{array}{l}\text { 11) Intervalo } \\
\text { entre Partos (em } \\
\text { meses) }\end{array}$} & IEPI & 0,08074 & $-0,40514$ & 0,30547 & 0,07323 & 0,09042 & 0,46539 & 0,26457 \\
\hline & IEP2 & 0,15905 & $-0,34807$ & 0,15730 & 0,24739 & 0,10975 & 0,79817 & 0,16302 \\
\hline & IEP3 & 0,13050 & $-0,07723$ & $-0,37572$ & 0,00702 & 0,36113 & 0,02762 & 0,65378 \\
\hline & IEP4 & 0,10274 & 0,29162 & $-0,37136$ & 0,05073 & 0,17868 & 0,25337 & 0,41087 \\
\hline & IEP5 & 0,09941 & 0,55269 & $-0,13171$ & 0,12304 & 0,01518 & 0,63509 & 0,03606 \\
\hline & IEP6 & 0,12410 & 0,76444 & 0,20119 & 0,15940 & 0,02398 & 0,65907 & 0,04565 \\
\hline & IEP7 & 0,13839 & 0,86198 & 0,42394 & 0,17237 & 0,09056 & 0,63913 & 0,15460 \\
\hline & IEP8 & 0,16507 & 0,94034 & 0,56392 & 0,16681 & 0,13030 & 0,51853 & 0,18648 \\
\hline
\end{tabular}

Continuando o estudo do $1 .^{\circ}$ eixo, têm-se associados aos intervalos entre partos maiores que 17 meses: em primeiro lugar, dias em lactação maiores do que 405 dias (de DL5 a DL8); seguido por número de inseminações maiores ou iguais a 5 (de NI5 a NI8); produção de leite por dia de intervalo entre partos entre 7 e $15 \mathrm{~kg} / \mathrm{dia}$ (PDI2 e PDI3). E associados ao lado negativo (Intervalos entre Partos menores do que 13 meses), têm-se: primeiramente, dias em lactação entre 255 e 330 dias (DL1 até DL3); seguido por número de inseminações menores ou iguais a 2 (NI1 e NI2); produção de leite por dia de intervalo entre partos maior do que $19 \mathrm{~kg} / \mathrm{dia}$ (de PDI5 a PDI8); e o ano de 1998. 
No $2 .^{\circ}$ eixo, verifica-se uma oposição de intervalos entre partos de 13 a 17 meses (IEP3 e IEP4), que se encontram no lado negativo do eixo, contra intervalos entre partos maiores do que 23 meses (IEP8), que se encontram no lado positivo do eixo, principalmente, descrevendo assim outras associações e reforçando as associações relacionadas ao $1 .^{\circ}$ eixo. As seguintes relações são observadas:

- Observa-se que dias em lactação entre 330 e 480 dias (DL4 e DL5) estão associados a intervalos entre partos de 13 a 17 meses, e que se reforça a associação entre intervalos entre partos menores que 13 meses e DL3, e de IEP8 com número de dias em lactação maiores do que 480 dias (de DL6 a DL8);

- A associação entre NIl e intervalos entre partos menores do que 13 meses é reforçada, assim como a associação entre IEP8 e NI8. Descreve-se também uma associação entre número de inseminações iguais a 3 ou 4 com intervalos entre partos de 13 a 17 meses;

- Quanto à produção de leite por dia de intervalo entre partos (PDI), verifica-se a associação de PDI4 com intervalos entre partos de 13 a 17 meses, PDI2 e PDI3 com IEP8, e reforça-se a associação de PDI8 com IEP1 e IEP2;

- Para estação do ano ao parto anterior, nota-se a associação de VER (meses de Dezembro a Fevereiro) com intervalos entre partos de 13 a 17 meses.

Antes de discutir as associações descritas anteriormente, averiguou-se se a variável suplementar (Reprodutor) tem alguma associação com a variável intervalo entre partos. Nos Anexos E e F são mostradas, respectivamente, as frequiências observadas e os perfis linha (em porcentagem) para o cruzamento da variável Intervalo entre Partos com a variável Reprodutor, no intuito de ajudar na interpretação do mapa de perfis.

$\mathrm{Na}$ Tabela 10 são apresentados os resultados da análise de correspondência referentes à variável suplementar. Com as coordenadas principais de cada um dos reprodutores, construiu-se um novo mapa de perfis, plotando-se sobre o primeiro mapa o número de cada reprodutor na coordenada especificada. O mapa é mostrado na Figura 3. 
Tabela 10. Resultados da Análise de Correspondência de tabelas sobrepostas para a variável suplementar (Reprodutor) para a 1. ${ }^{a}$ forma de categorizar.

\begin{tabular}{|c|c|c|c|c|}
\hline \multirow{2}{*}{ Reprodutores } & \multicolumn{2}{|c|}{ Coordenadas } & \multicolumn{2}{|c|}{ Co-seno quadrado } \\
\hline & 1. ${ }^{a} \mathrm{Dim}$. & 2. ${ }^{\mathrm{a}} \mathrm{Dim}$. & 1. Dim. & 2. $\mathrm{Dim}$. \\
\hline 1 & 0,46728 & $-0,20894$ & 0,35464 & 0,07090 \\
\hline 2 & $-0,24434$ & 0,00815 & 0,16882 & 0,00019 \\
\hline 3 & 0,07238 & 0,11686 & 0,01764 & 0,04599 \\
\hline 4 & $-0,39463$ & 0,02337 & 0,70547 & 0,00247 \\
\hline 5 & 0,51427 & $-0,07076$ & 0,40598 & 0,00769 \\
\hline 6 & $-0,63661$ & 0,66470 & 0,40703 & 0,44373 \\
\hline 7 & $-0,33611$ & 0,16463 & 0,56347 & 0,13519 \\
\hline 8 & 0,29803 & 0,20277 & 0,34783 & 0,16102 \\
\hline 9 & 0,18438 & 0,02763 & 0,15445 & 0,00347 \\
\hline 10 & 0,14963 & $-0,38083$ & 0,10721 & 0,69446 \\
\hline 11 & $-0,38199$ & $-0,18721$ & 0,45799 & 0,11000 \\
\hline 12 & $-0,09365$ & $-0,33593$ & 0,05629 & 0,72437 \\
\hline 13 & 0,36152 & 0,20570 & 0,22604 & 0,07318 \\
\hline 14 & 0,12764 & $-0,08257$ & 0,19173 & 0,08024 \\
\hline 15 & $-0,22547$ & $-0,15628$ & 0,23433 & 0,11258 \\
\hline 16 & 0,68901 & 0,01115 & 0,77819 & 0,00020 \\
\hline 17 & $-0,23108$ & 0,28796 & 0,10346 & 0,16066 \\
\hline 18 & 0,11077 & $-0,14171$ & 0,02980 & 0,04877 \\
\hline 19 & 0,78372 & 0,49934 & 0,46397 & 0,18835 \\
\hline 20 & 0,14141 & $-0,19241$ & 0,04728 & 0,08752 \\
\hline 21 & 0,14770 & 0,02802 & 0,17416 & 0,00627 \\
\hline 22 & $-0,46309$ & $-0,09168$ & 0,70066 & 0,02746 \\
\hline 23 & $-0,30318$ & $-0,02449$ & 0,47359 & 0,00309 \\
\hline 24 & 0,17998 & $-0,18955$ & 0,17159 & 0,19032 \\
\hline 25 & 0,07634 & $-0,21997$ & 0,03305 & 0,27441 \\
\hline 26 & 0,07252 & 0,16672 & 0,02507 & 0,13250 \\
\hline 27 & $-0,34568$ & 0,02856 & 0,29973 & 0,00205 \\
\hline 28 & $-0,02557$ & 0,02671 & 0,00367 & 0,00400 \\
\hline 29 & $-0,05349$ & 0,18703 & 0,02641 & 0,32289 \\
\hline 30 & 0,10852 & $-0,03577$ & 0,24530 & 0,02666 \\
\hline 31 & 0,08467 & $-0,05453$ & 0,09680 & 0,04015 \\
\hline 32 & $-0,16521$ & 0,15754 & 0,08384 & 0,07624 \\
\hline 33 & 0,02783 & $-0,11807$ & 0,02823 & 0,50815 \\
\hline 34 & 0,36265 & 0,21744 & 0,28455 & 0,10230 \\
\hline 35 & $-0,30097$ & $-0,10585$ & 0,28609 & 0,03538 \\
\hline 36 & -0.36557 & $-0,06990$ & 0,63312 & 0,02315 \\
\hline 37 & $-0,05775$ & $-0,01071$ & 0,02532 & 0,00087 \\
\hline 38 & $-0,06001$ & 0,25995 & 0,01227 & 0,23028 \\
\hline 39 & -0.03581 & 0,10249 & 0,00423 & 0,03467 \\
\hline 40 & 0,19056 & $-0,02058$ & 0,17374 & 0,00203 \\
\hline 41 & 0,07389 & $-0,23791$ & 0,01849 & 0,19168 \\
\hline 42 & $-0,07348$ & $-0,07770$ & 0,17618 & 0,19695 \\
\hline 43 & $-0,19944$ & $-0,41046$ & 0,08803 & 0,37287 \\
\hline 44 & 0,19000 & 0,51294 & 0,06800 & 0,49556 \\
\hline 45 & $-0,52955$ & 0,03717 & 0,87301 & 0,00430 \\
\hline 46 & $-0,10648$ & 0,06607 & 0,07782 & 0,02996 \\
\hline 47 & $-0,35052$ & 0,10671 & 0,55467 & 0,05140 \\
\hline 48 & $-0,10537$ & 0,25694 & 0,04068 & 0,24193 \\
\hline 49 & $-0,05057$ & 0,00056 & 0,01738 & 0,00000 \\
\hline so & 0,17294 & $-0,03759$ & 0,17399 & 0,00822 \\
\hline 51 & 0,05697 & 0,07299 & 0,06314 & 0,10366 \\
\hline 52 & $-0,10866$ & $-0,20781$ & 0,02878 & 0,10526 \\
\hline 53 & 0,22802 & $-0,17388$ & 0,18189 & 0,10577 \\
\hline 54 & $-0,32663$ & 0,09704 & 0,57609 & 0,05084 \\
\hline 55 & $-0,05361$ & 0,56355 & 0,00662 & 0,73133 \\
\hline 56 & 0,21217 & $-0,01644$ & 0,11941 & 0,00072 \\
\hline 57 & $-0,11565$ & 0,03241 & 0,11197 & 0,00879 \\
\hline 58 & $-0,07248$ & $-0,09439$ & 0,02905 & 0,04927 \\
\hline 59 & 0,09787 & $-0,46058$ & 0,02269 & 0,50254 \\
\hline 60 & $-0,30888$ & 0,53054 & 0,13312 & 0,39274 \\
\hline 61 & 0.17547 & 0.22185 & 0.07399 & 0,11828 \\
\hline
\end{tabular}



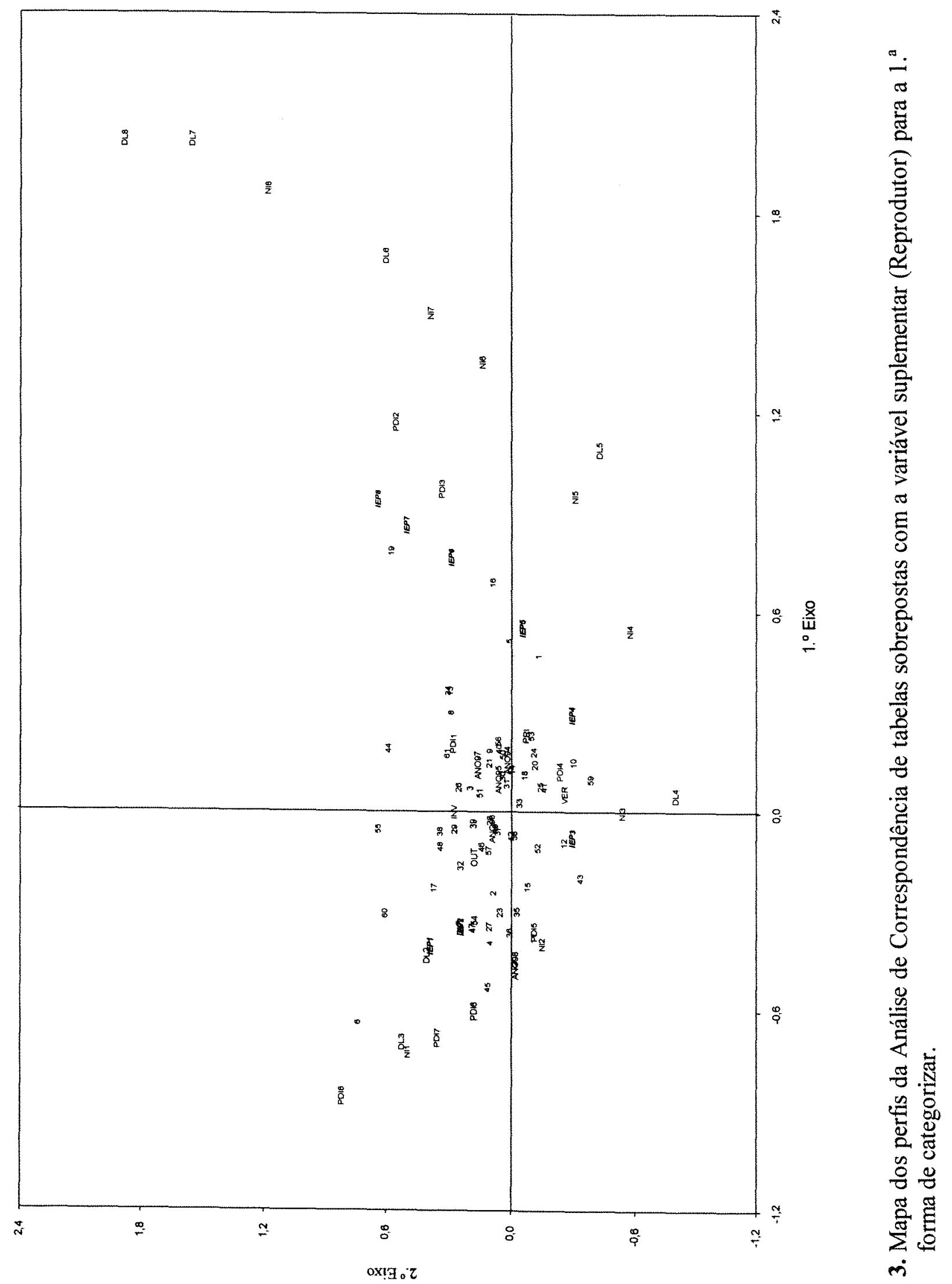

 
Mesmo com a dificuldade de interpretar o mapa devido à sobreposição de alguns pontos, pode-se verificar que a variável Reprodutor também está relacionada com o intervalo entre partos, pois os mesmos estão relativamente dispersos sobre o mapa. Verifica-se, por exemplo, que os reprodutores 1, 5, 16 e 19 estão associados com intervalos entre partos maiores que 17 meses, e que os reprodutores 6,22 e 45 estão associados com intervalos entre partos menores do que 13 meses. Note-se que esses reprodutores estão bem representados sobre o mapa, pois sua contribuição relativa é mais ou menos elevada.

Averiguando-se o Anexo $\mathrm{F}$, verifica-se que o reprodutor 6, por exemplo, apresentou $80 \%$ dos intervalos entre partos entre 11 e 13 meses, enquanto que para o reprodutor 16 apenas $13,8 \%$ dos intervalos encontram-se nessa mesma faixa, condizentes, é claro, com os resultados da análise de correspondência.

Complementando os resultados da análise de correspondência de tabelas sobrepostas para a categorização em 8 classes de igual amplitude pode-se inferir o seguinte:

$\Rightarrow$ Para a variável dias em lactação, já que os menores intervalos entre partos estão associados com dias em lactação também menores (IEP1 e IEP2 com DL1 a DL3), que os intervalos intermediários (entre 13 e 17 meses) estão associados com dias em lactação intermediários (entre 330 e 480 dias) e que intervalos entre partos maiores do que 17 meses estão associados com dias em lactação maiores do que 405 dias, pode-se supor que a maioria das vacas estão sendo "secas" conforme se aproxime a data do parto, isto é, a maioria das vacas continua produzindo leite até que se aproxime a data do parto;

$\Rightarrow$ Para número de inseminações, à medida que o intervalo entre partos aumenta o número de inseminações também aumenta, podendo-se supor que, ou as inseminações não estão sendo feitas de forma adequada e, então, têm-se muitas repetições de cio e novas inseminações até que se consiga a prenhez definitiva, ou as vacas realmente têm problemas reprodutivos que, no entanto, 
não estão sendo detectados e corrigidos em tempo hábil, ocasionando, assim um aumento no custo de produção;

$\Rightarrow$ Quanto à variável Produção por Dia de Intervalo entre Partos, nota-se que os maiores intervalos entre partos estão associados com as menores produções e, que os menores intervalos estão associados com as maiores produções de leite por dia de intervalo. Então, levando-se em conta somente essa variável e a variável número de inseminações (sem entrar na parte econômica) pode-se concluir que o intervalo entre partos menor do que 13 meses é o ideal, considerando-se essa análise, pois é onde se gasta o menor número de inseminações por parto. e onde têm-se as maiores produções por dia de intervalo entre partos;

$\Rightarrow$ Em se tratando de Estação do Ano ao parto anterior, verifica-se que os meses de Dezembro a Fevereiro estão associados com intervalos entre partos de 13 a 17 meses. Para as outras estações qualquer afirmação pode ser falsa pois as mesmas encontram-se muito próximas da origem dos eixos;

$\Rightarrow$ Note-se que o ano de 1998 ao parto anterior foi o único ano em que ocorreu uma certa associação de ano com intervalo entre partos, sendo este associado a intervalos menores do que 13 meses, pois os demais anos encontram-se todos bem próximos da origem dos dois eixos principais. Essa associação é devida, provavelmente, à data limite para a coleta dos dados (Setembro de 1999), que não permitiu que intervalos entre partos mais longos fossem observados.

Comparando-se os resultados obtidos pela análise de correspondência de tabelas sobrepostas, para essa $1 .^{a}$ forma de categorizar, com os resultados da Tabela 1 , nota-se uma certa igualdade de resultados, excetuando-se o efeito de rebanho e de ano ao parto anterior, que na última foram importantes fontes de variação no intervalo, mas não o foram nessa análise de correspondência. 
Como uma segunda forma de analisar os dados, optou-se por utilizar a análise de correspondência múltipla, considerando todas as variáveis disponiveis como ativas na análise, à exceção de Intervalo entre Partos e Reprodutor. Nessa análise a variável Intervalo entre Partos foi considerada como suplementar, ou ilustrativa, e a variável Reprodutor foi descartada. Isto é, buscaram-se as associações da variável Intervalo entre Partos com as outras variáveis no contexto das variáveis ativas.

A Tabela 11 ilustra a decomposição da inércia total $(5,60)$ da análise de correspondência múltipla para a $1 .^{\mathrm{a}}$ forma de categorizar, a qual foi decomposta em 56 eixos principais. $\mathrm{Na}$ análise de correspondência múltipla não se leva em conta a porcentagem de inércia explicada pelos eixos para determinar o número de fatores a estudar, mas se estes são interpretáveis, ou não. Assim, nesse contexto, optou-se, por estudar apenas os dois primeiros eixos principais, independentemente da variabilidade explicada por estes.

$\mathrm{Na}$ Tabela 12 são apresentados os resultados da análise de correspondência múltipla para a $1 .^{\mathrm{a}}$ forma de categorizar. A partir desses resultados construiu-se o mapa de perfis que é mostrado na Figura 4.

Note-se, apesar da visualização não ser das melhores, que as categorias da variável Intervalo entre Partos (IEP) encontram-se todas ao redor e próximas da origem dos eixos, não permitindo associá-las a nada, e além disso não estão bem representadas.

Pela observação da Figura 4, verifica-se também o chamado "Efeito Guttman", como na análise de correspondência de tabelas sobrepostas, porém relacionado a outras variáveis. Note-se a associação entre as variáveis Produção de Leite por Lactação, Pico de Lactação, Produção de Leite por Dia de Intervalo entre Partos, Dias em Lactação, Idade ao Parto anterior e Ordem de Lactação, as quais não são de interesse para discussão no presente momento. 
Tabela 11. Histograma dos autovalores da análise de correspondência múltipla para a $1 .^{\mathrm{a}}$ forma de categorizar.

\begin{tabular}{|c|c|c|c|c|}
\hline Eixos & Autovalores & Porcentagem & $\begin{array}{l}\text { Porcentagem } \\
\text { acumulada }\end{array}$ & $\begin{array}{ccccc}2 & 4 & 6 & 8 & 10 \\
- & +- & -+- & -+ & -+\end{array}$ \\
\hline 1 & 0,33400 & $5,96 \%$ & $5,96 \%$ & 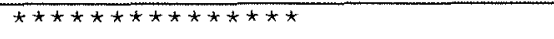 \\
\hline 2 & 0,27555 & $4,92 \%$ & $10,88 \%$ & 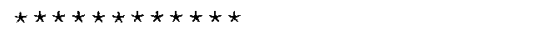 \\
\hline 3 & 0,23200 & $4,14 \%$ & $15,02 \%$ & 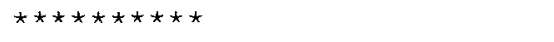 \\
\hline 4 & 0,19994 & $3,57 \%$ & $18,59 \%$ & 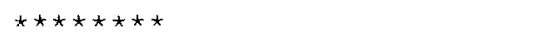 \\
\hline 5 & 0,18938 & $3,38 \%$ & $21,97 \%$ & 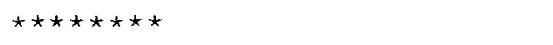 \\
\hline 6 & 0,17976 & $3,21 \%$ & $25,18 \%$ & 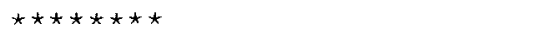 \\
\hline 7 & 0,16663 & $2,98 \%$ & $28.16 \%$ & 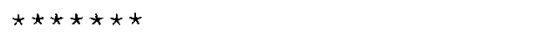 \\
\hline 8 & 0,15783 & $2,82 \%$ & $30,98 \%$ & $\star \star \star \star \star \star \star \star ~$ \\
\hline 9 & 0,15058 & $2,69 \%$ & $33,67 \%$ & 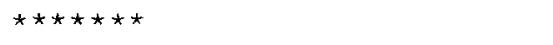 \\
\hline 10 & 0,13876 & $2,48 \%$ & 36,158 & 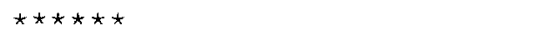 \\
\hline 11 & 0,13395 & $2,39 \%$ & $38,54 \%$ & 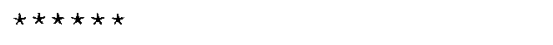 \\
\hline 12 & 0,12682 & $2,26 \%$ & $40,80 \%$ & 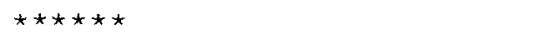 \\
\hline 13 & 0,12177 & $2,17 \%$ & $42,97 \%$ & 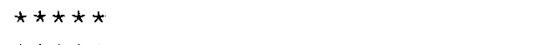 \\
\hline 14 & 0,11877 & $2,12 \%$ & $45,09 \%$ & 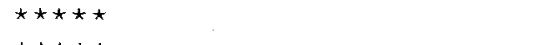 \\
\hline 15 & 0,11598 & $2,07 \%$ & $47,16 \%$ & 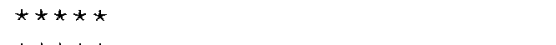 \\
\hline 16 & 0,11325 & $2,02 \%$ & $49,18 \%$ & 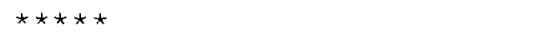 \\
\hline 17 & 0,11146 & $1,99 \%$ & $51,17 \%$ & 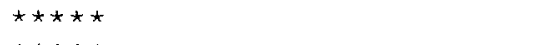 \\
\hline 18 & 0,10980 & $1,96 \%$ & $53,13 \%$ & 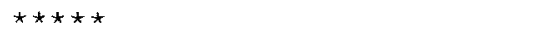 \\
\hline 19 & 0,10797 & $1,93 \%$ & $55,06 \%$ & 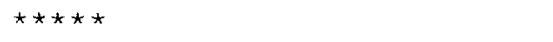 \\
\hline 20 & 0,10577 & $1,89 \%$ & $56,95 \%$ & 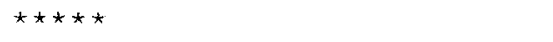 \\
\hline 21 & 0,10473 & $1,87 \%$ & $58,82 \%$ & 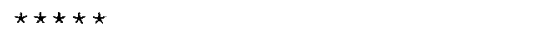 \\
\hline 22 & 0,10312 & 1,84 응 & $60,66 \%$ & 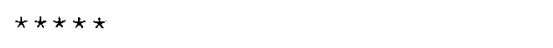 \\
\hline 23 & 0,10140 & $1,81 \%$ & $62,47 \%$ & 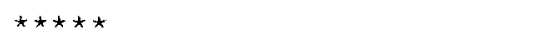 \\
\hline 24 & 0,10059 & $1,80 \%$ & $64,27 \%$ & 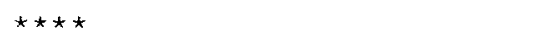 \\
\hline 25 & 0,09908 & $1,77 \%$ & $66,04 \%$ & $\star \star * *$ \\
\hline 26 & 0,09707 & $1,73 \%$ & $67,77 \%$ & $\star \star \star \star$ \\
\hline 27 & 0,09437 & $1,69 \%$ & $69,46 \%$ & $\star \star \star \star$ \\
\hline 28 & 0,09289 & $1,66 \%$ & $71,12 \%$ & $\star \star \star \star$ \\
\hline 29 & 0,09123 & $1,63 ㅇ$ & $72,75 \%$ & $\star \star \star \star \star$ \\
\hline 30 & 0,08996 & $1,61 \%$ & $74,36 \%$ & $\star \star \star \star$ \\
\hline 31 & 0,08894 & $1,59 \%$ & $75,95 \%$ & $\star \star \star \star \star$ \\
\hline 32 & 0,08702 & $1,55 \%$ & $77,50 \%$ & $\star \star \star \star \star$ \\
\hline 33 & 0,08515 & 1,52 음 & $79,02 \%$ & $\star \star \star \star \star$ \\
\hline 34 & 0,08338 & $1,49 \%$ & $80,51 \%$ & 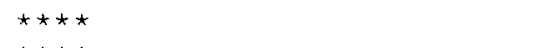 \\
\hline 35 & 0,08217 & $1,47 \%$ & $81,98 \%$ & $\star \star \star \star \star$ \\
\hline 36 & 0,08125 & $1,45 \%$ & $83,43 \%$ & $\star \star \star \star \star$ \\
\hline 37 & 0,07764 & $1,39 \%$ & $84,82 \%$ & $\star \star \star$ \\
\hline 38 & 0,07649 & $1,37 \mathrm{~s}$ & $86,19 \%$ & $\star \star \star$ \\
\hline 39 & 0,07521 & $1,34 \%$ & $87,53 \%$ & $\star \star \star *$ \\
\hline 40 & 0,07338 & $1,31 \%$ & 88,84 & $\star \star \star$ \\
\hline 41 & 0,06956 & $1,24 \%$ & $90,08 \%$ & $\star \star \star$ \\
\hline 42 & 0,06838 & $1,22 \%$ & $91,30 \%$ & $\star \star \star$ \\
\hline 43 & 0,06568 & $1,17 \%$ & $92,47 \%$ & $\star * \star$ \\
\hline 44 & 0,06006 & $1,07 \%$ & $93,54 \%$ & $\star \star \star$ \\
\hline 45 & 0,05741 & $1,03 \%$ & 94,57 응 & $\star \star \star *$ \\
\hline 46 & 0.05521 & $0,99 \%$ & $95,56 \%$ & $\star \star$ \\
\hline 47 & 0,04779 & $0,85 \%$ & $96,41 \%$ & $\star \star$ \\
\hline 48 & 0,04657 & $0,83 \%$ & $97,24 \%$ & $\star \star$ \\
\hline 49 & 0,03413 & $0,61 \%$ & $97,85 \%$ & $\star \star$ \\
\hline 50 & 0,02822 & $0,50 \%$ & $98,35 \%$ & $\star$ \\
\hline 51 & 0,02563 & $0,46 \frac{\circ}{\circ}$ & $98,81 \%$ & * \\
\hline 52 & 0,02040 & $0,36 \%$ & $99,17 \%$ & * \\
\hline 53 & 0,01829 & $0,33 \%$ & $99,50 \%$ & * \\
\hline 54 & 0,01404 & 0,25 응 & $99,75 \%$ & $\star$ \\
\hline 55 & 0,00763 & 0,14 응 & $99,89 \%$ & \\
\hline 56 & 0,00600 & $0,11 \%$ & $100,00 \%$ & \\
\hline
\end{tabular}

Inércia Total $=5,60$ 
Tabela 12. Resultados da Análise de Correspondência Múltipla para a $1 .^{\text {a }}$ forma de categorizar.

\begin{tabular}{|c|c|c|c|c|c|c|c|c|}
\hline \multirow{2}{*}{ Variáveis } & \multirow{2}{*}{ Categorias } & \multirow{2}{*}{ Inércia } & \multicolumn{2}{|c|}{ Coordenadas } & \multicolumn{2}{|c|}{ Contribuições } & \multicolumn{2}{|c|}{ Co-seno quadrado } \\
\hline & & & 1. ${ }^{\mathrm{a}} \mathrm{Dim}$. & 2. ${ }^{\mathrm{a}}$ Dim. & 1. ${ }^{\mathrm{a}} \mathrm{Dim}$. & 2. ${ }^{\mathrm{a}} \mathrm{Dim}$. & 1. ${ }^{\mathrm{a}} \mathrm{Dim}$. & 2..$^{\mathrm{a}}$ Dim. \\
\hline \multirow{8}{*}{$\begin{array}{l}\text { 1) Dias } \quad \text { em } \\
\text { Lactação }\end{array}$} & DL1 & 0,01770 & $-1,61161$ & 6,96686 & 0,00703 & 0,15922 & 0,02369 & 0,44273 \\
\hline & DL2 & 0,01706 & $-0,93025$ & 1,21805 & 0,01159 & 0,02408 & 0,04051 & 0,06945 \\
\hline & DL3 & 0,00996 & 0,08176 & $-0,14383$ & 0,00088 & 0,00332 & 0,00529 & 0,01638 \\
\hline & DL4 & 0,01284 & 0,23532 & $-0,14191$ & 0,00465 & 0,00205 & 0,02161 & 0,00786 \\
\hline & DL5 & 0,01567 & $-0,11964$ & $-0,05009$ & 0,00053 & 0,00011 & 0,00200 & 0,00035 \\
\hline & DL6 & 0,01679 & $-0,29053$ & $-0,08493$ & 0,00151 & 0,00016 & 0,00538 & 0,00046 \\
\hline & DL7 & 0,01730 & $-0,25058$ & $-0,12595$ & 0,00058 & 0,00018 & 0,00200 & 0,00051 \\
\hline & DL8 & 0,01768 & $-0,61752$ & 0,10879 & 0,00114 & 0,00004 & 0,00385 & 0,00012 \\
\hline \multirow{8}{*}{$\begin{array}{l}\text { 2) Pico de Lactação } \\
\text { (kg de leite) }\end{array}$} & $\mathrm{PCl}$ & 0,01770 & $-1,50561$ & 5,73480 & 0,00613 & 0,10788 & 0,02068 & 0,29999 \\
\hline & $\mathrm{PC} 2$ & 0,01703 & $-1,37852$ & 1,23371 & 0,02626 & 0,02549 & 0,09194 & 0,07363 \\
\hline & $\mathrm{PC} 3$ & 0,01492 & $-0,91880$ & $-0,12141$ & 0,04160 & 0,00088 & 0,16634 & 0,00290 \\
\hline & $\mathrm{PC} 4$ & 0,01155 & $-0,37201$ & $-0,39436$ & 0,01463 & 0,01992 & 0,07551 & 0,08485 \\
\hline & PC5 & 0,01312 & 0,48174 & $-0,04626$ & 0,01844 & 0,00021 & 0,08387 & 0,00077 \\
\hline & PC6 & 0,01572 & 1,29883 & 0,32399 & 0,06055 & 0,00457 & 0,22979 & 0,01430 \\
\hline & PC7 & 0,01728 & 1,87076 & 0,61912 & 0,03390 & 0,00450 & 0,11700 & 0,01281 \\
\hline & PC8 & 0,01769 & 1,64672 & 0,40286 & 0,00772 & 0,00056 & 0,02605 & 0,00156 \\
\hline \multirow{8}{*}{$\begin{array}{l}\text { 3) Produção de leite } \\
\text { por lactação (mil } \\
\mathrm{kg} \text { ) }\end{array}$} & PROD1 & 0,01773 & $-1,91079$ & 8,56472 & 0,00780 & 0,18997 & 0,02624 & 0,52722 \\
\hline & PROD2 & 0.01754 & $-1,54339$ & 2,78368 & 0,01255 & 0,04950 & 0,04268 & 0,13884 \\
\hline & PROD3 & 0,01671 & $-1,19147$ & 0,74603 & 0,02730 & 0,01297 & 0,09743 & 0,03820 \\
\hline & PROD4 & 0,01465 & $-0,78972$ & $-0,23121$ & 0,03349 & 0,00348 & 0,13630 & 0,01168 \\
\hline & PROD5 & 0,01197 & $-0,23296$ & $-0,42168$ & 0,00536 & 0,02127 & 0,02669 & 0,08746 \\
\hline & PROD6 & 0,01296 & 0,51488 & $-0,11859$ & 0,02179 & 0,00140 & 0,10030 & 0,00532 \\
\hline & PROD7 & 0,01616 & 1,40817 & 0,36055 & 0,05649 & 0,00449 & 0,20851 & 0,01367 \\
\hline & PROD8 & 0,01728 & 1,86851 & 0,64013 & 0,03382 & 0,00481 & 0,11672 & 0,01370 \\
\hline \multirow{8}{*}{$\begin{array}{l}\text { 4) Produção } \\
\text { Leite por Dia de } \\
\text { Intervalo entre } \\
\text { partos }(\mathrm{kg} / \mathrm{dia})\end{array}$} & PDI1 & 0,01764 & $-1,89652$ & 6,76555 & 0,01332 & 0,20547 & 0,04505 & 0,57326 \\
\hline & PDI2 & 0,01667 & $-1,31948$ & 0,73962 & 0,03472 & 0,01322 & 0,12423 & 0,03903 \\
\hline & PDI3 & 0,01494 & $-0,54487$ & $-0,03329$ & 0,01450 & 0,00007 & 0,05789 & 0,00022 \\
\hline & PDI4 & 0,01392 & $-0,29614$ & $-0,22568$ & 0,00578 & 0,00407 & 0,02477 & 0,01439 \\
\hline & PDI5 & 0,01285 & 0,06919 & $-0,33654$ & 0,00040 & 0,01152 & 0,00186 & 0,04409 \\
\hline & PDI6 & 0,01470 & 0,63667 & $-0,11566$ & 0,02148 & 0,00086 & 0,08716 & 0,00288 \\
\hline & PDI7 & 0,01671 & 1,55691 & 0,39153 & 0,04661 & 0,00357 & 0,16636 & 0,01052 \\
\hline & PDI8 & 0,01757 & 2,06663 & 0,73075 & 0,02068 & 0,00313 & 0,07022 & 0,00878 \\
\hline \multirow{8}{*}{$\begin{array}{l}\text { 5) Idade ao Parto } \\
\text { anterior }\end{array}$} & IDP1 & 0,01231 & $-0,70169$ & $-0,47747$ & 0,04580 & 0,02570 & 0,22189 & 0,10274 \\
\hline & IDP2 & 0,01515 & $-0,69375$ & $-0,11607$ & 0,02187 & 0,00074 & 0,08611 & 0,00241 \\
\hline & IDP3 & 0,01379 & 0,20900 & 0,22671 & 0,00298 & 0,00425 & 0,01289 & 0,01517 \\
\hline & IDP4 & 0,01561 & 0,64236 & 0,36344 & 0,01552 & 0,00602 & 0,05927 & 0,01897 \\
\hline & IDP5 & 0,01635 & 0,89337 & 0,53812 & 0,02012 & 0,00885 & 0,07338 & 0,02663 \\
\hline & IDP6 & 0,01687 & 1,34033 & 0,29465 & 0,02968 & 0,00174 & 0,10493 & 0,00507 \\
\hline & IDP7 & 0,01742 & 0,86424 & 0,24214 & 0,00543 & 0,00052 & 0,01857 & 0,00146 \\
\hline & IDP8 & 0,01749 & 1,21243 & 0.05794 & 0,00900 & 0,00002 & 0,03070 & 0,00007 \\
\hline 6) Ordem & $\mathrm{LI}$ & 0,00981 & $-0,71538$ & $-0,37515$ & 0,06903 & 0,02301 & 0,41961 & 0,11539 \\
\hline \multirow{4}{*}{ Lactação } & L2 & 0,01221 & 0,24642 & 0,23210 & 0,00575 & 0,00618 & 0,02810 & 0,02493 \\
\hline & L3 & 0,01509 & 0,90464 & 0.52321 & 0,03800 & 0,01541 & 0,15022 & 0,05025 \\
\hline & $\mathrm{L} 4$ & 0,01682 & 1,38897 & 0,22608 & 0,03352 & 0,00108 & 0,11887 & 0,00315 \\
\hline & L5 & 0,01750 & 1,17213 & 0,06601 & 0,00822 & 0,00003 & 0,02801 & 0,00009 \\
\hline
\end{tabular}


Tabela 12. Resultados da Análise de Correspondência Múltipla para a $1 .^{a}$ forma de categorizar (continuação).

\begin{tabular}{|c|c|c|c|c|c|c|c|c|}
\hline \multirow{2}{*}{ Variáveis } & \multirow{2}{*}{ Categorias } & \multirow{2}{*}{ Inércia } & \multicolumn{2}{|c|}{ Coordenadas } & \multicolumn{2}{|c|}{ Contribuicóes } & \multicolumn{2}{|c|}{ Co-seno quadrado } \\
\hline & & & 1. ${ }^{\mathrm{a}} \mathrm{Dim}$. & 2. $\mathrm{Dim}$. & 1. ${ }^{\mathrm{a}} \mathrm{Dim}$. & 2. Dim. & 1. ${ }^{\mathrm{a}} \mathrm{Dim}$. & $2{ }^{\mathrm{a}} \mathrm{Dim}$. \\
\hline \multirow{8}{*}{$\begin{array}{l}\text { 7) Número de } \\
\text { Inseminações }\end{array}$} & NII & 0,01172 & $-0,10324$ & 0,00366 & 0,00110 & 0,00000 & 0,00558 & 0,00001 \\
\hline & NI2 & 0,01402 & 0,25293 & $-0,10755$ & 0,00412 & 0,00090 & 0,01752 & 0,00317 \\
\hline & NI3 & 0,01527 & 0,06508 & 0,05942 & 0,00018 & 0,00019 & 0,00072 & 0,00060 \\
\hline & NI4 & 0,01620 & 0,06917 & 0,17378 & 0,00013 & 0,00102 & 0.00049 & 0,00309 \\
\hline & NI5 & 0,01670 & $-0,06727$ & 0,00726 & 0,00009 & 0,00000 & 0.00031 & 0,00000 \\
\hline & NI6 & 0,01701 & $-0,10212$ & 0,08126 & 0,00015 & 0,00011 & 0,00052 & 0,00033 \\
\hline & NI7 & 0,01736 & $-0,32047$ & 0,09720 & 0,00086 & 0,00010 & 0,00297 & 0,00027 \\
\hline & NI8 & 0,01673 & $-0,26204$ & $-0,15703$ & 0,00130 & 0,00057 & 0,00464 & 0.00167 \\
\hline \multirow{5}{*}{$\begin{array}{l}\text { 8) Ano ao Parto } \\
\text { anterior }\end{array}$} & ANO94 & 0,01555 & $-0,68366$ & $-0,04188$ & 0,01804 & 0,00008 & 0,06918 & 0,00026 \\
\hline & ANO95 & 0,01409 & $-0,62035$ & $-0,08459$ & 0,02434 & 0,00055 & 0.10305 & 0,00192 \\
\hline & ANO96 & 0,01317 & 0,17472 & $-0,05564$ & 0,00240 & 0,00030 & 0,01087 & 0,00110 \\
\hline & ANO97 & 0,01317 & 0,38942 & 0,07404 & 0,01192 & 0,00052 & 0,05401 & 0,00195 \\
\hline & ANO98 & 0,01545 & 0.52755 & 0,13693 & 0,01122 & 0,00092 & 0,04330 & 0,00292 \\
\hline \multirow{4}{*}{$\begin{array}{l}\text { 9) Estação do Ano } \\
\text { ao Parto anterior }\end{array}$} & INV & 0,01240 & $-0,01829$ & $-0,11918$ & 0,00003 & 0,00157 & 0,00015 & 0,00625 \\
\hline & OUT & 0,01182 & 0,15760 & 0,09530 & 0,00252 & 0,00111 & 0.01270 & 0,00464 \\
\hline & PRI & 0,01496 & $-0,06888$ & $-0,12859$ & 0,00023 & 0.00097 & 0,00092 & 0.00320 \\
\hline & VER & 0,01439 & $-0,18829$ & 0.12893 & 0,00206 & 0,00117 & 0,00854 & 0,00400 \\
\hline \multirow[t]{4}{*}{ 10) Rebanho } & COL & 0,01053 & 0,09283 & $-0,05614$ & 0,00106 & 0,00047 & 0,00600 & 0,00220 \\
\hline & NAM & 0,01285 & 0,10294 & 0,00271 & 0,00089 & 0,00000 & 0,00413 & 0,00000 \\
\hline & SM & 0,01517 & $-0,62833$ & 0,41315 & 0,01777 & 0,00931 & 0,06985 & 0,03020 \\
\hline & SMP & 0,01502 & 0,17309 & -0.25060 & 0,00143 & 0.00362 & 0,00566 & 0,01186 \\
\hline \multirow{8}{*}{$\begin{array}{l}\text { 11) Intervalo entre } \\
\text { Partos (em meses) }\end{array}$} & IEP1 & $\cdot$ & $-0,08102$ & 0,07474 & & & 0,00060 & 0,00051 \\
\hline & IEP2 & . & 0,05581 & $-0,01472$ & . & & 0,00192 & 0,00013 \\
\hline & IEP3 & . & 0,15075 & $-0,04629$ & . & . & 0,00640 & 0,00060 \\
\hline & IEP4 & . & 0,03316 & 0,00615 & . & . & 0,00014 & 0,00000 \\
\hline & IEPS & . & $-0,23768$ & 0,11254 & . & . & 0,00459 & 0,00103 \\
\hline & IEP6 & . & $-0,10575$ & $-0,06189$ & . & . & 0,00060 & 0,00021 \\
\hline & IEP7 & . & $-0,37788$ & $-0,06682$ & . & . & 0,00646 & 0,00020 \\
\hline & IEP8 & . & $-0,33344$ & 0.18347 & . & & 0.00406 & 0,00123 \\
\hline
\end{tabular}

Como não ocorreu uma discriminação das categorias da variável intervalo entre partos na análise de correspondência múltipla para a categorização em 8 classes de igual amplitude, pode-se inferir que esse método não propiciou bons resultados para essa $1 .^{\text {a }}$ forma de categorizar, e portanto, deve-se ter os devidos cuidados na aplicação do mesmo, quando as variáveis encontram-se nas mesmas condições deste trabalho. 


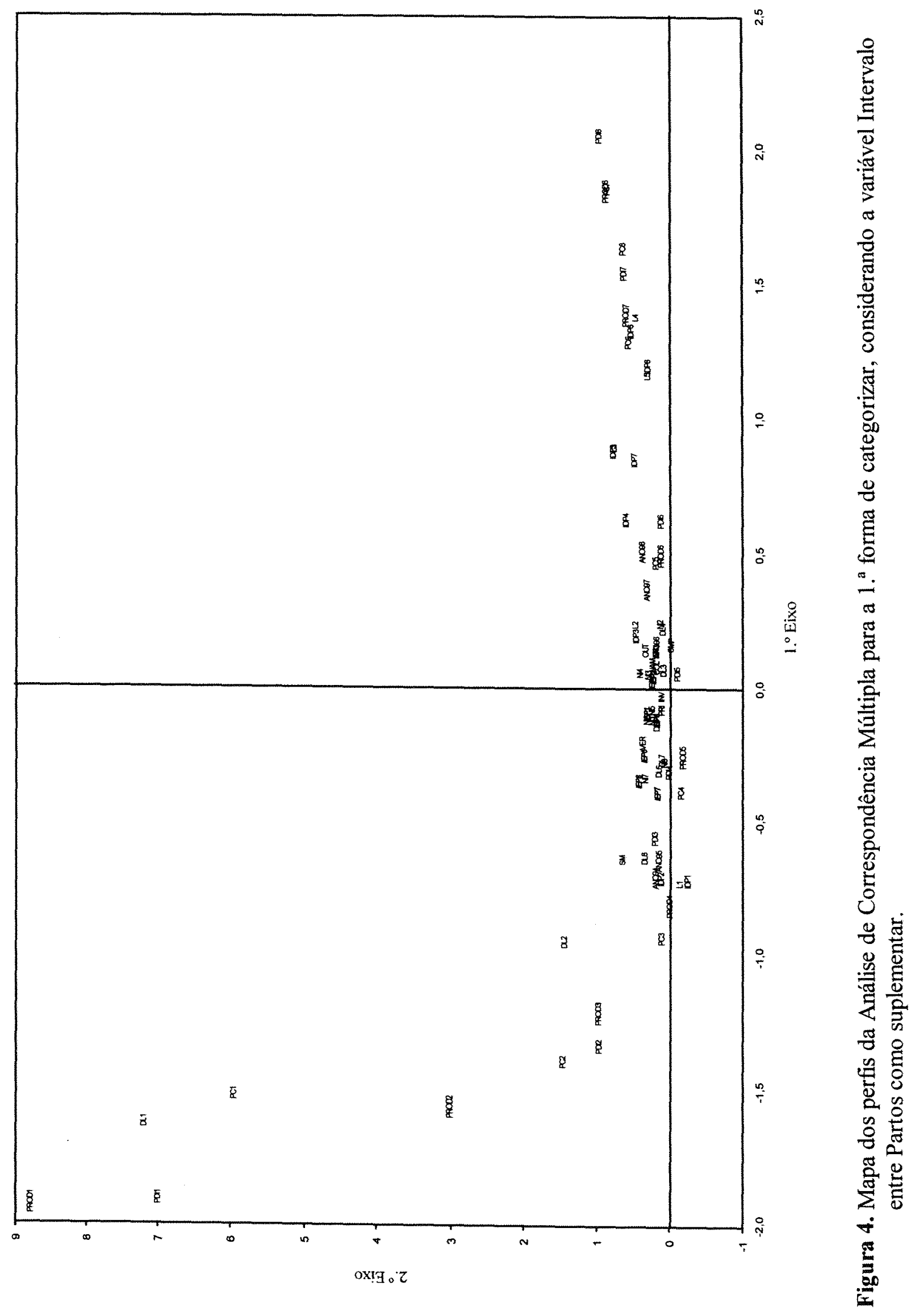


Para confirmar os resultados da análise de correspondência de tabelas sobrepostas, quanto à variável Reprodutor, procedeu-se a uma terceira análise de correspondência. Nessa análise, somente foram consideradas as variáveis Intervalo entre Partos e Reprodutor, efetuando-se a análise de correspondência simples para o cruzamento dessas duas variáveis.

A Tabela 13 ilustra a decomposição da inércia total $(0,24181)$ da análise de correspondência simples para a $1 .{ }^{\text {a }}$ forma de categorizar, cuja inércia foi decomposta em sete eixos principais.

Tabela 13. Histograma dos autovalores da análise de correspondência simples para a $1 .^{\mathrm{a}}$ forma de categorizar.

\begin{tabular}{|c|c|c|c|c|}
\hline Eixos & Autovalores & Porcentagem & $\begin{array}{l}\text { Porcentagem } \\
\text { acumulada }\end{array}$ & $\begin{array}{ccccc}5 & 10 & 15 & 20 & 25 \\
- & - & -+ & - & +\end{array}$ \\
\hline 1 & 0.06323 & $26,15 \%$ & $26,15 \%$ & 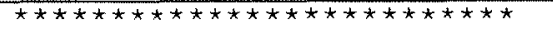 \\
\hline 2 & 0,04315 & $17,84 \%$ & 43,99 응 & 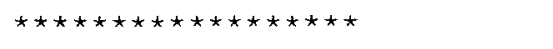 \\
\hline 3 & 0,03952 & $16,34 \%$ & $60,33 \%$ & 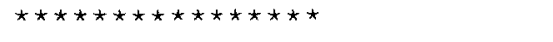 \\
\hline 4 & 0,03093 & $12,79 \%$ & $73,12 \%$ & 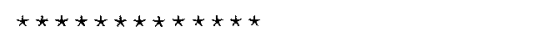 \\
\hline 5 & 0,02678 & $11,07 \frac{\circ}{\circ}$ & $84,19 ㅇ$ & 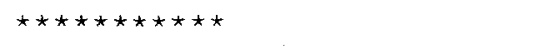 \\
\hline 6 & 0,02080 & $8,60 \%$ & $92,80 \%$ & 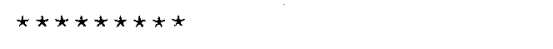 \\
\hline 7 & 0,01740 & $7,19 \%$ & $100,00 \%$ & 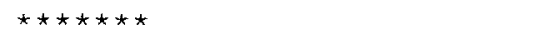 \\
\hline
\end{tabular}

Inércia Total $=0,24181$

Optou-se, como forma de confirmação, por estudar-se apenas os dois primeiros eixos principais, apesar de os mesmos explicarem apenas 43,99\% da variabilidade total da tabela de contingência.

$\mathrm{Na}$ Tabela 14 são apresentados os resultados da análise de correspondência simples para o cruzamento da variável Intervalo entre Partos com a variável Reprodutor. A partir desses resultados construiu-se o mapa de perfis que é mostrado na Figura 5.

Note-se, que realmente a variável Reprodutor influenciou o Intervalo entre Partos, isto é, determinados reprodutores propiciaram intervalos entre partos de menor tempo, outros de tempo intermediário e outros, ainda, longos intervalos entre partos. 
Tabela 14. Resultados da Análise de Correspondência Simples para a $1 .^{\text {a }}$ forma de categorizar.

\begin{tabular}{|c|c|c|c|c|c|c|c|c|}
\hline \multirow{2}{*}{ Variáveis } & \multirow{2}{*}{ Categorias } & \multirow{2}{*}{ Inércia } & \multicolumn{2}{|c|}{ Coordenadas } & \multicolumn{2}{|c|}{ Contribuições } & \multicolumn{2}{|c|}{ Co-seno Quadrado } \\
\hline & & & 1. ${ }^{\mathrm{a}} \mathrm{Dim}$. & 2. ${ }^{\mathrm{a}} \mathrm{Dim}$. & 1. ${ }^{\mathrm{a}} \mathrm{Dim}$. & 2. ${ }^{\mathrm{a}} \mathrm{Dim}$. & 1. ${ }^{\mathrm{a}} \mathrm{Dim}$. & 2. ${ }^{\mathrm{a}} \mathrm{Dim}$. \\
\hline \multirow[t]{48}{*}{ 1) Reprodutor } & 1 & 0,02180 & 0,35215 & $-0,17885$ & 0,01679 & 0,00635 & 0,20141 & 0,05195 \\
\hline & 2 & 0,02714 & $-0,37251$ & 0,07155 & 0,04072 & 0,00220 & 0,39238 & 0,01447 \\
\hline & 3 & 0,01577 & 0,00591 & 0,19066 & 0,00001 & 0,01082 & 0,00012 & 0,12243 \\
\hline & 4 & 0,00912 & $-0,35124$ & $-0,13259$ & 0,01949 & 0,00407 & 0,55886 & 0,07964 \\
\hline & 5 & 0,01922 & 0,54507 & $-0,39329$ & 0,03353 & 0,02558 & 0,45607 & 0,23744 \\
\hline & 6 & 0,02938 & $-0,48961$ & 0,08139 & 0,02705 & 0,00110 & 0,24075 & 0,00665 \\
\hline & 7 & 0,00671 & $-0,24195$ & $-0,04956$ & 0,00749 & 0,00046 & 0,29198 & 0,01225 \\
\hline & 8 & 0,04321 & 0,41667 & 0,10042 & 0,11233 & 0,00956 & 0,67990 & 0,03949 \\
\hline & 9 & 0,01559 & 0,32039 & 0,00491 & 0,02780 & 0,00001 & 0,46634 & 0,00011 \\
\hline & 10 & 0,00986 & 0,06320 & $-0,20547$ & 0,00072 & 0,01117 & 0,01913 & 0,20216 \\
\hline & 11 & 0,01943 & $-0,39364$ & 0,12107 & 0,03614 & 0,00501 & 0,48636 & 0,04601 \\
\hline & 12 & 0,00521 & $-0,15976$ & $-0,20809$ & 0,00326 & 0,00812 & 0,16383 & 0,27794 \\
\hline & 13 & 0,01706 & 0,46078 & 0,19462 & 0,02396 & 0,00626 & 0,36720 & 0,06551 \\
\hline & 14 & 0,00970 & 0,11331 & $-0,20787$ & 0,00560 & 0,02763 & 0,15108 & 0,50850 \\
\hline & 15 & 0,00726 & $-0,17941$ & $-0,04678$ & 0,00412 & 0,00041 & 0,14837 & 0,01009 \\
\hline & 16 & 0,03481 & 0,69334 & 0,24517 & 0,10488 & 0,01922 & 0,78801 & 0,09853 \\
\hline & 17 & 0,01625 & $-0,13121$ & 0,28418 & 0,00207 & 0,01425 & 0,03336 & 0,15647 \\
\hline & 18 & 0,01458 & $-0,12515$ & 0,05106 & 0,00212 & 0,00052 & 0,03804 & 0,00633 \\
\hline & 19 & 0,05730 & 0,69945 & 0,76640 & 0,08098 & 0,14247 & 0,36956 & 0,44368 \\
\hline & 20 & 0,01415 & 0,22048 & $-0,47899$ & 0,00622 & 0,04300 & 0,11492 & 0,54241 \\
\hline & 21 & 0,01676 & 0,17277 & 0,15164 & 0,01527 & 0,01724 & 0,23829 & 0,18357 \\
\hline & 22 & 0,01265 & $-0,35118$ & $-0,06660$ & 0,01949 & 0,00103 & 0,40295 & 0,01449 \\
\hline & 23 & 0,01757 & $-0,32652$ & 0,20634 & 0,03690 & 0,02159 & 0,54930 & 0,21935 \\
\hline & 24 & 0,01486 & 0,10211 & 0,10416 & 0,00314 & 0,00478 & 0,05523 & 0,05747 \\
\hline & 25 & 0,04961 & 0,11053 & $-0,39852$ & 0,01314 & 0,25040 & 0,06929 & 0,90073 \\
\hline & 26 & 0,02022 & 0,06624 & 0,27052 & 0,00162 & 0,03954 & 0,02091 & 0,34885 \\
\hline & 27 & 0,03608 & $-0,43430$ & 0,03298 & 0,06527 & 0,00055 & 0,47310 & 0,00273 \\
\hline & 28 & 0,01860 & $-0,15923$ & 0,07566 & 0,01011 & 0,00334 & 0,14215 & 0,03209 \\
\hline & 29 & 0,01023 & $-0,05081$ & 0,17126 & 0,00093 & 0,01552 & 0,02383 & 0,27075 \\
\hline & 30 & 0,00312 & 0,12936 & $-0,09933$ & 0,00415 & 0,00359 & 0,34852 & 0,20550 \\
\hline & 31 & 0,00699 & 0,08623 & $-0,12768$ & 0,00269 & 0,00863 & 0,10040 & 0,22011 \\
\hline & 32 & 0,01665 & $-0,26103$ & 0,45748 & 0,01333 & 0,06000 & 0,20931 & 0,64293 \\
\hline & 33 & 0,00545 & 0,01571 & $-0,12799$ & 0,00019 & 0,01824 & 0,00900 & 0,59711 \\
\hline & 34 & 0,01364 & 0,32598 & 0,02087 & 0,01199 & 0,00007 & 0,22993 & 0,00094 \\
\hline & 35 & 0,01370 & $-0,43429$ & $-0,08073$ & 0,03122 & 0,00158 & 0,59567 & 0,02058 \\
\hline & 36 & 0,01537 & $-0,37050$ & $-0,05956$ & 0,03821 & 0,00145 & 0,65033 & 0,01680 \\
\hline & 37 & 0,00829 & $-0,01569$ & $-0,05217$ & 0,00006 & 0,00096 & 0,00187 & 0,02067 \\
\hline & 38 & 0,01963 & 0,04362 & 0,09652 & 0,00049 & 0,00349 & 0,00648 & 0,03175 \\
\hline & 39 & 0,01013 & $-0,11056$ & 0,47226 & 0,00156 & 0,04180 & 0,04035 & 0,73620 \\
\hline & 40 & 0,01974 & 0,23041 & $-0,06011$ & 0,01917 & 0,00191 & 0,25401 & 0,01729 \\
\hline & 41 & 0,01627 & 0,08404 & $-0,33583$ & 0,00149 & 0,03482 & 0,02391 & 0,38191 \\
\hline & 42 & 0,00699 & $-0,07819$ & $-0,02533$ & 0,00534 & 0,00082 & 0,19949 & 0,02093 \\
\hline & 43 & 0,01689 & $-0,25527$ & 0,08405 & 0,00932 & 0,00148 & 0,14422 & 0,01563 \\
\hline & 44 & 0,01776 & 0,03939 & 0,22746 & 0,00020 & 0,00970 & 0,00292 & 0,09745 \\
\hline & 45 & 0,01643 & $-0,49937$ & $-0,10963$ & 0,04878 & 0,00345 & 0,77632 & 0,03741 \\
\hline & 46 & 0,01003 & $-0,07465$ & 0,12634 & 0,00147 & 0,00616 & 0,03825 & 0,10956 \\
\hline & 47 & 0,01002 & $-0,27922$ & 0,05571 & 0,01349 & 0,00079 & 0,35197 & 0,01401 \\
\hline & 48 & 0,01127 & 0,03213 & 0,16690 & 0,00016 & 0,00645 & 0,00378 & 0,10208 \\
\hline
\end{tabular}


Tabela 14. Resultados da Análise de Correspondência Simples para a $1 .^{\mathrm{a}}$ forma de categorizar (continuação).

\begin{tabular}{|c|c|c|c|c|c|c|c|c|}
\hline \multirow{2}{*}{ Variáveis } & \multirow{2}{*}{ Categorias } & \multirow{2}{*}{ Inércia } & \multicolumn{2}{|c|}{ Coordenadas } & \multicolumn{2}{|c|}{ Contribuiçōes } & \multicolumn{2}{|c|}{ Co-seno Quadrado } \\
\hline & & & 1. ${ }^{\mathrm{a}} \mathrm{Dim}$. & 2. ${ }^{\mathrm{a}} \mathrm{Dim}$. & 1. ${ }^{\mathrm{a}} \mathrm{Dim}$. & 2. $\mathrm{Dim}$. & 1. ${ }^{\mathbf{a}}$ Dim. & 2. ${ }^{a} \mathrm{Dim}$. \\
\hline \multirow[t]{13}{*}{ 1) Reprodutor } & 49 & 0,00840 & $-0,06385$ & 0,11855 & 0,00089 & 0,00449 & 0,02769 & 0,09548 \\
\hline & 50 & 0,00913 & 0,09642 & $-0,15710$ & 0,00189 & 0,00735 & 0,05408 & 0,14357 \\
\hline & 51 & 0,00586 & 0,01281 & 0,00406 & 0,00007 & 0,00001 & 0,00319 & 0,00032 \\
\hline & 52 & 0,01372 & $-0,05347$ & 0,01614 & 0,00037 & 0,00005 & 0,00697 & 0,00063 \\
\hline & 53 & 0,00844 & 0,12622 & $-0,13088$ & 0,00180 & 0,00283 & 0,05574 & 0,05993 \\
\hline & 54 & 0,00984 & $-0,36021$ & 0,08166 & 0,02636 & 0,00199 & 0,70062 & 0,03601 \\
\hline & 55 & 0,01880 & 0,05926 & 0,11539 & 0,00058 & 0,00323 & 0,00809 & 0,03066 \\
\hline & 56 & 0,01780 & 0,32705 & $-0,10597$ & 0,01931 & 0,00297 & 0,28374 & 0,02979 \\
\hline & 57 & 0,01152 & $-0,08351$ & $-0,05701$ & 0,00257 & 0,00176 & 0,05838 & 0,02721 \\
\hline & 58 & 0,00854 & $-0,13468$ & $-0,24643$ & 0,00328 & 0,01607 & 0,10030 & 0,33579 \\
\hline & 59 & 0,02076 & 0,08840 & $-0,01873$ & 0,00147 & 0,00010 & 0,01851 & 0,00083 \\
\hline & 60 & 0,02397 & $-0,30691$ & 0,18607 & 0,01205 & 0,00649 & 0,13143 & 0,04831 \\
\hline & 61 & 0,01473 & 0,19082 & 0,52676 & 0,00493 & 0,05507 & 0,08751 & 0,66689 \\
\hline \multirow{8}{*}{$\begin{array}{l}\text { 2) Intervalo } \\
\text { entre Partos } \\
\text { (em meses) }\end{array}$} & IEP1 & 0,13672 & $-0,33651$ & 0,25394 & 0,14909 & 0,12442 & 0,28516 & 0,16238 \\
\hline & IEP2 & 0,10567 & $-0,14432$ & $-0,00698$ & 0,12552 & 0,00043 & 0,31065 & 0,00073 \\
\hline & IEP3 & 0,09732 & $-0,05521$ & $-0,00371$ & 0,01059 & 0,00007 & 0,02847 & 0,00013 \\
\hline & IEP4 & 0,12937 & 0,06184 & $-0,41022$ & 0,00673 & 0,43415 & 0,01361 & 0,59882 \\
\hline & IEP5 & 0,12829 & 0,48329 & $-0,02824$ & 0,27764 & 0,00139 & 0,56593 & 0,00193 \\
\hline & IEP6 & 0,11478 & 0,12673 & 0,33055 & 0,01293 & 0,12890 & 0,02945 & 0,20040 \\
\hline & IEP7 & 0,13750 & 0,55814 & $-0,17051$ & 0,21327 & 0,02917 & 0,40562 & 0,03786 \\
\hline & IEP8 & 0,15035 & 0,60565 & 0,58735 & 0,20421 & 0,28146 & 0,35519 & 0,33405 \\
\hline
\end{tabular}

Observa-se que os resultados da análise de correspondência simples estão condizentes com os resultados da análise de correspondência de tabelas sobrepostas considerando a variável Reprodutor como suplementar, pois os reprodutores $1,5,16 \mathrm{e}$ 19 continuam associados aos maiores intervalos entre partos nesta análise, que inclui, ainda, o 8 e o 13. Do mesmo modo os reprodutores 6,22 e 45 mostram-se relacionados aos menores intervalos entre partos, podendo-se incluir, também, nesta análise, os reprodutores $2,4,11,27,35,36$ e 54 . Note-se, contudo, que na análise de correspondência simples ocorreu uma maior discriminação dos reprodutores, podendo-se, assim, visualizar uma maior quantidade de reprodutores distantes da origem dos eixos, e portanto, associados a determinadas classes de intervalo entre partos. 


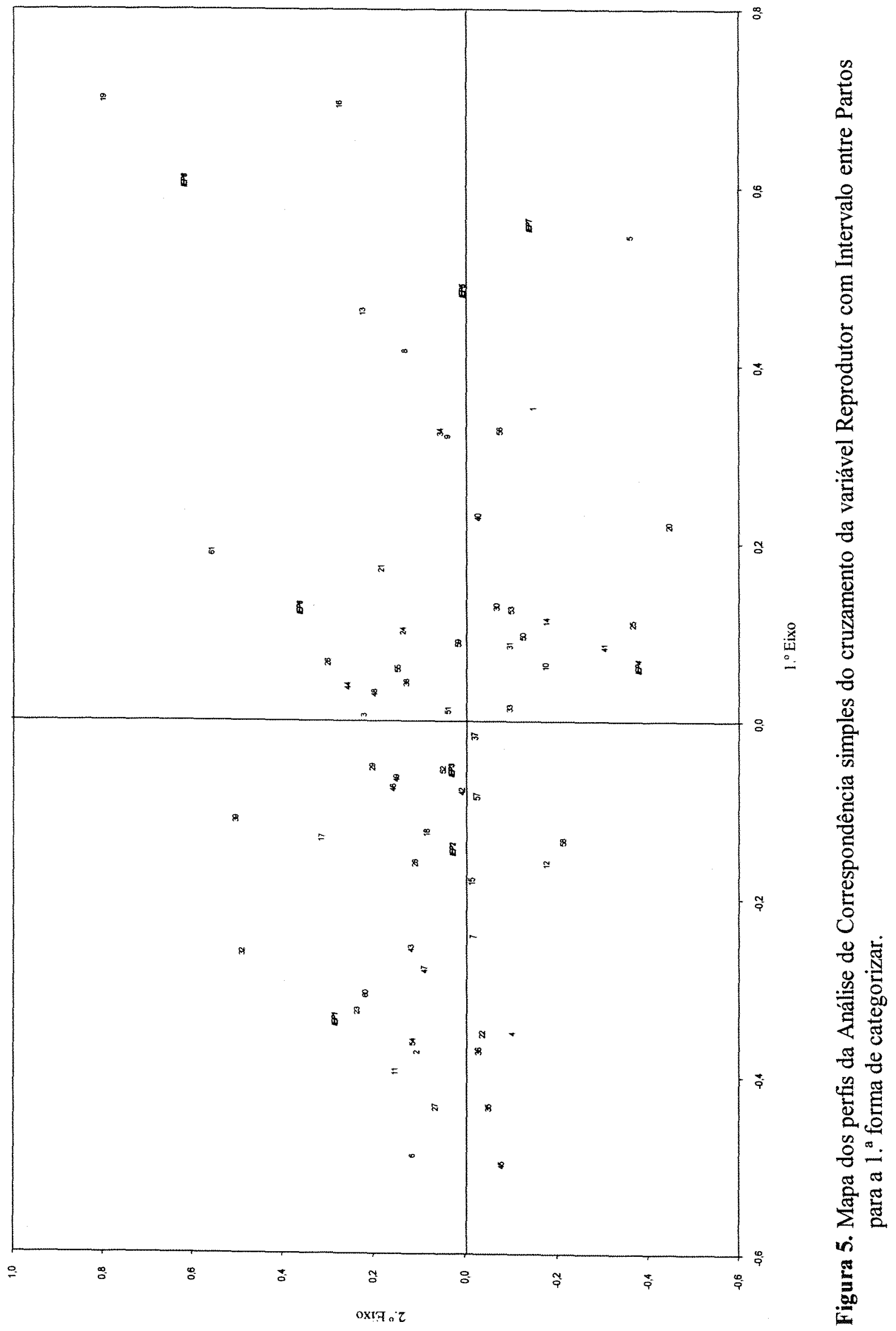


Verifica-se que os resultados obtidos na análise de correspondência simples para essa $1 .^{a}$ forma de categorizar são também condizentes com os resultados da Tabela 1, que mostra que a variável Reprodutor influenciou significativamente o Intervalo entre Partos por 7 vezes, das 12 em que foi estudada.

\subsection{Categorização em 4 classes de igual freqüência}

Para melhor visualizar a composição da amostra, quanto a cada variável disponível, resumiram-se os dados em tabelas de freqüências e a partir dessas tabelas construíram-se histogramas ou gráficos de colunas de acordo com a natureza da variável.

A Tabela 15 ilustra os resultados preliminares para todas as variáveis para a $2 .^{a}$ forma de categorizar. Note-se que a variável Reprodutor não é mostrada, pelos mesmos motivos descritos para a $1 .^{\text {a }}$ forma de categorizar.

Verifica-se que as 6 primeiras variáveis, incluindo a "variável resposta" (Intervalo entre Partos), apresentam classes uniformemente distribuídas, o que é consequiência da forma como foram categorizadas.

Observa-se que aproximadamente $50 \%$ dos intervalos entre partos foram menores ou iguais a 13,2 meses e, que apenas $25 \%$ dos intervalos foram maiores do que 16,2 meses. Verifica-se, também, que aproximadamente $50 \%$ das vacas apresentaram: mais do que 332 dias em lactação; mais do que 34,6 kg de leite no pico de lactação; mais do que 19,5 $\mathrm{kg}$ de leite por dia de intervalo entre partos; mais do que $8068 \mathrm{~kg}$ de leite por lactação e menos do que 37,2 meses de idade ao parto anterior.

Para as 5 últimas variáveis da Tabela 15 , nota-se que os resultados são idênticos aos da $1 .^{\mathrm{a}}$ forma de categorizar, excetuando-se a variável Número de Inseminações, em que se diminuiu o número de categorias de 8 para apenas 5 , agrupando-se as 4 últimas categorias da $1 .^{a}$ forma em uma única categoria na $2 .^{a}$ forma de categorizar. 
Tabela 15. Freqüências observadas para as categorias de cada variável para a $2 .^{a}$ forma de categorizar.

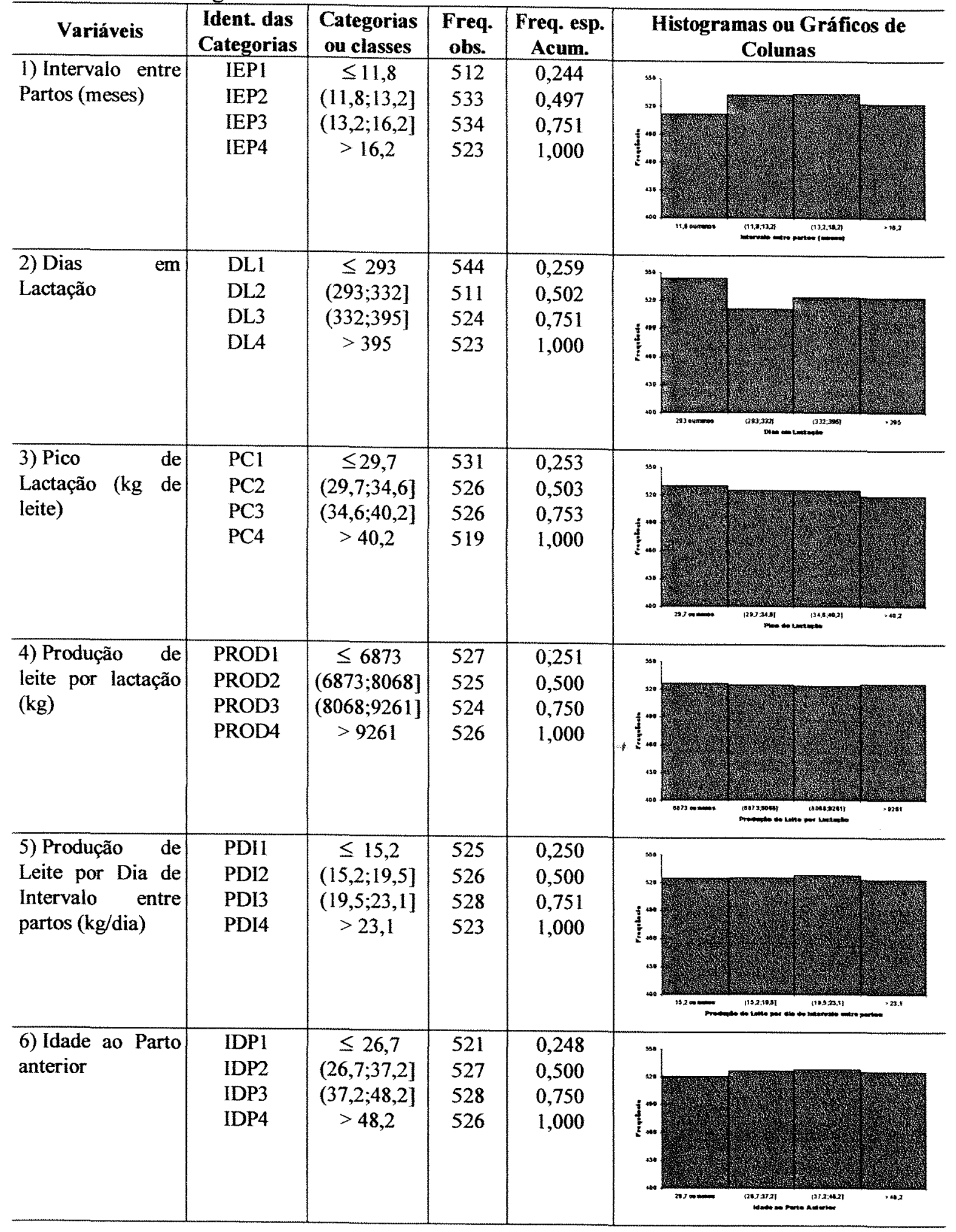


Tabela 15. Freqüências observadas para as categorias de cada variável para a $2 .^{a}$ forma de categorizar (continuação).

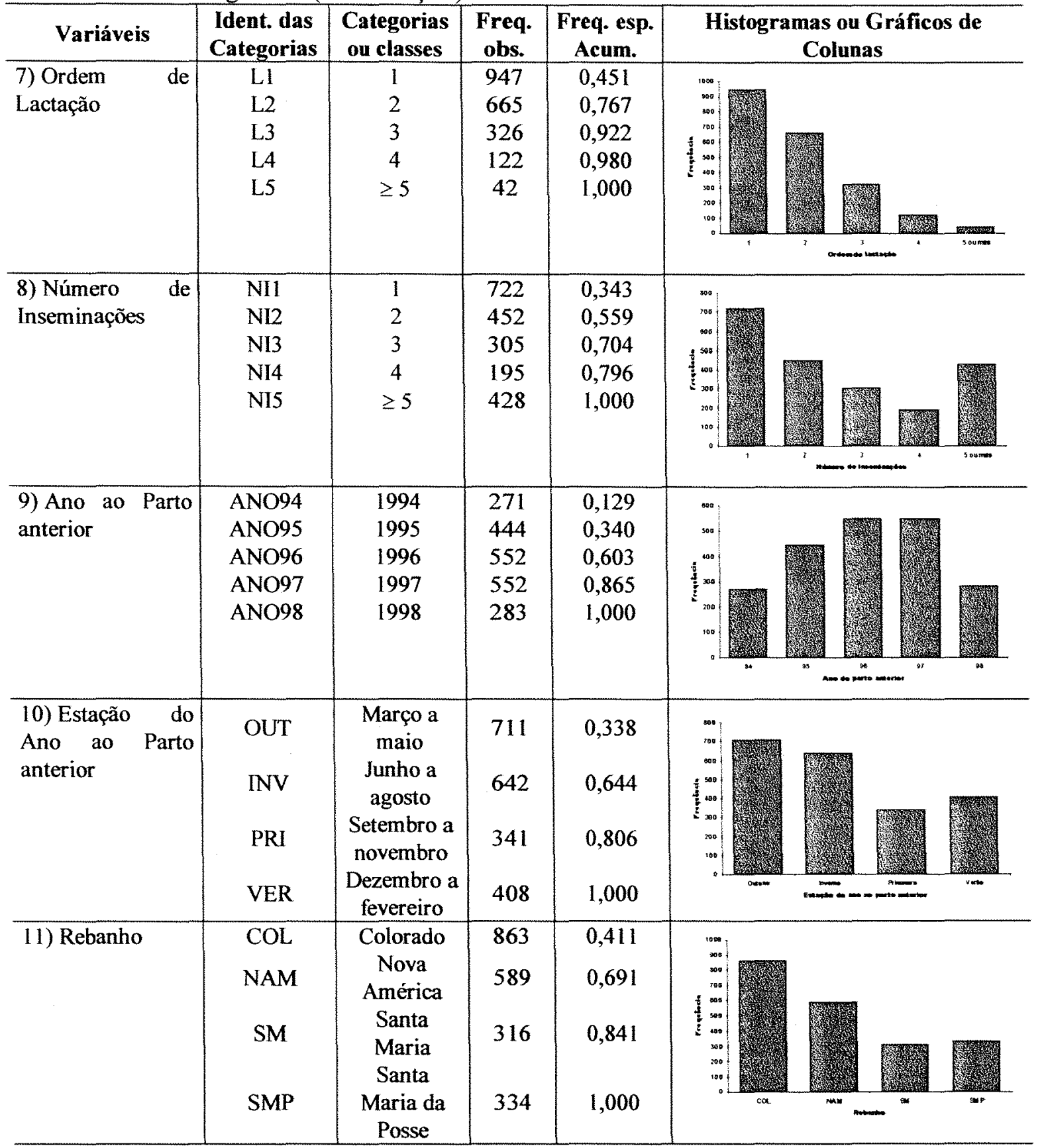

Continuando a análise, como o interesse primordial está ligado em identificar variáveis associadas com o Intervalo entre Partos, procedeu-se ao cruzamento desta variável com as outras 11 variáveis, como se elas fossem "explicativas" e a variável Intervalo entre Partos fosse "resposta". A metodologia da análise de correspondência foi, 
então, aplicada, analisando-se conjuntamente todas as tabelas de contingência geradas a partir desse cruzamento (Análise de Correspondência de tabelas sobrepostas), e considerando-se a variável Reprodutor como suplementar, pelos mesmos motivos descritos para a $1 .^{a}$ forma de categorizar. Utilizou-se o PROC CORRESP do SAS para efetuar a análise (Anexo B).

No Anexo G são mostradas as freqüências observadas para o cruzamento da variável Intervalo entre Partos com as variáveis ativas, enquanto no Anexo $H$ são ilustrados os mesmos resultados do primeiro, porém considerando os perfis linha (em porcentagem) das categorias de cada variável ativa, no intuito de ajudar na interpretação do mapa de perfis.

$\mathrm{Na}$ análise de correspondência, a inércia total da tabela de contingência dos dados é decomposta em eixos ou fatores principais, e a cada eixo está associado um autovalor ou inércia principal e por conseguinte uma porcentagem de inércia. A Tabela 16 ilustra essa decomposição, cuja inércia total $(0,27046)$ foi decomposta em três eixos principais.

Tabela 16. Histograma dos autovalores da análise de correspondência de tabelas sobrepostas na 2. ${ }^{a}$ forma de categorizar.

\begin{tabular}{|c|c|c|c|c|}
\hline Eixos & Autovalores & Porcentagem & $\begin{array}{l}\text { Porcentagem } \\
\text { acumulada }\end{array}$ & 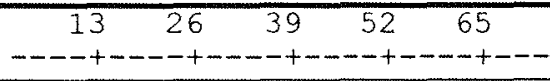 \\
\hline 1 & 0,17321 & $64,04 \frac{3}{5}$ & $64,04 \%$ & 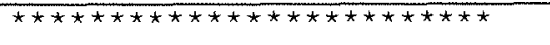 \\
\hline 2 & 0,06859 & $25,36 \%$ & $89,40 \%$ & 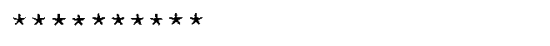 \\
\hline 3 & 0,02866 & $10,60 \%$ & 100,00 응 & $\star \star \star \star$ \\
\hline
\end{tabular}

Inércia Total $=0,27046$

Observe-se que os dois primeiros eixos explicaram $89,40 \%$ da inércia total da tabela, o que é razoável. Optou-se, como nos demais casos, por estudarem-se apenas esses dois eixos principais.

Com finalidade de facilitar a visualização do mapa de perfis, e por conseqüência a interpretação da análise, fizeram-se dois mapas de perfis: o primeiro, para estudar a associação das variáveis ativas com o Intervalo entre Partos e o segundo para verificar a possivel associação da variável suplementar (Reprodutor) com a variável Intervalo entre Partos. 
$\mathrm{Na}$ Tabela 17 são apresentados os resultados da análise de correspondência de tabelas sobrepostas referentes às variáveis ativas. Esses resultados possibilitam a geração e a interpretação de um gráfico bidimensional - mapa de perfis definido pelas coordenadas principais de $1 .^{\mathrm{a}}$ e $2 .^{\mathrm{a}}$ dimensão.

A partir desses resultados construiu-se um mapa de perfis, considerandose apenas as variáveis ativas e a variável Intervalo entre Partos. Esse mapa é mostrado na Figura 6.

Note-se que somente as variáveis mais contributivas para a análise foram plotadas no mapa para facilitar a visualização.

Na Figura 6, observa-se, também, o chamado "Efeito Guttman", como na análise de tabelas sobrepostas para a $1 .^{\mathrm{a}}$ forma de categorizar.

Pelo estudo do $1 .^{\circ}$ eixo, verifica-se que para a variável objeto principal do estudo (IEP), existe uma oposição entre IEP4 (lado negativo do eixo) e IEP1 (lado positivo do eixo).

Continuando o estudo do $1 .^{\circ}$ eixo, têm-se associados aos intervalos entre partos maiores do que 16,2 meses: em primeiro lugar, DL4; seguido por número de inseminações maior ou igual a 4 e PDI1. Relacionados ao lado positivo (Intervalos entre Partos menores ou iguais a 11,8 meses), têm-se: primeiramente, dias em lactação menores ou iguais a 332 dias; seguido por número de inseminações iguais a 1 e produção de leite por dia de intervalo entre partos menor ou igual a $15,2 \mathrm{~kg} / \mathrm{dia}$.

No 2. ${ }^{\circ}$ eixo, verifica-se uma oposição de IEP3 (lado negativo do eixo) e IEP1 (lado positivo do eixo), sendo associadas a IEPl as mesmas categorias descritas no 1. ${ }^{\circ}$ eixo, e a IEP3 as seguintes categorias: NI2, NI3 e DL3. 
Tabela 17. Resultados da Análise de Correspondência de tabelas sobrepostas para as variáveis ativas para a $2{ }^{a}$ forma de categorizar.

\begin{tabular}{|c|c|c|c|c|c|c|c|c|}
\hline \multirow{2}{*}{ Variáveis } & \multirow{2}{*}{ Categorias } & \multirow{2}{*}{ Inércia } & \multicolumn{2}{|c|}{ Coordenadas } & \multicolumn{2}{|c|}{ Contribuiç̃es } & \multicolumn{2}{|c|}{ Co-seno Quadrado } \\
\hline & & & 1. ${ }^{\mathrm{D}} \mathrm{Dim}$. & 2. ${ }^{a}$ Dim. & 1. ${ }^{\mathrm{a}} \mathrm{Dim}$ & 2. ${ }^{\mathrm{D}} \mathrm{Dim}$ & 1. ${ }^{\mathrm{a}} \mathrm{Dim}$. & 2. $\mathrm{Dim}$ \\
\hline \multirow{4}{*}{$\begin{array}{l}\text { 1) Dias em } \\
\text { Lactação }\end{array}$} & DL1 & 0,13739 & 0,83322 & 0,77486 & 0,10373 & 0,22655 & 0,48354 & 0,41817 \\
\hline & & & 0,60856 & $-0,28526$ & 0,05198 & 0,02884 & 0,33640 & 0,07392 \\
\hline & DL3 & 0,09120 & $-0,20383$ & $-0,85923$ & 0,00598 & 0,26833 & 0,04199 & 0,74611 \\
\hline & DL4 & 0,15597 & $-1,25706$ & 0,33362 & 0,22699 & 0,04038 & 0,93206 & 0,06565 \\
\hline \multirow{4}{*}{$\begin{array}{l}\text { 2) Pico de Lactação } \\
\text { (kg de leite) }\end{array}$} & $\mathrm{PCl}$ & 0,00182 & 0,13625 & $-0,01075$ & 0,00271 & 0,00004 & 0,95123 & 0,00592 \\
\hline & PC2 & 0,00043 & $-0,05553$ & $-0,01208$ & 0,00045 & 0,00005 & 0,66878 & 0,03164 \\
\hline & PC3 & 0,00015 & 0,04043 & 0,00192 & 0,00024 & 0,00000 & 0,99775 & 0,00225 \\
\hline & PC4 & 0,00145 & $-0,12410$ & 0,02129 & 0,00220 & 0,00016 & 0,96742 & 0,02848 \\
\hline \multirow{4}{*}{$\begin{array}{l}\text { 3) Produção de leite } \\
\text { por lactação }(\mathrm{kg})\end{array}$} & PRODI & 0,00398 & 0,13577 & 0,15638 & 0,00267 & 0,00894 & 0,42902 & 0,56915 \\
\hline & PROD2 & 0,00090 & 0,06967 & 0,06875 & 0,00070 & 0,00172 & 0,50049 & 0,48733 \\
\hline & PROD3 & 0,00040 & $-0,01698$ & $-0,05417$ & 0,00004 & 0,00107 & 0,06674 & 0,67914 \\
\hline & PROD4 & 0,00602 & $-0,18864$ & $-0,17132$ & 0,00514 & 0,01071 & 0,54652 & 0,45077 \\
\hline \multirow{4}{*}{$\begin{array}{l}\text { 4) Produção de } \\
\text { Leite por Dia de } \\
\text { Intervalo entre } \\
\text { partos (kg/dia) }\end{array}$} & PDI1 & 0,07924 & $-0,87451$ & 0,27695 & 0,11027 & 0,02793 & 0,89133 & 0,08939 \\
\hline & PDI2 & 500 & $-0,1$ & 4229 & 0,00362 & 0,00739 & 6333 & 0,37437 \\
\hline & PDI3 & 1695 & 0,37802 & 8821 & 0,02072 & 0,01297 & 0,78278 & 0,19405 \\
\hline & PDI4 & 0,03989 & 0,65542 & 0,05512 & 0,06171 & 0,00110 & 0,99081 & 0,00701 \\
\hline \multirow{4}{*}{$\begin{array}{l}\text { 5) Idade ao Parto } \\
\text { anterior }\end{array}$} & IDP1 & 034 & 0,03 & 0,04588 & 0,00014 & 0,00076 & 7046 & 0,57016 \\
\hline & IDP2 & 0,00044 & 0,06370 & 0,01701 & 0,00059 & 0,00011 & 85789 & 114 \\
\hline & IDP3 & 0,00037 & $-0,00259$ & $-0,05671$ & 0,00000 & 0,00118 & 169 & \\
\hline & IDP4 & 0,00082 & $-0,09252$ & 0555 & 0,001 & 001 & & \\
\hline \multirow{5}{*}{$\begin{array}{l}\text { 6) Ordem de } \\
\text { Lactação }\end{array}$} & $\mathrm{Ll}$ & 095 & 0,04 & 631 & 0,00 & 208 & 600 & \\
\hline & L2 & 0,00053 & $-0,0$ & $-0,06400$ & 0,00 & 189 & & 254 \\
\hline & L3 & 0,00042 & $-0,04$ & 0,04608 & 0,00 & 0,00048 & 0,28942 & 0,28717 \\
\hline & L4 & 0,00107 & $-0,08$ & $-0,19013$ & 0,00024 & 0,00306 & 0,14145 & 0,72368 \\
\hline & L5 & 0,00045 & $-0,07369$ & $-0,06159$ & 0,00006 & 0,00011 & 0,08891 & 0,06212 \\
\hline \multirow{5}{*}{$\begin{array}{l}\text { 7) Número de } \\
\text { Inseminações }\end{array}$} & NII & 0,10260 & 0,80633 & 0,39249 & 0,12893 & 0,07715 & 0,80475 & 0,19068 \\
\hline & $\mathrm{N} 12$ & 0,02741 & 0,30644 & $-0,47108$ & 0,01166 & 0,06958 & 0,27242 & 0,64380 \\
\hline & NI3 & 0,02166 & $-0,13384$ & $-0,60572$ & 0,00150 & 0,07762 & 0,04436 & 0,90859 \\
\hline & NI4 & 0,02102 & $-0,64840$ & $-0,35348$ & 0,02252 & 0,01690 & 0,68610 & 0,20391 \\
\hline & NI5 & 0,14113 & $-1,29303$ & 0,42809 & 0,19654 & 0,05440 & 0,89185 & 0,09776 \\
\hline \multirow{5}{*}{$\begin{array}{l}\text { 8) Ano ao Parto } \\
\text { anterior }\end{array}$} & ANO94 & 0,00124 & $-0,15828$ & $-0,02307$ & 0,00186 & 0,00010 & 0,96471 & 0,02049 \\
\hline & ANO95 & 0,00116 & $-0,10961$ & $-0,03157$ & 0,00147 & 0,00031 & 0,81080 & 0,06725 \\
\hline & ANO96 & 0,00046 & 0,05852 & $-0,01363$ & 0,00052 & 0,00007 & 0,71917 & 0,03901 \\
\hline & ANO97 & 0,00388 & $-0,11573$ & 0,16121 & 0,00203 & 0,00995 & 0,33495 & 0,64989 \\
\hline & ANO98 & 0,01179 & 0,43513 & $-0,21624$ & 0,01472 & 0,00918 & 0,79915 & 0,19736 \\
\hline \multirow{4}{*}{$\begin{array}{l}\text { 9) Estação do Ano } \\
\text { ao Parto anterior }\end{array}$} & INV & 0,00258 & 0,02551 & 0,11909 & 0,00011 & 0,00632 & 0,02853 & 0,62151 \\
\hline & OUT & 0,00354 & 0,16822 & $-0,00573$ & 0,00553 & 0,00002 & 0,99848 & 0,00116 \\
\hline & PRI & 0,00475 & $-0,25133$ & 0,09656 & 0,00592 & 0,00221 & 0,79810 & 0,11780 \\
\hline & VER & 0,00631 & $-0,12323$ & $-0,25811$ & 0,00170 & 0,01885 & 0,17276 & 0,75796 \\
\hline \multirow[t]{4}{*}{ 10) Rebanho } & $\mathrm{COL}$ & 0,00014 & 0,01278 & $-0,01445$ & 0,00004 & 0,00013 & 0,18041 & 0,23078 \\
\hline & NAM & 0,00128 & 0,04861 & 0,08367 & 0,00038 & 0,00286 & 0,19057 & 0,56473 \\
\hline & $\mathrm{SM}$ & 0,00194 & $-0,16291$ & 0,07198 & 0,00230 & 0,00114 & 0,76090 & 0,14855 \\
\hline & SMP & 0,00196 & 0,03540 & $-0,17831$ & 0,00011 & 0,00737 & 0,03763 & 0,95497 \\
\hline 11) Intervalo entre & IEPI & 0,28298 & 0,44861 & 0,31360 & 0,28301 & 0,34925 & 0,64051 & 0,31299 \\
\hline \multirow[t]{3}{*}{ Partos (em meses) } & IEP2 & 0,15932 & 0,29163 & $-0,15831$ & 0,12450 & 0,09265 & 0,50048 & 0,14748 \\
\hline & IEP3 & 0,14849 & $-0,10005$ & $-0,33564$ & 0,01468 & 0,41727 & 0,06332 & 0,71261 \\
\hline & IEP4 & 0,40921 & $-0,63423$ & 0,19703 & 0,57781 & 0,14083 & 0,90430 & 0,08727 \\
\hline
\end{tabular}




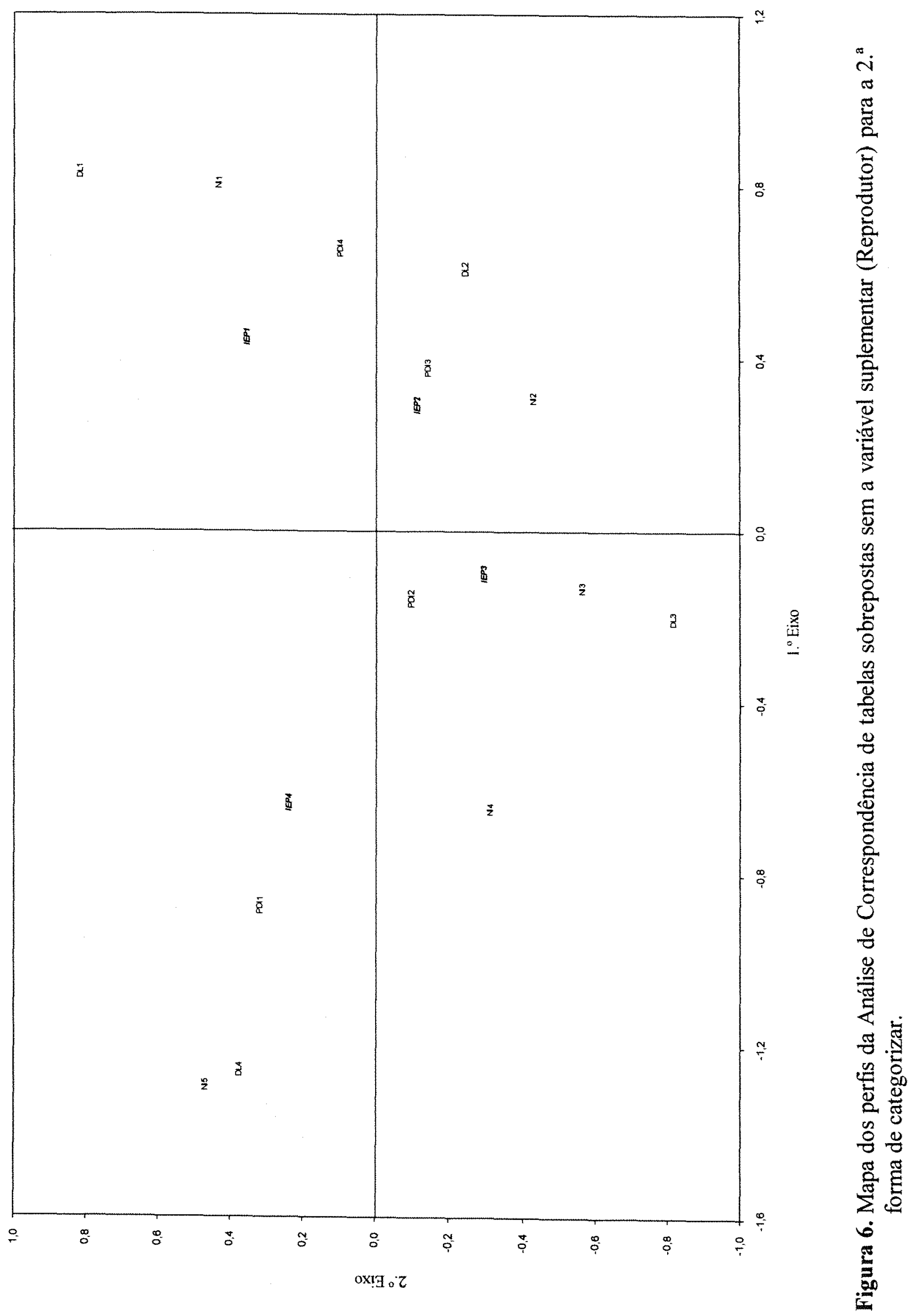


Antes de se discutirem as associações descritas anteriormente, vejamos se a variável suplementar (Reprodutor) está associada com a variável intervalo entre partos. Nos Anexos I e J são mostradas, respectivamente, as freqüências observadas e os perfis linha (em porcentagem) para o cruzamento da variável Intervalo entre Partos com a variável Reprodutor, no intuito de ajudar na interpretação do mapa de perfis.

A Tabela 18 mostra os resultados da análise de correspondência referentes à variável suplementar. Com as coordenadas principais de cada um dos reprodutores, construiu-se um novo mapa de perfis, plotando-se sobre o primeiro mapa o número de cada reprodutor na coordenada especificada. O mapa é mostrado na Figura 7.

Mesmo com a dificuldade de interpretar o mapa devido à sobreposição de alguns pontos, pode-se verificar que a variável Reprodutor também está relacionada com o intervalo entre partos, pois os mesmos estão relativamente dispersos sobre o mapa. Verifica-se, por exemplo, que os reprodutores 1, 5, 16 e 19 estão associados com intervalos entre partos maiores que 16,2 meses (IEP4), e que os reprodutores $6,22,45$ e 60 estão associados com IEP1. Note-se que esses reprodutores estão bem representados sobre o mapa, pois sua contribuição relativa é mais ou menos elevada. Além disso, podese associar outros reprodutores a IEP2 e IEP3.

Averiguando-se o Anexo $\mathrm{H}$, verifica-se que as filhas do reprodutor 6 , por exemplo, apresentaram $53,3 \%$ dos intervalos entre partos menores que 11,8 meses, e $40 \%$ dos intervalos entre 11,8 e 13,2 meses, enquanto que as filhas do reprodutor 16 apresentaram 55,2\% dos intervalos maiores que 16,2 meses. Esses resultados são condizentes, é claro, com os da análise de correspondência.

Complementando os resultados da análise de correspondência de tabelas sobrepostas para a categorização em 4 classes de igual freqüência, pode-se inferir que as variáveis Dias em Lactação, Número de Inseminações, Produção de Leite por Dia de Intervalo entre Partos e Reprodutor (efeito genético) estão associadas com a variável Intervalo entre Partos, segundo essa metodologia. 
Tabela 18. Resultados da Análise de Correspondência de tabelas sobrepostas para a variável suplementar (Reprodutor) para a 2. ${ }^{\text {a }}$ forma de categorizar.

\begin{tabular}{|c|c|c|c|c|}
\hline \multirow{2}{*}{ Reprodutor } & \multicolumn{2}{|c|}{ Coordenadas } & \multicolumn{2}{|c|}{ Co-seno quadrado } \\
\hline & 1. ${ }^{a}$ Dim. & 2. ${ }^{\mathrm{a}} \mathrm{Dim}$. & 1. ${ }^{\mathrm{a}} \mathrm{Dim}$. & 2. ${ }^{\mathrm{a}} \mathrm{Dim}$ \\
\hline 1 & $-0,50751$ & 0,01067 & 0,99886 & 0,00044 \\
\hline 2 & 0,19552 & 0,11227 & 0,45913 & 0,15140 \\
\hline 3 & $-0,02095$ & 0,20605 & 0,01020 & 0,98708 \\
\hline 4 & 0,43366 & $-0,21850$ & 0,79046 & 0,20066 \\
\hline 5 & $-0,53811$ & 0,08839 & 0,97074 & 0,02619 \\
\hline 6 & 0,75358 & 0,44700 & 0,69539 & 0,24467 \\
\hline 7 & 0,38386 & $-0,03437$ & 0,72938 & 0,00585 \\
\hline 8 & $-0,25562$ & 0,18041 & 0,65284 & 0,32519 \\
\hline 9 & $-0,15144$ & $-0,05886$ & 0,57911 & 0,08747 \\
\hline 10 & $-0,20042$ & $-0,32217$ & 0,23641 & 0,61090 \\
\hline 11 & 0,29135 & $-0,16846$ & 0,67537 & 0,22579 \\
\hline 12 & 0,08692 & $-0,07405$ & 0,08084 & 0,05867 \\
\hline 13 & $-0,36466$ & 0,11806 & 0,84532 & 0,08861 \\
\hline 14 & $-0,25514$ & $-0,19146$ & 0,46101 & 0,25960 \\
\hline 15 & 0,06473 & $-0,18004$ & 0,06854 & 0,53027 \\
\hline 16 & $-0,64990$ & 0,21377 & 0,84205 & 0,09110 \\
\hline 17 & 0,36405 & 0,00126 & 0,84581 & 0,00001 \\
\hline 18 & $-0,17651$ & 0,26034 & 0,14250 & 0,31000 \\
\hline 19 & $-0,65802$ & 0,30933 & 0,79746 & 0,17623 \\
\hline 20 & $-0,29058$ & 0,52417 & 0,22126 & 0,71995 \\
\hline 21 & $-0,11069$ & 0,06265 & 0,58067 & 0,18604 \\
\hline 22 & 0,45162 & $-0,13269$ & 0,90731 & 0,07832 \\
\hline 23 & 0,26014 & 0,02766 & 0,97112 & 0,01098 \\
\hline 24 & $-0,28100$ & $-0,15834$ & 0,75854 & 0,24085 \\
\hline 25 & $-0,11274$ & $-0,10418$ & 0,44601 & 0,38089 \\
\hline 26 & $-0,06847$ & 0,09102 & 0,12252 & 0,21649 \\
\hline 27 & 0,34130 & 0,15485 & 0,64620 & 0,13302 \\
\hline 28 & 0,01321 & 0,05944 & 0,01149 & 0,23257 \\
\hline 29 & 0,10486 & 0,09095 & 0,53778 & 0,40459 \\
\hline 30 & $-0,09974$ & $-0,00280$ & 0,31038 & 0,00024 \\
\hline 31 & $-0,02064$ & $-0,03123$ & 0,00720 & 0,01649 \\
\hline 32 & 0,14277 & $-0,08398$ & 0.41226 & 0,14265 \\
\hline 33 & $-0,02004$ & $-0,14651$ & 0,01821 & 0,97288 \\
\hline 34 & $-0,27677$ & 0,28333 & 0,47119 & 0,49381 \\
\hline 35 & 0,37049 & 0,12247 & 0,38851 & 0,04246 \\
\hline 36 & 0,39347 & 0,03473 & 0,66317 & 0,00517 \\
\hline 37 & 0,01417 & $-0,30802$ & 0,00088 & 0,41381 \\
\hline 38 & 0,10453 & 0,02560 & 0,55582 & 0,03335 \\
\hline 39 & 0,04459 & $-0,02057$ & 0,22380 & 0,04762 \\
\hline 40 & $-0,18894$ & 0,18547 & 0,50836 & 0,48989 \\
\hline 41 & $-0,20240$ & 0,02430 & 0,80568 & 0,01161 \\
\hline 42 & 0,05431 & $-0,08914$ & 0,22945 & 0,61802 \\
\hline 43 & 0,12985 & $-0,46225$ & 0,07084 & 0,89771 \\
\hline 44 & $-0,02886$ & 0,36454 & 0,00396 & 0,63111 \\
\hline 45 & 0,49234 & $-0,11085$ & 0,94784 & 0,04805 \\
\hline 46 & 0,16357 & $-0,13413$ & 0,47379 & 0,31859 \\
\hline 47 & 0,33716 & 0,05205 & 0,97664 & 0,02328 \\
\hline 48 & 0,16957 & $-0,13179$ & 0,17755 & 0,10725 \\
\hline 49 & 0,05887 & $-0,13774$ & 0,12756 & 0,69823 \\
\hline 50 & $-0,26250$ & 0,08126 & 0,84810 & 0,08128 \\
\hline 51 & $-0,00423$ & 0,04899 & 0.00707 & 0,94755 \\
\hline 52 & 0,12009 & $-0,14021$ & 0,42268 & 0,57619 \\
\hline 53 & $-0,30423$ & $-0,13766$ & 0,80714 & 0,16525 \\
\hline 54 & 0,40499 & 0,02153 & 0,90243 & 0,00255 \\
\hline 55 & 0,09575 & 0,31867 & 0,02463 & 0,27279 \\
\hline 56 & $-0,24467$ & $-0,17133$ & 0,37581 & 0,18427 \\
\hline 57 & 0,14710 & 0,13175 & 0,34963 & 0,28048 \\
\hline 58 & 0,07133 & $-0,18178$ & 0,05474 & 0,35552 \\
\hline 59 & $-0,11164$ & $-0,23430$ & 0.16864 & 0,74277 \\
\hline 60 & 0,50783 & 0,58892 & 0.41798 & 0,56213 \\
\hline 61 & -0.15577 & $-0,06485$ & 0.11951 & 0,02071 \\
\hline
\end{tabular}




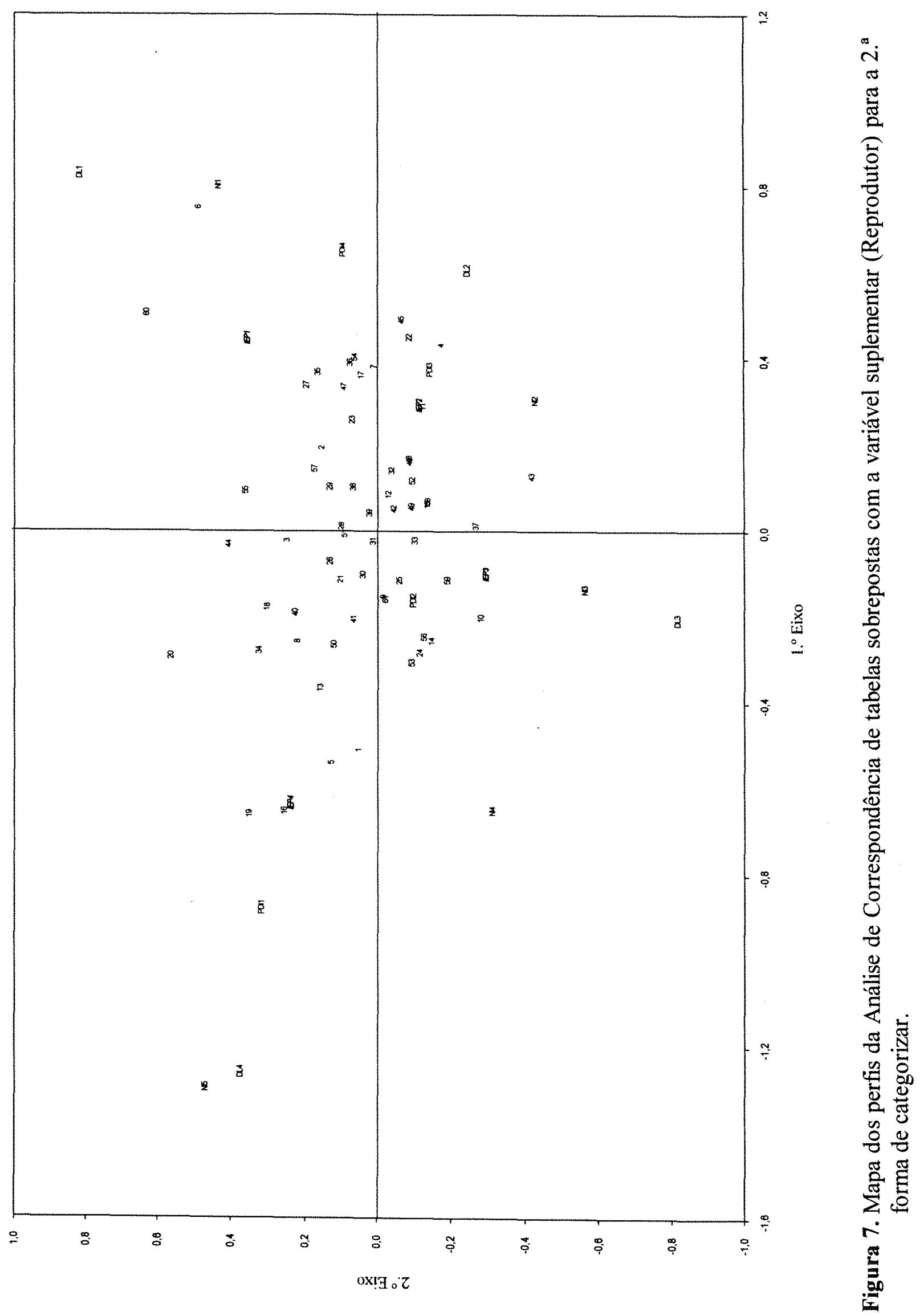


Os resultados da Análise de Correspondência de tabelas sobrepostas para a $2{ }^{a}$ forma de categorizar são condizentes, até certo ponto, com os resumos de resultados apresentados na Tabela 1, onde Dias em Lactação e Número de Inseminações (Serviços por concepção), apesar de estudados poucas vezes, tiveram influência no intervalo entre partos em $100 \%$ dos casos, e a variável Reprodutor foi uma importante causa de variação. Na Tabela 1 , observa-se que o Ano de parto anterior e o Rebanho apresentaram-se influentes na variação do intervalo entre partos, o que contraria os resultados obtidos pela última análise.

Como uma segunda forma de analisar os dados, optou-se por utilizar a análise de correspondência múltipla, considerando todas as variáveis disponiveis como ativas na análise, à exceção de Intervalo entre Partos e Reprodutor. Nessa análise a variável Intervalo entre Partos foi considerada como suplementar, ou ilustrativa, e a variável Reprodutor foi descartada. Isto é, buscaram-se as associações da variável Intervalo entre Partos com as outras variáveis no contexto das variáveis ativas.

A Tabela 19 ilustra a decomposição da inércia total $(3,30)$ da análise de correspondência múltipla para a $2 .^{\text {a }}$ forma de categorizar, a qual foi decomposta em 33 eixos principais. Nessa análise não se leva em conta a porcentagem de inércia explicada pelos eixos para determinar o número de fatores a estudar, mas se estes são interpretáveis, ou não. Assim, nesse contexto, optou-se, por estudar apenas os dois primeiros eixos principais, independendo da variabilidade explicada por estes.

$\mathrm{Na}$ Tabela 20 são apresentados os resultados da análise de correspondência múltipla para a $2 .^{\text {a }}$ forma de categorizar. A partir desses resultados construiu-se o mapa de perfis que é mostrado na Figura 8. 
Tabela 19. Histograma dos autovalores da análise de correspondência múltipla para a $2 .^{\mathrm{a}}$ forma de categorizar.

\begin{tabular}{|c|c|c|c|c|}
\hline Eixos & Autovalores & Porcentagem & Porcentagem & $8 \quad 10$ \\
\hline 1 & 0,32063 & $9,72 \frac{\circ}{5}$ & $\frac{\text { acumulada }}{972^{\circ}}$ & 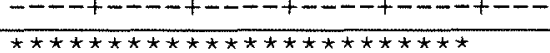 \\
\hline 2 & 0,22118 & $\begin{array}{l}9,128 \\
6,70 \%\end{array}$ & $9,72 \%$ & 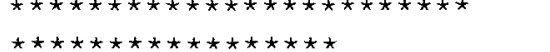 \\
\hline 3 & 0,18638 & $5,65 \%$ & $22,07 \%$ & 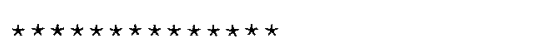 \\
\hline 4 & 0,18210 & $5,52 \%$ & $27,59 \%$ & 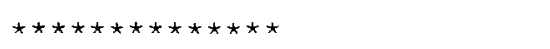 \\
\hline 5 & 0,14788 & $4,48 \%$ & $32,07 \%$ & 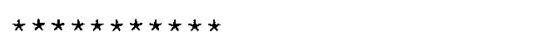 \\
\hline 6 & 0,13451 & $4,08 \%$ & $36,15 \%$ & 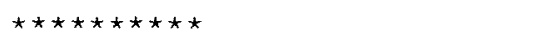 \\
\hline 7 & 0,11875 & $3,60 \%$ & $39,75 \%$ & 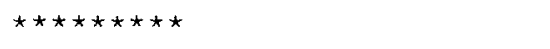 \\
\hline 8 & 0,11658 & $3,53 \%$ & $43,28 \%$ & 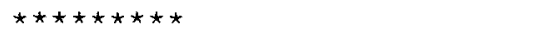 \\
\hline 9 & 0,11496 & $3,48 \%$ & $46,76 \%$ & 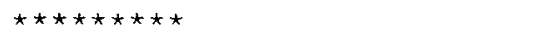 \\
\hline 10 & 0,10823 & $3,28 \%$ & $50,04 \%$ & 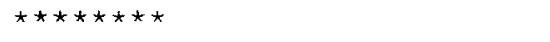 \\
\hline 11 & 0,10737 & $3,25 \%$ & $53,29 \%$ & 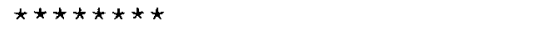 \\
\hline 12 & 0,10653 & $3,23 \%$ & 56,52 웅 & 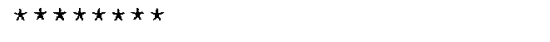 \\
\hline 13 & 0,10365 & $3,14 \frac{\mathrm{o}}{\mathrm{\sigma}}$ & $59,66 \%$ & 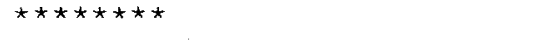 \\
\hline 14 & 0,10216 & $3,10 \%$ & $62,76 \%$ & 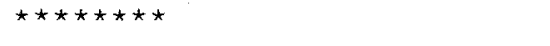 \\
\hline 15 & 0,09738 & $2,95 \%$ & $65,71 \%$ & 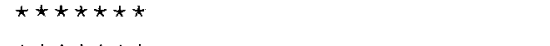 \\
\hline 16 & 0,09554 & $2,90 \%$ & 68,61 응 & 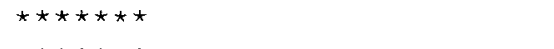 \\
\hline 17 & 0,09499 & $2,88 \%$ & $71,49 \%$ & 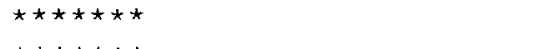 \\
\hline 18 & 0.09365 & $2,84 \%$ & $74,33 \%$ & 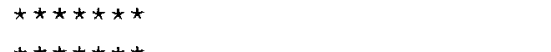 \\
\hline 19 & 0,09010 & $2,73 \%$ & $77,06 \%$ & 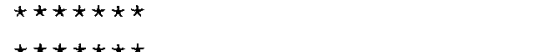 \\
\hline 20 & 0,08772 & $2,66 \%$ & $79,72 \%$ & 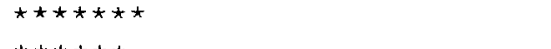 \\
\hline 21 & 0,08540 & $2,59 \%$ & $82,31 \%$ & 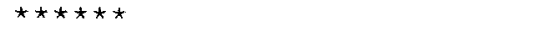 \\
\hline 22 & 0,08245 & $2,50 \%$ & $84,81 \%$ & $\star \star \star \star \star \star$ \\
\hline 23 & 0,08180 & $2,48 \%$ & $87,29 \%$ & 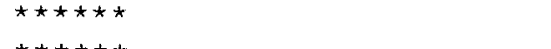 \\
\hline 24 & 0,07504 & $2,27 \%$ & $89,56 \%$ & 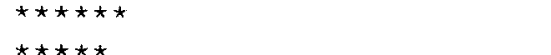 \\
\hline 25 & 0,07068 & $2,14 \%$ & $91,70 \%$ & $\begin{array}{l}* \star \star \star \star \star \\
\star \star \star \star \star \star *\end{array}$ \\
\hline 26 & 0,06684 & $2,03 \%$ & $93,73 \%$ & 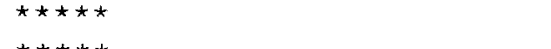 \\
\hline 27 & 0,06131 & $1,86 \%$ & $95,59 \%$ & 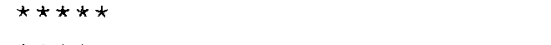 \\
\hline 28 & 0,05448 & $1,65 \%$ & $97,24 \%$ & $\star \star \star \star$ \\
\hline 29 & 0,02727 & $0,83 \%$ & $98,07 \%$ & ** \\
\hline 30 & 0,02305 & $0,70 \%$ & $98,77 \%$ & 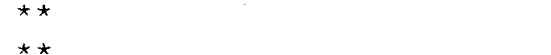 \\
\hline 31 & 0,02095 & $0,63 \frac{0}{3}$ & $99,40 \%$ & $* *$ \\
\hline 32 & 0,01243 & $0,38 \%$ & $99,78 \%$ & * \\
\hline 33 & 0,00802 & $0,22 \%$ & $100,00 \%$ & $\star$ \\
\hline
\end{tabular}

Pelas Figura 8 e Tabela 20, observa-se que apenas a categoria IEP4, da variável Intervalo entre Partos, pode ser associada a categorias de outras variáveis, pois é a única categoria dessa variável que se apresenta bem representada no mapa $\left(\cos ^{2}=\right.$ 0,54637, para o $2 .^{\circ}$ eixo principal). IEP4 está associada com DL4 e NI5, o que é condizente com a análise de correspondência de tabelas sobrepostas. IEP1 e IEP2 podem estar associados com NI1, DL2, PDI3 e DL1, porém não estão bem representados no mapa $\left(\cos ^{2}=0,19665\right.$ e $\cos ^{2}=0,13207$, respectivamente, para o $2 .^{\circ}$ eixo principal), o que dificulta fazer qualquer afirmativa. 
Tabela 20. Resultados da Análise de Correspondência Múltipla para a $2 .^{a}$ forma de categorizar.

\begin{tabular}{|c|c|c|c|c|c|c|c|c|}
\hline \multirow{2}{*}{ Variáveis } & \multirow{2}{*}{ Categorias } & \multirow{2}{*}{ Inércia } & \multicolumn{2}{|c|}{ Coordenadas } & \multicolumn{2}{|c|}{ Contribuição } & \multicolumn{2}{|c|}{ Co-seno quadrado } \\
\hline & & & 1. ${ }^{\mathrm{a}} \mathrm{Dim}$. & 2. ${ }^{\mathrm{a}} \mathrm{Dim}$. & 1. ${ }^{\text {a Dim. }}$ & 2. ${ }^{a}$ Dim. & 1. ${ }^{\mathrm{a}} \mathrm{Dim}$. & 2. ${ }^{\mathrm{a}} \mathrm{Dim}$. \\
\hline \multirow{4}{*}{$\begin{array}{l}\text { 1) Dias } \\
\text { Lactação }\end{array}$} & DL1 & 0,02246 & $-0,15573$ & $-0,58608$ & 0,00196 & 0,04019 & 0,00847 & \\
\hline & & & 0,14969 & $-0,66769$ & 0,00170 & 0,04900 & 0,00720 & \\
\hline & & & 0,21426 & $-0,02188$ & 0,00357 & 0,00005 & 0,01524 & \\
\hline & & & $-0,19894$ & & 0,00307 & 0,18544 & 0,01311 & \\
\hline \multirow{4}{*}{$\begin{array}{llll}\text { 2) Pico } & & \text { de } \\
\text { Lactação } & (\mathrm{kg} & \mathrm{de} \\
\text { leite }) & & \\
\end{array}$} & & & $-0,98771$ & 0,01210 & 0,07686 & 0,00002 & 0,32974 & 0005 \\
\hline & $\mathrm{PC} 2$ & & $-0,47745$ & $-0,14365$ & 0,01779 & 0,00233 & 0,07608 & 0,00689 \\
\hline & PC3 & & 0,28699 & $-0,27636$ & 0,00643 & 0,00864 & 0,02749 & 0,02549 \\
\hline & $\mathrm{PC} 4$ & 0,02282 & 1,20358 & 0,41329 & 0,11155 & 0,01907 & 0,47493 & 0,05600 \\
\hline \multirow{4}{*}{$\begin{array}{l}\text { 3) Produção de } \\
\text { leite por lactação } \\
(\mathrm{kg})\end{array}$} & PROD1 & & $-0,97214$ & 0,17116 & 0,07390 & 0,00332 & 0,31622 & 0,00980 \\
\hline & & & $-0,41559$ & $-0,27628$ & 0,01345 & 0,00862 & 0,05750 & 0,02541 \\
\hline & PROD3 & 2275 & 0,24301 & $-0,25428$ & 0,00459 & 0,00729 & 0,01961 & 0,02147 \\
\hline & & & 1,14670 & 0,35759 & 0,10262 & 0,01447 & 0,43886 & 0,04268 \\
\hline \multirow{4}{*}{$\begin{array}{l}\text { 4) Produção } \\
\text { Leite por Dia } \\
\text { Intervalo entre } \\
\text { partos (kg/dia) }\end{array}$} & & & $-0,77263$ & 491 & 0,04650 & 514 & & 996 \\
\hline & & & $-0,32540$ & 683 & 0,00826 & 395 & 534 & 165 \\
\hline & PD & & 0,07 & 044 & 0,00042 & 658 & 181 & 759 \\
\hline & PDI4 & & 1,02861 & 0994 & 0,08211 & 925 & 045 & 613 \\
\hline \multirow{4}{*}{$\begin{array}{l}\text { 5) Idade ao Parto } \\
\text { anterior }\end{array}$} & & & $-0,74589$ & $-0,36064$ & 0,04301 & 458 & & 286 \\
\hline & & & $-0,60785$ & $-0,09413$ & 0,02889 & 100 & 2363 & 296 \\
\hline & & & 0,30281 & $-0,02475$ & 0,00718 & 0007 & & 0021 \\
\hline & & & 1,04385 & 0,47637 & 0,08504 & 0,02567 & 0,36367 & 0,07574 \\
\hline \multirow{5}{*}{$\begin{array}{l}\text { 6) Ordem } \\
\text { Lactação }\end{array}$} & $\mathrm{Ll}$ & & $-0,74944$ & $-0,24515$ & 0,07892 & & & 0,04928 \\
\hline & L2 & 072 & 0,27884 & 396 & 0,00767 & 000 & 598 & 001 \\
\hline & L3 & & 0,98132 & 420 & 658 & 1713 & & 4483 \\
\hline & $\mathrm{L}$ & & 1,3 & & & & & 733 \\
\hline & & & 1,0 & & & & & \\
\hline \multirow{5}{*}{$\begin{array}{l}\text { 7) Número } \\
\text { Inseminações }\end{array}$} & & & 122 & 368 & 110 & 9782 & 536 & 957 \\
\hline & & & 763 & 9865 & 0,00517 & 1545 & 112 & 4354 \\
\hline & & & 0,07074 & 7940 & 0,00023 & 0,00041 & 0,00085 & 0107 \\
\hline & & & 0,04668 & 3480 & 0,00006 & 2265 & 0,00022 & 5521 \\
\hline & & 0,02413 & $-0,19413$ & 1,36851 & 0,00239 & 0,17241 & 964 & 7884 \\
\hline \multirow{5}{*}{$\begin{array}{l}\text { 8) Ano ao Parto } \\
\text { anterior }\end{array}$} & ANO94 & 0,02640 & $-0,70403$ & 0,21559 & 0,01993 & 0,00271 & 0,07336 & 0,00688 \\
\hline & & 0,02390 & $-0,64426$ & 0,16407 & 0,02734 & 0,00257 & 0,11115 & 0,00721 \\
\hline & & & 0,17514 & $-0,14231$ & 0,00251 & 0240 & 0,01092 & 0,00721 \\
\hline & & & 0,40528 & & & 508 & 850 & 0,01522 \\
\hline & ANO & & & 957 & 283 & 116 & 755 & 5408 \\
\hline \multirow{4}{*}{$\begin{array}{l}\text { 9) Estação do Ano } \\
\text { ao Parto anterior }\end{array}$} & & & & 422 & & 287 & & $\longdiv { 9 1 5 }$ \\
\hline & $\mathrm{OU}$ & 05 & & 733 & 0,002 & 790 & & 642 \\
\hline & & & $-0,09859$ & 802 & 0,00049 & 1104 & 188 & 0,02916 \\
\hline & & 0,02442 & $-0,14023$ & 0,29879 & 0,00119 & 0,00783 & 0,00474 & 0,02150 \\
\hline \multirow[t]{4}{*}{ 10) Rebanho } & $\mathrm{COL}$ & 0,01786 & 0,08605 & $-0,02146$ & 0,00095 & 0,00009 & 0,00516 & 0,00032 \\
\hline & NAM & 0,02181 & 0,08430 & 0,13541 & 0,00062 & 0,00232 & 0,00277 & 0,00714 \\
\hline & SM & 0,02575 & $-0,59510$ & 0,32559 & 0,01661 & 0,00721 & 0,06266 & 0,01876 \\
\hline & & 0,02549 & 0,19204 & $-0,49139$ & 0,00183 & 0,01735 & 0,00697 & 0,04562 \\
\hline 11) Intervalo entre & & . & $-0,02113$ & $-0,78146$ & & & 0,00014 & 0,19665 \\
\hline \multirow[t]{3}{*}{ Partos (em meses) } & & . & 0,11207 & $-0,62352$ & & & 0,00427 & 0,13207 \\
\hline & & 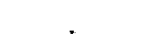 & 0,12559 & 0,11373 & & & & 0,00440 \\
\hline & & & $-0,22176$ & 1,20433 & & & 0,01629 & 0,54637 \\
\hline
\end{tabular}




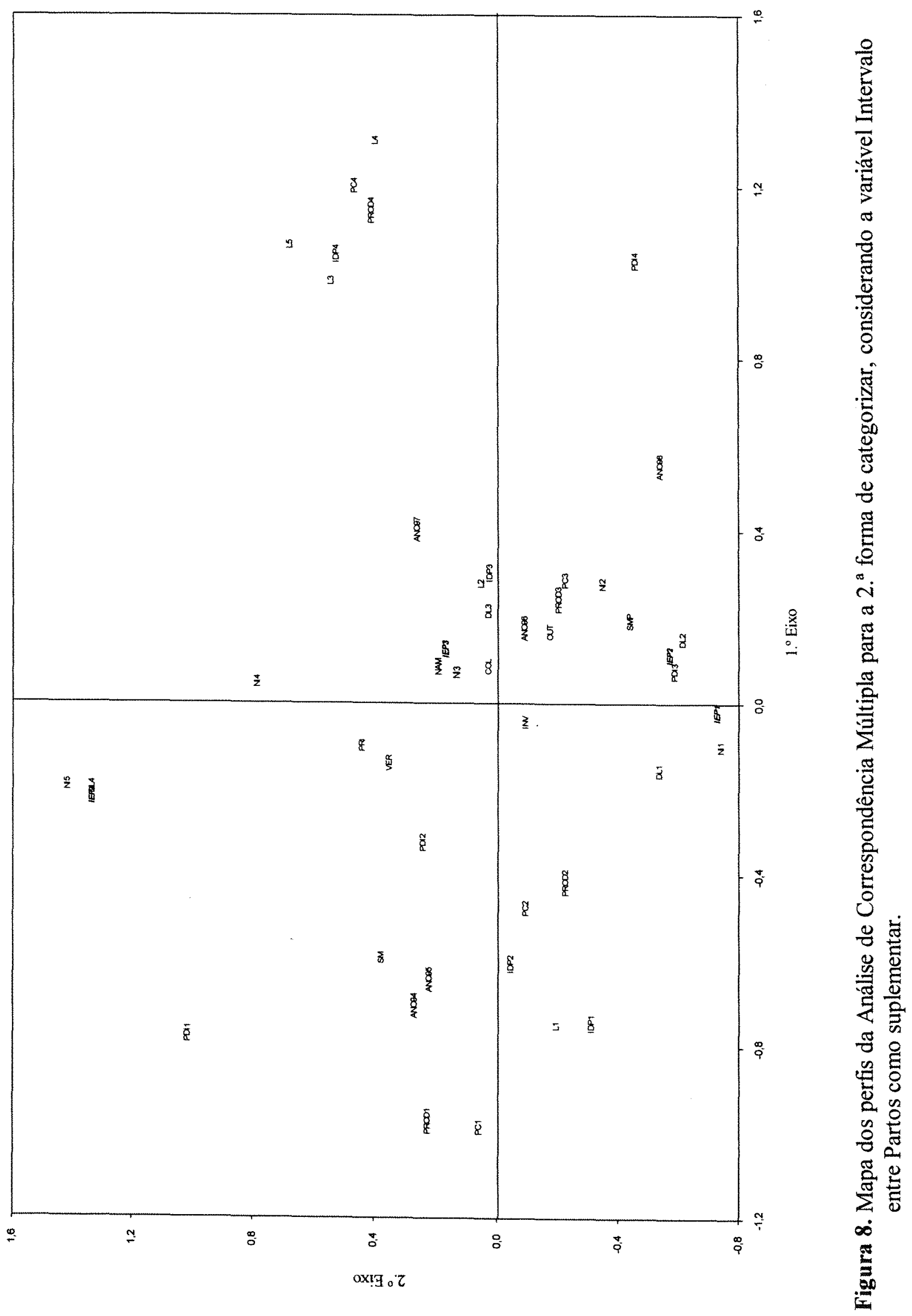


Verifica-se que outras associações são observadas, no entanto, não é de interesse discuti-las aqui, pois o maior interesse deste trabalho é identificar variáveis associadas com o Intervalo entre Partos.

Note-se, que mesmo com a $2 .^{\text {a }}$ forma de categorizar, os resultados obtidos não são ideais para análise de correspondência múltipla, pois não ocorreu a devida discriminação das categorias da variável Intervalo entre Partos como era esperado.

Para confirmar os resultados da análise de correspondência de tabelas sobrepostas, quanto à variável Reprodutor, procedeu-se a uma terceira análise de correspondência para a $2 .^{\mathrm{a}}$ forma de categorizar. Nessa análise somente foram consideradas as variáveis Intervalo entre Partos e Reprodutor, efetuando-se a análise de correspondência simples para o cruzamentos dessas duas variáveis.

A Tabela 21 ilustra a decomposição da inércia total $(0,11488)$ da análise de correspondência simples para a $2 .^{a}$ forma de categorizar, cuja inércia foi decomposta em três eixos principais.

Tabela 21. Histograma dos autovalores da análise de correspondência simples para a $2 .^{\mathrm{a}}$ forma de categorizar.

\begin{tabular}{|c|c|c|c|c|}
\hline Eixos & Autovalores & Porcentagem & $\begin{array}{l}\text { Porcentagem } \\
\text { acumulada }\end{array}$ & $\begin{array}{ccccc}11 & 22 & 33 & 44 & 55 \\
- & -\end{array}$ \\
\hline 1 & 0,06169 & $53,70 \%$ & $53,70 \%$ & 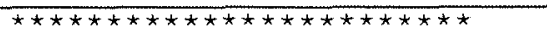 \\
\hline 2 & 0,02865 & $24,94 \%$ & $78,64 \%$ & 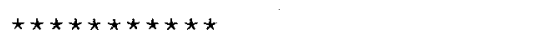 \\
\hline 3 & 0,02454 & $21,36 \%$ & $100,00 \%$ & 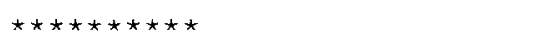 \\
\hline
\end{tabular}

Como forma de confirmação, optou-se por estudar-se apenas os dois primeiros eixos principais, os quais explicam $78,64 \%$ da variabilidade total da tabela de contingência.

$\mathrm{Na}$ Tabela 22 são apresentados os resultados da análise de correspondência simples para o cruzamento da variável Intervalo entre Partos com a variável Reprodutor. A partir desses resultados construiu-se o mapa de perfis que é mostrado na Figura 9. 
Tabela 22. Resultados da Análise de Correspondência Simples para a 2. categorizar.

\begin{tabular}{|c|c|c|c|c|c|c|c|c|}
\hline \multirow{2}{*}{ Variáveis } & \multirow{2}{*}{ Categorias } & \multirow{2}{*}{ Inércia } & \multicolumn{2}{|c|}{ Coordenadas } & \multicolumn{2}{|c|}{ Contribuições } & \multicolumn{2}{|c|}{ Co-seno Quadrado } \\
\hline & & & 1. ${ }^{\mathrm{a}} \mathrm{Dim}$. & 2. ${ }^{a}$ Dim. & $1^{\mathbf{a}} \mathrm{Dim}$. & 2. ${ }^{\mathrm{a}} \mathrm{Dim}$ & $1 .^{2}$ Dim. & $2 .^{a} \mathrm{Dim}$. \\
\hline \multirow[t]{48}{*}{ 1) Reprodutor } & 1 & 0,01922 & $-0,50411$ & $-0,01846$ & 0,03528 & 0,00010 & 0,98551 & 0,00132 \\
\hline & 2 & 0,01345 & 0,21229 & 0,12307 & 0,01356 & 0,00981 & 0,54129 & 0,18191 \\
\hline & 3 & 0,00481 & $-0,03390$ & 0,20452 & 0,00024 & 0,01875 & 0,02672 & 0,97250 \\
\hline & 4 & 0,02069 & 0,43451 & $-0,19318$ & 0,03058 & 0,01301 & 0,79355 & 0,15686 \\
\hline & 5 & 0,01853 & $-0,53259$ & 0,05732 & 0,03281 & 0,00082 & 0,95095 & 0,01101 \\
\hline & 6 & 0,05073 & 0,68829 & 0,48981 & 0,05480 & 0,05976 & 0,58011 & 0,29379 \\
\hline & 7 & 0,01422 & 0,34871 & $-0,01197$ & 0,01594 & 0,00004 & 0,60193 & 0,00071 \\
\hline & 8 & 0,03565 & $-0,26948$ & 0,16550 & 0,04816 & 0,03911 & 0,72556 & 0,27367 \\
\hline & 9 & 0,00590 & $-0,16256$ & $-0,06730$ & 0,00734 & 0,00271 & 0,66727 & 0,11436 \\
\hline & 10 & 0,01689 & $-0,15712$ & $-0,33336$ & 0,00457 & 0,04429 & 0,14530 & 0,65407 \\
\hline & 11 & 0,01614 & 0,31323 & $-0,15161$ & 0,02346 & 0,01183 & 0,78061 & 0,18288 \\
\hline & 12 & 0,00658 & 0,13011 & $-0,06932$ & 0,00222 & 0,00136 & 0,18114 & 0,05141 \\
\hline & 13 & 0,00977 & $-0,35272$ & 0,09680 & 0,01439 & 0,00233 & 0,79089 & 0,05957 \\
\hline & 14 & 0,03392 & $-0,26935$ & $-0,20552$ & 0,03245 & 0,04068 & 0,51381 & 0,29914 \\
\hline & 15 & 0,00430 & 0,09627 & $-0,17624$ & 0,00122 & 0,00877 & 0,15161 & 0,50811 \\
\hline & 16 & 0,06024 & $-0,68029$ & 0,17636 & 0,10351 & 0,01498 & 0,92263 & 0,06201 \\
\hline & 17 & 0,01038 & 0,33782 & 0,02237 & 0,01408 & 0,00013 & 0,72831 & 0,00319 \\
\hline & 18 & 0,01630 & $-0,14039$ & 0,24932 & 0,00274 & 0,01858 & 0,09015 & 0,28430 \\
\hline & 19 & 0,04947 & $-0,65103$ & 0,27089 & 0,07191 & 0,02681 & 0,78060 & 0,13515 \\
\hline & 20 & 0,02687 & $-0,33803$ & 0,50682 & 0,01498 & 0,07251 & 0,29941 & 0,67309 \\
\hline & 21 & 0,00594 & $-0,12285$ & 0,05629 & 0,00792 & 0,00358 & 0,71527 & 0,15017 \\
\hline & 22 & 0,01955 & 0,46191 & $-0,10663$ & 0,03456 & 0,00396 & 0,94910 & 0,05057 \\
\hline & 23 & 0,01327 & 0,26053 & 0,04249 & 0,02408 & 0,00138 & 0,97406 & 0,02591 \\
\hline & 24 & 0,01724 & $-0,26764$ & $-0,17422$ & 0,02210 & 0,02016 & 0,68815 & 0,29158 \\
\hline & 25 & 0,01688 & $-0,09562$ & $-0,11058$ & 0,01008 & 0,02903 & 0,32084 & 0,42907 \\
\hline & 26 & 0,00776 & $-0,09527$ & 0,08715 & 0,00343 & 0,00618 & 0,23719 & 0,19849 \\
\hline & 27 & 0,03434 & 0,35671 & 0,17391 & 0,04514 & 0,02310 & 0,70587 & 0,16779 \\
\hline & 28 & 0,00333 & 0,02481 & 0,05996 & 0,00025 & 0,00316 & 0,04053 & 0,23663 \\
\hline & 29 & 0,00406 & 0,09364 & 0,09687 & 0,00325 & 0,00748 & 0,42892 & 0,45893 \\
\hline & 30 & 0,00438 & $-0,07745$ & $-0,00872$ & 0,00153 & 0,00004 & 0,18715 & 0,00237 \\
\hline & 31 & 0,01175 & 0,01527 & $-0,03269$ & 0,00009 & 0,00085 & 0,00394 & 0,01807 \\
\hline & 32 & 0,00532 & 0,12494 & $-0,07545$ & 0,00313 & 0,00246 & 0,31570 & 0,11514 \\
\hline & 33 & 0,00923 & $-0,00953$ & $-0,14744$ & 0,00007 & 0,03646 & 0,00412 & 0,98524 \\
\hline & 34 & 0,01010 & $-0,27896$ & 0,26688 & 0,00900 & 0,01774 & 0,47867 & 0,43812 \\
\hline & 35 & 0,03219 & 0,42250 & 0,14293 & 0,03029 & 0,00746 & 0,50526 & 0,05783 \\
\hline & 36 & 0,03577 & 0,42619 & 0,05689 & 0,05183 & 0,00199 & 0,77804 & 0,01386 \\
\hline & 37 & 0,03038 & $-0,02024$ & $-0,30621$ & 0,00010 & 0,04982 & 0,00179 & 0,40896 \\
\hline & 38 & 0,00277 & 0,11454 & 0,03144 & 0,00344 & 0,00056 & 0,66742 & 0,05029 \\
\hline & 39 & 0,00063 & 0,03389 & $-0,01787$ & 0,00015 & 0,00009 & 0,12924 & 0,03594 \\
\hline & 40 & 0,01396 & $-0,19568$ & 0,17431 & 0,01417 & 0,02422 & 0,54528 & 0,43268 \\
\hline & 41 & 0,00590 & $-0,18783$ & 0,01252 & 0,00762 & 0,00007 & 0,69383 & 0,00308 \\
\hline & 42 & 0,00618 & 0,05248 & $-0,08581$ & 0,00246 & 0,01418 & 0,21424 & 0,57279 \\
\hline & 43 & 0,01873 & 0,16672 & $-0,45415$ & 0,00407 & 0,06507 & 0,11679 & 0,86652 \\
\hline & 44 & 0,01482 & $-0,08829$ & 0,36266 & 0,00102 & 0,03713 & 0,03702 & 0,62460 \\
\hline & 45 & 0,02754 & 0,49748 & $-0,08245$ & 0,04963 & 0,00294 & 0,96770 & 0,02658 \\
\hline & 46 & 0,00819 & 0,15399 & $-0,12438$ & 0,00640 & 0,00899 & 0,41990 & 0,27394 \\
\hline & 47 & 0,01109 & 0,33073 & 0,07131 & 0,01940 & 0,00194 & 0,93977 & 0,04369 \\
\hline & 48 & 0,01408 & 0,12704 & $-0,12138$ & 0,00261 & 0,00514 & 0,09967 & 0,09098 \\
\hline
\end{tabular}


Tabela 22. Resultados da Análise de Correspondência Simples para a $2 .^{\text {a }}$ forma de categorizar (continuação).

\begin{tabular}{|c|c|c|c|c|c|c|c|c|}
\hline \multirow{2}{*}{ Variáveis } & \multirow{2}{*}{ Categorias } & \multirow{2}{*}{ Inércia } & \multicolumn{2}{|c|}{ Coordenadas } & \multicolumn{2}{|c|}{ Contribuições } & \multicolumn{2}{|c|}{ Co-seno Quadrado } \\
\hline & & & 1. a Dim. & 2. ${ }^{a}$ Dim. & 1. ${ }^{\mathrm{a}} \mathrm{Dim}$. & 2. ${ }^{\mathrm{a}} \mathrm{Dim}$. & 1. ${ }^{a}$ Dim. & 2. ${ }^{\mathrm{a}} \mathrm{Dim}$. \\
\hline & 49 & 0,00326 & 0,05628 & $-0,13404$ & 0,00071 & 0,00865 & 0,11659 & 0,66123 \\
\hline & 50 & 0,00908 & $-0,27474$ & 0,06616 & 0,01572 & 0,00196 & 0,92902 & 0,05388 \\
\hline & 51 & 0,00061 & $-0,00544$ & 0,04865 & 0,00001 & 0,00228 & 0,01170 & 0,93452 \\
\hline & 52 & 0,00240 & 0,12751 & $-0,13310$ & 0,00213 & 0,00500 & 0,47654 & 0,51919 \\
\hline & 53 & 0,00712 & $-0,28496$ & $-0,15497$ & 0,00939 & 0,00598 & 0,70813 & 0,20942 \\
\hline & 54 & 0,02032 & 0,38052 & 0,04491 & 0,03015 & 0,00090 & 0,79668 & 0,01110 \\
\hline & 55 & 0,03392 & 0,00444 & 0,32433 & 0,00000 & 0,03843 & 0,00005 & 0,28256 \\
\hline & 56 & 0,01583 & $-0,26947$ & $-0,18473$ & 0,01344 & 0,01360 & 0,45586 & 0,21424 \\
\hline & 57 & 0,01256 & 0,15927 & 0,13977 & 0,00959 & 0,01590 & 0,40990 & 0,31568 \\
\hline & 58 & 0,00924 & 0,11383 & $-0,17770$ & 0,00240 & 0,01258 & 0,13940 & 0,33974 \\
\hline & 59 & 0,00765 & $-0,08566$ & $-0,24043$ & 0,00141 & 0,02400 & 0,09927 & 0,78214 \\
\hline & 60 & 0,04344 & 0,45294 & 0,61724 & 0,02690 & 0,10755 & 0,33251 & 0,61750 \\
\hline & 61 & 0,01513 & $-0,20923$ & $-0,07312$ & 0,00608 & 0,00160 & 0,21562 & 0,02633 \\
\hline 2) Intervalo & IEPI & 0,27035 & 0,27278 & 0,21266 & 0,29381 & 0,38448 & 0,58357 & 0,35469 \\
\hline entre Partos & IEP2 & 0,18475 & 0,12989 & $-0,09501$ & 0,06935 & 0,07989 & 0,20156 & 0,10785 \\
\hline (meses) & IEP3 & 0,17460 & $-0,00203$ & $-0,21916$ & 0,00002 & 0,42589 & 0,00005 & 0,60834 \\
\hline & IEP4 & 0,37031 & $-0,39734$ & 0,11241 & 0,63682 & 0,10974 & 0,92342 & 0,07391 \\
\hline
\end{tabular}

Nota-se, que realmente a variável Reprodutor influenciou o Intervalo entre Partos, isto é, determinados reprodutores propiciaram intervalos entre partos de menor tempo, outros de tempo intermediário e outros, ainda, longos intervalos entre partos.

Pode-se ver facilmente que os reprodutores $1,5,16$ e 19 estão associados com os maiores intervalos entre partos, e que os reprodutores $6,22,45$ e 60 estão associados com os menores intervalos entre partos, o que é condizente com os resultados obtidos para a análise de tabelas sobrepostas. No entanto, ocorreu discriminação de uma maior quantidade de reprodutores na análise do correspondência simples, o que é interessante.

Verifica-se que os resultados dessa análise de correspondência são condizentes com os resultados apresentados na Tabela 1, pois em ambas o efeito de reprodutor mostrou-se influente na variação do intervalo entre partos. 


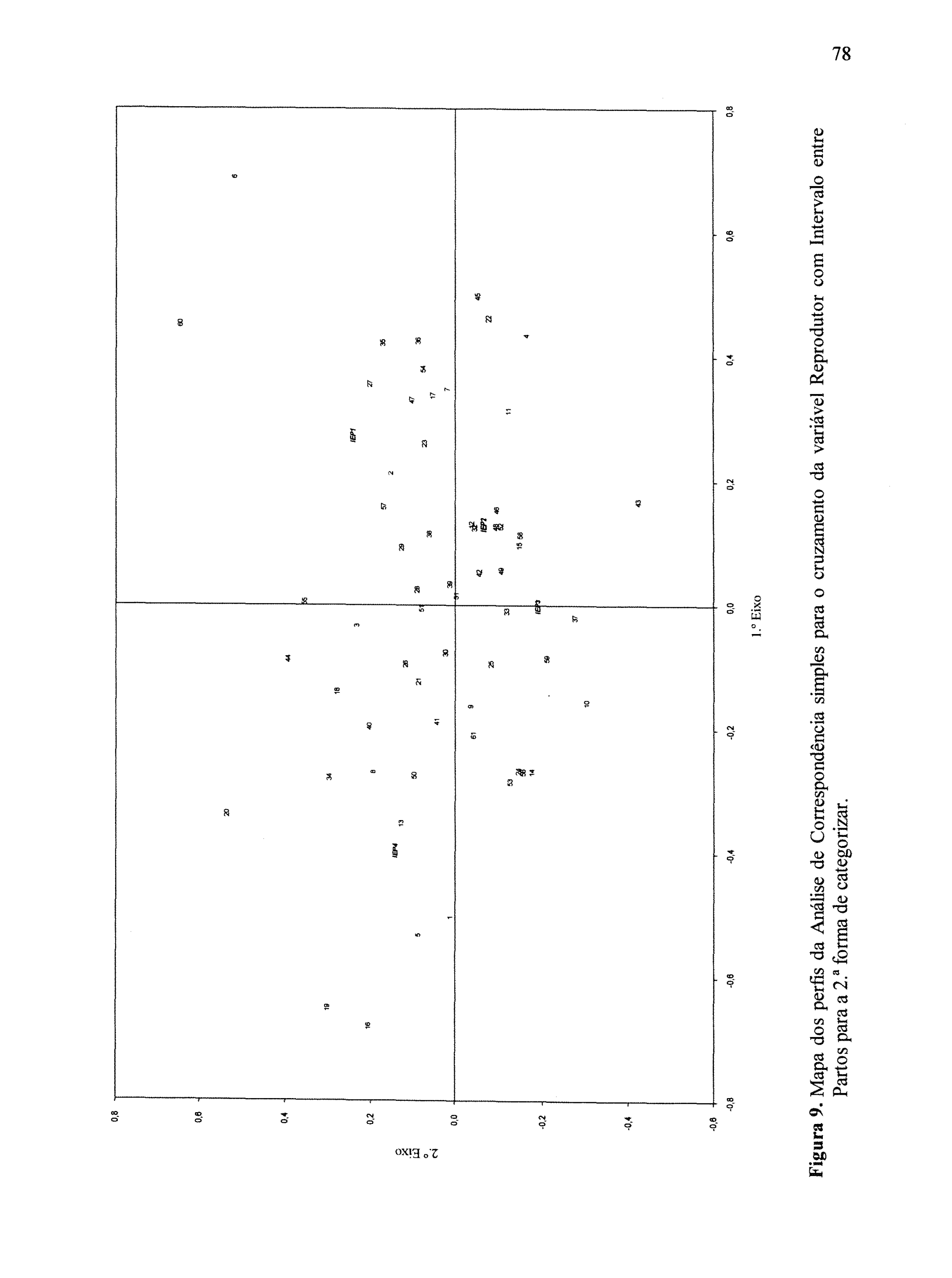




\subsection{Considerações finais}

Analisando-se conjuntamente as duas formas de categorizar e as metodologias de análise de correspondência, de tabelas sobrepostas e múltipla, verifica-se facilmente que para as tabelas sobrepostas ambas as formas de categorizar forneceram resultados conclusivos. Enquanto que a análise de correspondência múltipla, considerando a variável Intervalo entre Partos como suplementar, para a categorização em 8 classes de igual amplitude não forneceu resultados desejáveis, e para a categorização em 4 classes de igual freqüência obtiveram-se melhores resultados, porém não tão conclusivos quanto os resultados da análise de correspondência de tabelas sobrepostas.

Note-se que para a análise de correspondência de tabelas sobrepostas, a categorização em 8 classes de igual freqüência discriminou mais variáveis como associadas com o Intervalo entre Partos do que a $2 .^{a}$ forma de categorizar. Poder-se-ia, então, afirmar que a categorização em 4 classes de igual freqüência proporcionou a visualização das associações mais grosseiras, enquanto a categorização em 8 classes de igual amplitude possibilitou a observação destas mesmas associações, porém, de forma mais fina, e de outras associações que não foram discriminadas pela $2 .{ }^{\mathrm{a}}$ forma de categorizar.

Pode-se, ainda, para ambas as formas de categorizar na análise de tabelas sobrepostas, determinar o melhor intervalo entre partos, baseando-se simplesmente nas variáveis: Número de Inseminações e Produção de Leite por Dia de Intervalo entre Partos, sem levar em conta outras questões. Para a $1 .^{a}$ forma de categorizar, intervalos entre partos menores do que 13 meses são desejáveis, pois estão associados a um menor número de inseminações por parto e a uma maior produção de leite por dia de intervalo, e além disso, a classe IEP2 é mais freqüente $\left(38,1 \%\right.$ das observações). Para a $2 .^{a}$ forma de categorizar, intervalos entre partos menores ou iguais a 11,8 meses são desejáveis, pois estão também associados com um menor número de inseminações por parto e a uma maior produção de leite por dia de intervalo. Juntando-se as duas análises pode-se afirmar 
que intervalos entre partos menores que 13 meses são a solução. Salienta-se que essas afirmações foram feitas baseando-se apenas nos resultados da análise constante neste trabalho, e que podem existir outros fatores que determinem o resultado econômico.

Em se tratando de análise de correspondência múltipla, não se pôde fazer qualquer afirmação quanto ao melhor intervalo entre partos, isso porque as categorias da variảvel Intervalo entre Partos não foram devidamente discriminadas por esse método. É claro que esses resultados não tiram os méritos da análise de correspondência múltipla, pois são conseqüência da configuração das variáveis relacionadas a este estudo.

Para o efeito genético (Reprodutor), a análise de correspondência de tabelas sobrepostas, considerando essa variável como suplementar, foi conclusiva para ambas as formas de categorizar, discriminando reprodutores associados com as diversas categorias de Intervalos entre Partos. Além disso, esses resultados foram condizentes com os resultados da análise de correspondência simples para o cruzamento de Reprodutor com Intervalo entre Partos. Salienta-se, contudo que na análise de correspondência simples os reprodutores apresentaram-se mais dispersos sobre o mapa de perfis.

Para finalizar, note-se que a metodologia de análise de correspondência mostrou-se muito útil neste caso, possibilitando identificar variáveis associadas com intervalo entre partos, tendo a vantagem de não exigir qualquer suposição inicial quanto ao modelo ou à distribuição fundamental. Porém, deve-se salientar que podem existir outras variáveis que estão mais associadas com a variável de interesse que não foram abordadas aqui por motivo de não se terem dados disponiveis a respeito. Essas variáveis podem trazer respostas mais interessantes do que as encontradas neste trabalho, e portanto, não se deve considerá-lo como uma resposta final ao problema, mas sim um início que deve ter continuidade. 


\section{CONCLUSÕES}

De acordo com as metodologias e condições empregadas neste trabalho, $\mathrm{e}$ com base nos resultados obtidos, pôde-se chegar às seguintes conclusões:

1) A análise de correspondência, principalmente de tabelas sobrepostas, mostrouse uma ferramenta eficiente quando se trata de analisar dados observacionais, onde o interesse é verificar as associações entre "variáveis resposta" e "variáveis explicativas", como no presente caso. A grande vantagem da análise de correspondência é a não existência de pressuposições a "priori" para a realização da análise, o que é comum na maioria dos métodos utilizados;

2) A análise de correspondência múltipla não foi suficientemente discriminatória para o fenômeno em estudo, devido, possivelmente, ao desequilíbrio nas massas quando da categorização em 8 classes de igual amplitude, e/ou à própria configuração das variáveis, em ambas as formas de categorizar, que não permitiram uma boa discriminação da variável intervalo entre partos. Discutir e buscar as razões disso não são de interesse do presente trabalho, mas podem resultar em trabalho futuro;

3) A análise de correspondência simples para o cruzamento da variável Reprodutor com a variável Intervalo entre Partos apresentou-se como uma ferramenta importante na confirmação dos resultados da análise de correspondência de tabelas sobrepostas onde a variável Reprodutor foi considerada como suplementar;

4) A categorização em 8 classes de igual amplitude para as variáveis quantitativas contínuas mostrou-se mais discriminatória na análise de tabelas 
sobrepostas, isto é, discriminou mais variáveis como associadas com o intervalo entre partos do que a categorização em 4 classes de igual freqüência;

5) Observando-se todas as análises de correspondência realizadas no presente trabalho, conjuntamente, pode-se afirmar que as seguintes variáveis estão associadas com o intervalo entre partos: Dias em Lactação; Número de Inseminações; Produção de Leite por Dia de Intervalo entre Partos e Reprodutor (efeito genético). Outras variáveis como Ano do Parto Anterior e Estação do Ano ao Parto Anterior estão mais fracamente associadas ao intervalo entre partos;

6) Pelos resultados obtidos, o Intervalo entre Partos menor ou igual a 13 meses é o desejável nas condições do presente trabalho;

7) Devem-se realizar novos estudos para aprimoramento da metodologia e busca de soluções para os problemas encontrados, através de abordagens interdisciplinares estatístico-zootécnicas. 
ANEXOS 
Anexo A. Programa para a análise de correspondência considerando a categorização em 8 classes de igual amplitude.

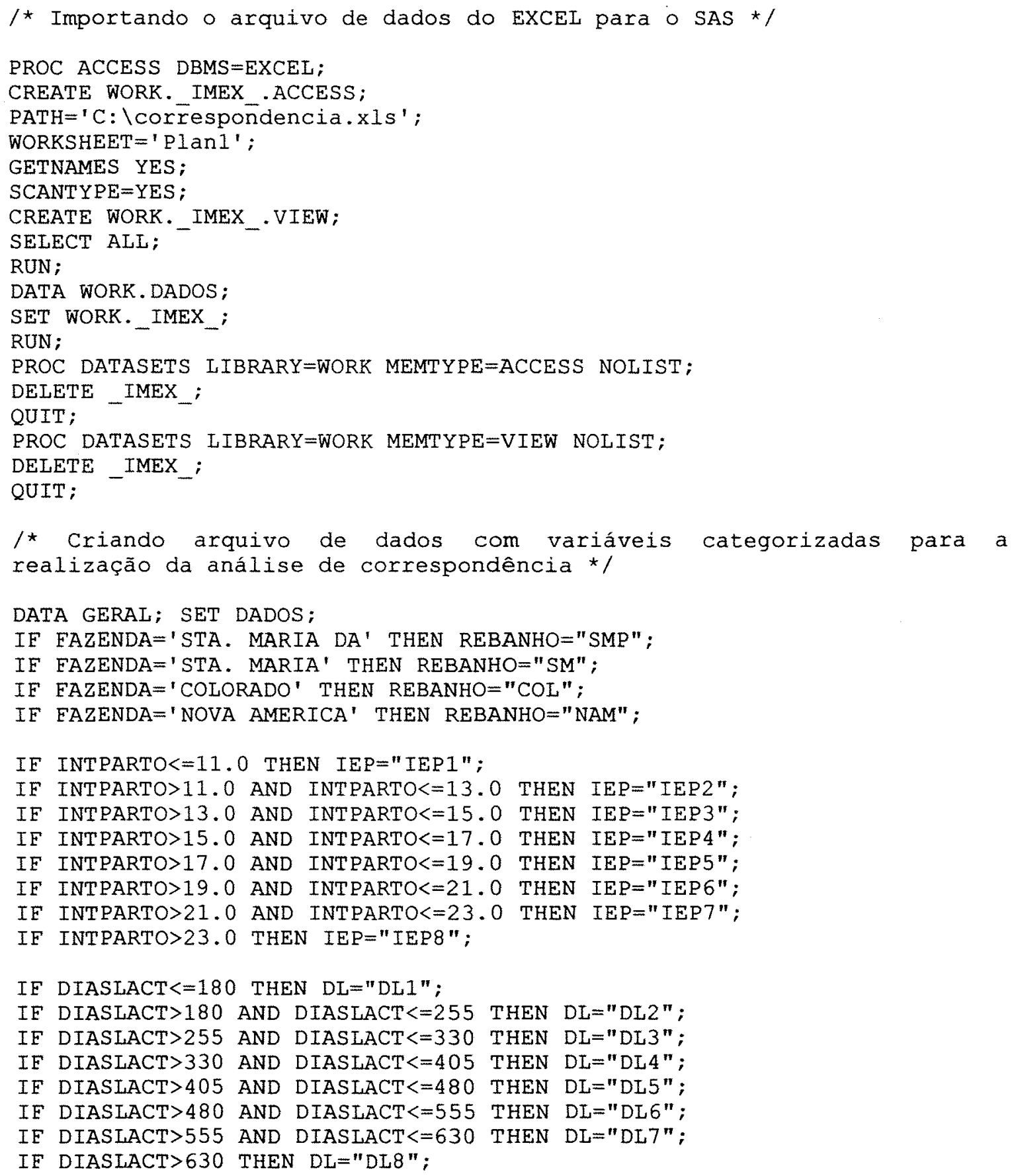




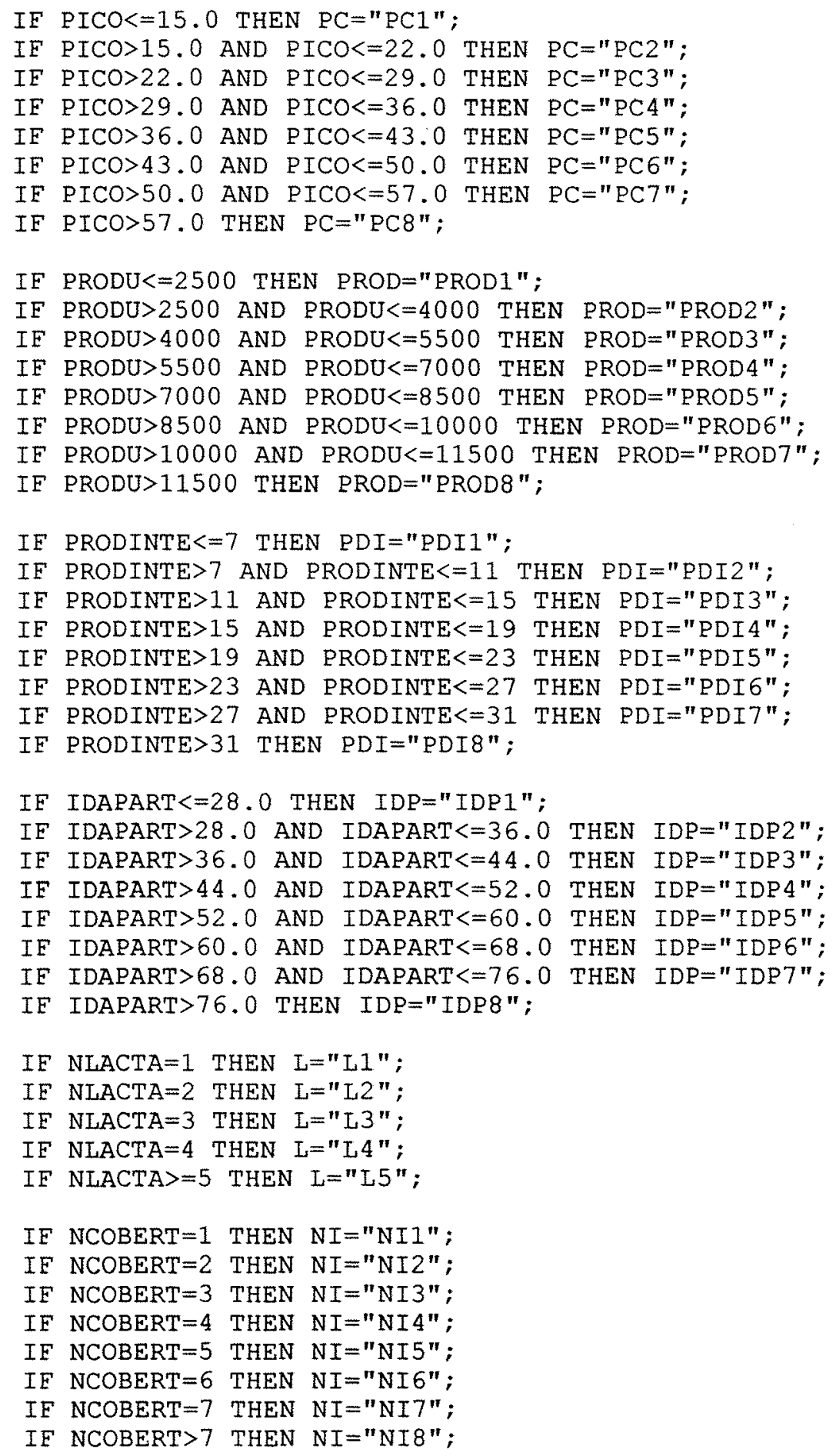




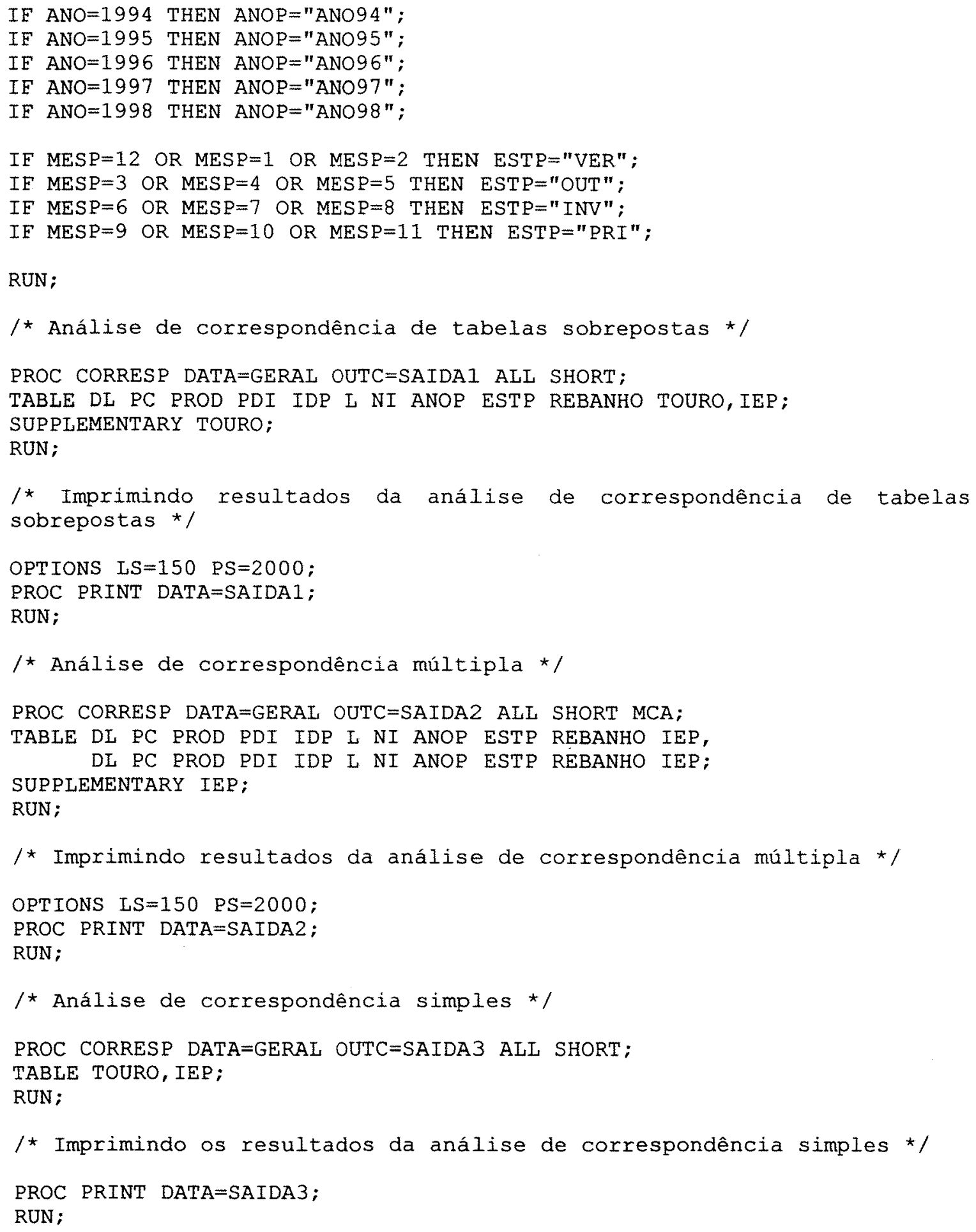


Anexo B. Programa para a análise de correspondência considerando a categorização em 4 classes de igual freqüência.

/* Importando o arquivo de dados do EXCEL para o SAS */

PROC ACCESS DBMS=EXCEL;

CREATE WORK. IMEX . ACCESS;

PATH =' C: \correspoñdencia.$x I s^{\prime}$;

WORKSHEET = 'Plan 1 ';

GETNAMES YES;

SCANTYPE=YES;

CREATE WORK._IMEX_.VIEW;

SELECT ALL;

RUN;

DATA WORK. DADOS;

SET WORK. IMEX ;

RUN;

PROC DATASETS LIBRARY=WORK MEMTYPE=ACCESS NOLIST;

DELETE _ IMEX_;

QUIT;

PROC DATASETS LIBRARY=WORK MEMTYPE=VIEW NOLIST;

DELETE _IMEX_;

QUIT;

/* Criando arquivo de dados com variáveis categorizadas para a realização da análise de correspondência */

DATA GERAL; SET DADOS;

IF EAZENDA='STA. MARIA DA' THEN REBANHO="SMP";

IE EAZENDA='STA. MARIA' THEN REBANHO="SM" ;

IF FAZENDA='COLORADO' THEN REBANHO="COL";

IE FAZENDA='NOVA AMERICA' THEN REBANHO="NAM" ;

IF INTPARTO $=11.8$ THEN IEP="IEP1" ;

IE INTPARTO $>11.8$ AND INTPARTO $\angle=13.2$ THEN IEP="IEP2";

IE INTPARTO>13.2 AND INTPARTO<=16.2 THEN IEP="IEP3";

IF INTPARTO>16.2 THEN IEP="IEP4";

IF DIASTACT $<=293$ THEN DL="DLI";

IE DIASLACT $>293$ AND DIASLACT $<=332$ THEN DL="DL2";

IF DIASLACT $>332$ AND DIASLACT $<=395$ THEN DL="DL3";

IF DIASLACT>395 THEN DL="DL4";

IE PICO $<=29.7$ THEN PC="PC1";

IE PICO $>29.7$ AND PICO $<=34.6$ THEN PC="PC2";

IF $\mathrm{PICO}>34.6$ AND $\mathrm{PICO}<=40.2$ THEN $\mathrm{PC}=" \mathrm{PC} 3 "$;

IF PICO $>40.2$ THEN PC="PC4";

IF PRODU $<=6873$ THEN PROD="PRODI";

IF PRODU $>6873$ AND PRODU $<=8068$ THEN PROD="PROD2" ;

IF PRODU $>8068$ AND PRODU $<=9261$ THEN PROD="PROD3";

IE PRODU>9261 THEN PROD="PROD4"; 


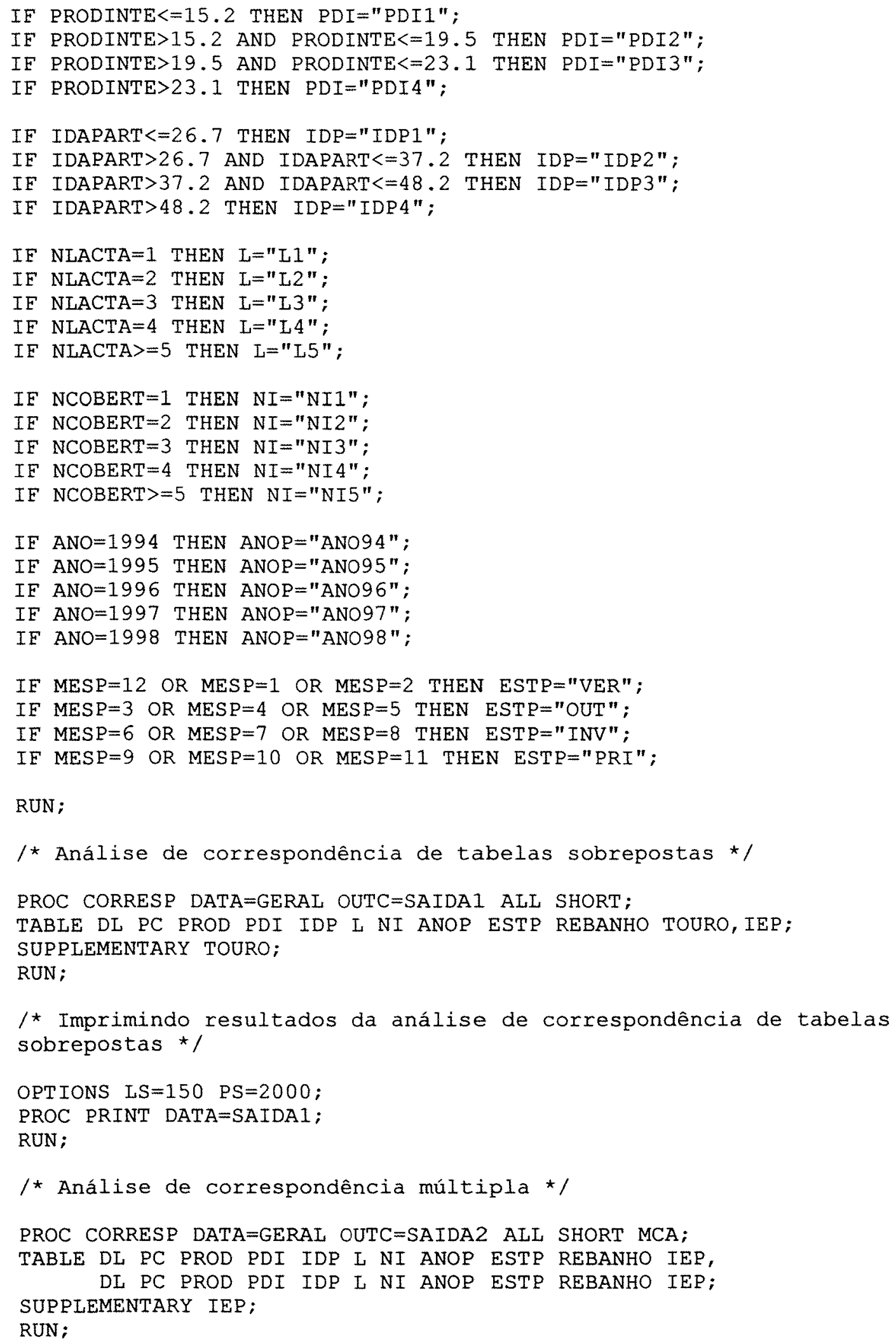


/* Imprimindo resultados da análise de correspondência múltipla */ OPT IONS LS $=150$ PS $=2000$;

PROC PRINT DATA=SAIDA2;

RUN;

/* Análise de correspondência simples */

PROC CORRESP DATA=GERAL OUTC=SAIDA3 ALL SHORT;

TABLE TOURO, IEP;

RUN;

/* Imprimindo os resultados da análise de correspondência simples */ PROC PRINT DATA=SAIDA3;

RUN; 
Anexo C. Freqüências observadas para o cruzamento da variável Intervalo entre Partos com as variáveis ativas para a $1 .^{a}$ forma de categorizar.

\begin{tabular}{|c|c|c|c|c|c|c|c|c|c|c|}
\hline \multirow{2}{*}{ Variáveis Ativas } & \multirow{2}{*}{ Classes } & \multicolumn{8}{|c|}{ IEP: Intervalo entre Partos } & \multirow{2}{*}{ Total } \\
\hline & & IEP1 & IEP2 & IEP3 & IEP4 & IEP5 & IEP6 & IEP7 & IEP8 & \\
\hline \multirow{8}{*}{$\begin{array}{l}\text { 1) Dias } \\
\text { Lactação }\end{array}$} & $\mathrm{DLI}$ & 3 & 9 & 4 & 1 & 1 & 0 & 0 & 1 & 19 \\
\hline & DL2 & 31 & 37 & 8 & 8 & 8 & 1 & 1 & 0 & 94 \\
\hline & DL3 & 140 & 682 & 70 & 14 & 10 & 8 & 4 & 1 & 929 \\
\hline & DL4 & 1 & 72 & 373 & 85 & 26 & 12 & 14 & 7 & 590 \\
\hline & DL5 & 0 & 0 & 7 & 125 & 72 & 22 & 17 & 15 & 258 \\
\hline & DL6 & 0 & 0 & 0 & 1 & 41 & 55 & 16 & 13 & 126 \\
\hline & DL7 & 0 & 0 & 0 & 0 & 0 & 9 & 37 & 19 & 65 \\
\hline & DL8 & 0 & 1 & 0 & 0 & 0 & 0 & 2 & 18 & 21 \\
\hline \multirow{8}{*}{$\begin{array}{lll}\text { 2) Pico } & & \mathrm{de} \\
\text { Lactação } & (\mathrm{kg} & \mathrm{de} \\
\text { leite }) & & \end{array}$} & $\mathrm{PCl}$ & 1 & 13 & 4 & 0 & 1 & 0 & 0 & 0 & 19 \\
\hline & $\mathrm{PC} 2$ & 8 & 39 & 21 & 11 & 12 & 2 & 2 & 2 & 97 \\
\hline & PC3 & 39 & 142 & 74 & 38 & 19 & 14 & 12 & 8 & 346 \\
\hline & PC4 & 57 & 275 & 170 & 81 & 55 & 37 & 38 & 29 & 742 \\
\hline & PC5 & 47 & 222 & 134 & 51 & 34 & 28 & 25 & 17 & 558 \\
\hline & PC6 & 16 & 79 & 39 & 45 & 30 & 16 & 13 & 14 & 252 \\
\hline & PC7 & 6 & 24 & 16 & 4 & 7 & 7 & 1 & 3 & 68 \\
\hline & PC8 & 1 & 7 & 4 & 4 & 0 & 3 & 0 & 1 & 20 \\
\hline \multirow{8}{*}{$\begin{array}{l}\text { 3) Produção de } \\
\text { leite por lactação } \\
\text { (mil kg) }\end{array}$} & PRODI & 2 & 8 & 4 & 0 & 1 & 0 & 0 & 0 & 15 \\
\hline & PROD2 & 4 & 18 & 6 & 3 & 5 & 0 & 1 & 0 & 37 \\
\hline & PROD3 & 21 & 50 & 22 & 16 & 14 & 5 & 4 & 3 & 135 \\
\hline & PROD4 & 54 & 149 & 67 & 32 & 32 & 18 & 18 & 7 & 377 \\
\hline & PRODS & 58 & 288 & 147 & 66 . & 44 & 35 & 30 & 25 & 693 \\
\hline & PROD6 & 25 & 211 & 148 & 71 & 38 & 32 & 29 & 23 & 577 \\
\hline & PROD7 & 10 & 59 & 53 & 31 & 19 & 8 & 9 & 11 & 200 \\
\hline & PROD8 & 1 & 18 & 15 & 15 & 5 & 9 & 0 & 5 & 68 \\
\hline \multirow{8}{*}{$\begin{array}{l}\text { 4) Produção } \\
\text { Leite por Dia } \\
\text { Intervalo entre } \\
\text { partos (kg/dia) }\end{array}$} & PDII & 2 & 9 & 5 & 3 & 2 & 0 & 1 & 4 & 26 \\
\hline & PDI2 & 1 & 18 & 12 & 15 & 26 & 14 & 24 & 30 & 140 \\
\hline & PDI3 & 9 & 44 & 48 & 39 & 55 & 56 & 57 & 35 & 343 \\
\hline & PDI4 & 31 & 129 & 115 & 90 & 58 & 26 & 9 & 5 & 463 \\
\hline & PDI5 & 59 & 259 & 180 & 64 & 16 & 11 & 0 & 0 & 589 \\
\hline & PDI6 & 40 & 231 & 81 & 19 & 1 & 0 & 0 & 0 & 372 \\
\hline & PDI7 & 19 & 91 & 21 & 4 & 0 & 0 & 0 & 0 & 135 \\
\hline & PDI8 & 14 & 20 & 0 & 0 & 0 & 0 & 0 & 0 & 34 \\
\hline \multirow{8}{*}{$\begin{array}{l}\text { 5) Idade ao Parto } \\
\text { anterior }\end{array}$} & IDP1 & 56 & 261 & 141 & 67 & 43 & 32 & 34 & 19 & 653 \\
\hline & IDP2 & 33 & 135 & 57 & 30 & 26 & 12 & 12 & 14 & 319 \\
\hline & IDP3 & 37 & 183 & 112 & 49 & 31 & 30 & 18 & 19 & 479 \\
\hline & IDP4 & 21 & 98 & 56 & 33 & 27 & 9 & 11 & 9 & 264 \\
\hline & IDP5 & 16 & 56 & 39 & 27 & 14 & 16 & 7 & 2 & 177 \\
\hline & IDP6 & 5 & 35 & 36 & 17 & 8 & 5 & 6 & 4 & 116 \\
\hline & IDP7 & 5 & 19 & 12 & 5 & 6 & 1 & 2 & 1 & 51 \\
\hline & IDP8 & 2 & 14 & 9 & 6 & 3 & 2 & 1 & 6 & 43 \\
\hline
\end{tabular}




\begin{tabular}{|c|c|c|c|c|c|c|c|c|c|c|}
\hline \multirow{2}{*}{ Variáveis Ativas } & \multirow{2}{*}{ Classes } & \multicolumn{8}{|c|}{ IEP: Intervalo entre Partos } & \multirow{2}{*}{ Total } \\
\hline & & IEPI & IEP2 & IEP3 & IEP4 & IEP5 & IEP6 & IEP7 & IEP8 & \\
\hline 6) Ordem & $\mathrm{Ll}$ & 85 & 387 & 189 & 96 & 67 & 43 & 45 & 35 & 947 \\
\hline \multirow[t]{4}{*}{ Lactação } & $\mathrm{L} 2$ & 51 & 243 & 158 & 72 & 52 & 38 & 24 & 27 & 665 \\
\hline & L3 & 27 & 118 & 69 & 43 & 28 & 20 & 16 & 5 & 326 \\
\hline & L4 & 8 & 38 & 40 & 15 & 8 & 4 & 5 & 4 & 122 \\
\hline & L5 & 4 & 15 & 6 & 8 & 3 & 2 & 1 & 3 & 42 \\
\hline 7) Número de & NII & 159 & 468 & 77 & 15 & 1 & 1 & 0 & 1 & 722 \\
\hline \multirow[t]{7}{*}{ Inseminações } & $\mathrm{N} / 2$ & 11 & 236 & 155 & 32 & 15 & 1 & 1 & 1 & 452 \\
\hline & NI3 & 3 & 77 & 139 & 53 & 18 & 4 & 7 & 4 & 305 \\
\hline & NI4 & 0 & 16 & 65 & 54 & 33 & 14 & 8 & 5 & 195 \\
\hline & NI5 & 2 & 4 & 18 & 44 & 36 & 15 & 11 & 6 & 136 \\
\hline & NI6 & 0 & 0 & 7 & 19 & 27 & 26 & 15 & 6 & 100 \\
\hline & NI7 & 0 & 0 & 1 & 12 & 13 & 15 & 10 & 8 & 59 \\
\hline & NI8 & 0 & 0 & 0 & 5 & 15 & 31 & 39 & 43 & 133 \\
\hline \multirow{5}{*}{$\begin{array}{l}\text { 8) Ano ao Parto } \\
\text { anterior }\end{array}$} & ANO94 & 15 & 92 & 58 & 39 & 27 & 13 & 14 & 13 & 271 \\
\hline & ANO95 & 33 & 157 & 93 & 53 & 48 & 18 & 24 & 18 & 444 \\
\hline & ANO96 & 55 & 208 & 133 & 56 & 31 & 23 & 22 & 24 & 552 \\
\hline & ANO97 & 44 & 202 & 91 & 69 & 46 & 50 & 31 & 19 & 552 \\
\hline & ANO98 & 28 & 142 & 87 & 17 & 6 & 3 & 0 & 0 & 283 \\
\hline \multirow{4}{*}{$\begin{array}{l}\text { 9) Estação do Ano } \\
\text { ao Parto anterior }\end{array}$} & INV & 62 & 269 & 118 & 41 & 41 & 49 & 42 & 20 & 642 \\
\hline & OUT & 69 & 310 & 162 & 56 & 29 & 23 & 27 & 35 & 711 \\
\hline & PRI & 25 & 98 & 62 & 58 & 54 & 24 & 15 & 5 & 341 \\
\hline & VER & 19 & 124 & 120 & 79 & 34 & 11 & 7 & 14 & 408 \\
\hline \multirow[t]{4}{*}{ 10) Rebanho } & $\mathrm{COL}$ & 67 & 335 & 184 & 105 & 59 & 49 & 37 & 27 & 863 \\
\hline & NAM & 67 & 226 & 115 & 62 & 47 & 26 & 22 & 24 & 589 \\
\hline & $\mathrm{SM}$ & 24 & 110 & 61 & 35 & 29 & 18 & 22 & 17 & 316 \\
\hline & SMP & 17 & 130 & 102 & 32 & 23 & 14 & 10 & 6 & 334 \\
\hline \multicolumn{2}{|l|}{ Total } & 1750 & 8010 & 4620 & 2340 & 1580 & 1070 & 910 & 740 & 21020 \\
\hline
\end{tabular}


Anexo D. Perfis linha (em porcentagem) das variáveis ativas para a $1 .^{\mathrm{a}}$ forma de categorizar.

\begin{tabular}{|c|c|c|c|c|c|c|c|c|c|c|}
\hline \multirow{2}{*}{ Variáveis Ativas } & \multirow{2}{*}{ Classes } & \multicolumn{8}{|c|}{ IEP: Intervalo entre Partos } & \multirow{2}{*}{ Total } \\
\hline & & IEPI & IEP2 & IEP3 & IEP4 & IEP5 & IEP6 & IEP7 & IEP8 & \\
\hline 1) Dias & DL1 & $15,8 \%$ & $47,4 \%$ & $21,1 \%$ & $5,3 \%$ & $5,3 \%$ & $0,0 \%$ & $0,0 \%$ & $5,3 \%$ & 19 \\
\hline \multirow[t]{7}{*}{ Lactação } & DL2 & $33,0 \%$ & $39,4 \%$ & $8,5 \%$ & $8,5 \%$ & $8,5 \%$ & $1,1 \%$ & $1,1 \%$ & $0,0 \%$ & 94 \\
\hline & DL3 & $15,1 \%$ & $73,4 \%$ & $7,5 \%$ & $1,5 \%$ & $1,1 \%$ & $0,9 \%$ & $0,4 \%$ & $0,1 \%$ & 929 \\
\hline & DL4 & $0,2 \%$ & $12,2 \%$ & $63,2 \%$ & $14,4 \%$ & $4,4 \%$ & $2,0 \%$ & $2,4 \%$ & $1,2 \%$ & 590 \\
\hline & DL5 & $0,0 \%$ & $0,0 \%$ & $2,7 \%$ & $48,4 \%$ & $27,9 \%$ & $8,5 \%$ & $6,6 \%$ & $5,8 \%$ & 258 \\
\hline & DL6 & $0,0 \%$ & $0,0 \%$ & $0,0 \%$ & $0,8 \%$ & $32,5 \%$ & $43,7 \%$ & $12,7 \%$ & $10,3 \%$ & 126 \\
\hline & DL7 & $0,0 \%$ & $0,0 \%$ & $0,0 \%$ & $0,0 \%$ & $0,0 \%$ & $13,8 \%$ & $56,9 \%$ & $29,2 \%$ & 65 \\
\hline & DL8 & $0,0 \%$ & $4,8 \%$ & $0,0 \%$ & $0,0 \%$ & $0,0 \%$ & $0,0 \%$ & $9,5 \%$ & $85,7 \%$ & 21 \\
\hline \multirow{8}{*}{\begin{tabular}{lll|} 
2) Pico & & de \\
Lactação & $(\mathrm{kg}$ & $\mathrm{de}$ \\
leite) & & \\
\end{tabular}} & $\mathrm{PCl}$ & $5,3 \%$ & $68,4 \%$ & $21,1 \%$ & $0,0 \%$ & $5,3 \%$ & $0,0 \%$ & $0,0 \%$ & $0,0 \%$ & 19 \\
\hline & $\mathrm{PC} 2$ & $8,2 \%$ & $40,2 \%$ & $21,6 \%$ & $11,3 \%$ & $12,4 \%$ & $2,1 \%$ & $2,1 \%$ & $2,1 \%$ & 97 \\
\hline & $\mathrm{PC} 3$ & $11,3 \%$ & $41,0 \%$ & $21,4 \%$ & $11,0 \%$ & $5,5 \%$ & $4,0 \%$ & $3,5 \%$ & $2,3 \%$ & 346 \\
\hline & $\mathrm{PC} 4$ & $7,7 \%$ & $37,1 \%$ & $22,9 \%$ & $10,9 \%$ & $7,4 \%$ & $5,0 \%$ & $5,1 \%$ & $3,9 \%$ & 742 \\
\hline & PC5 & $8,4 \%$ & $39,8 \%$ & $24,0 \%$ & $9,1 \%$ & $6,1 \%$ & $5,0 \%$ & $4,5 \%$ & $3,0 \%$ & 558 \\
\hline & PC6 & $6,3 \%$ & $31,3 \%$ & $15,5 \%$ & $17,9 \%$ & $11,9 \%$ & $6,3 \%$ & $5,2 \%$ & $5,6 \%$ & 252 \\
\hline & PC7 & $8,8 \%$ & $35,3 \%$ & $23,5 \%$ & $5,9 \%$ & $10,3 \%$ & $10,3 \%$ & $1,5 \%$ & $4,4 \%$ & 68 \\
\hline & PC8 & $5,0 \%$ & $35,0 \%$ & $20,0 \%$ & $20,0 \%$ & $0,0 \%$ & $15,0 \%$ & $0,0 \%$ & $5,0 \%$ & 20 \\
\hline \multirow{8}{*}{$\begin{array}{l}\text { 3) Produção de } \\
\text { leite por lactação } \\
\text { (mil kg) }\end{array}$} & PROD 1 & $13,3 \%$ & $53,3 \%$ & $26,7 \%$ & $0,0 \%$ & $6,7 \%$ & $0,0 \%$ & $0,0 \%$ & $0,0 \%$ & 15 \\
\hline & PROD2 & $10,8 \%$ & $48,6 \%$ & $16,2 \%$ & $8,1 \%$ & $13,5 \%$ & $0,0 \%$ & $2,7 \%$ & $0,0 \%$ & 37 \\
\hline & PROD3 & $15,6 \%$ & $37,0 \%$ & $16,3 \%$ & $11,9 \%$ & $10,4 \%$ & $3,7 \%$ & $3,0 \%$ & $2,2 \%$ & 135 \\
\hline & PROD4 & $14,3 \%$ & $39,5 \%$ & $17,8 \%$ & $8,5 \%$ & $8,5 \%$ & $4,8 \%$ & $4,8 \%$ & $1,9 \%$ & 377 \\
\hline & PROD5 & $8,4 \%$ & $41,6 \%$ & $21,2 \%$ & $9,5 \%$ & $6,3 \%$ & $5,1 \%$ & $4,3 \%$ & $3,6 \%$ & 693 \\
\hline & PROD6 & $4,3 \%$ & $36,6 \%$ & $25,6 \%$ & $12,3 \%$ & $6,6 \%$ & $5,5 \%$ & $5,0 \%$ & $4,0 \%$ & 577 \\
\hline & PROD7 & $5,0 \%$ & $29,5 \%$ & $26,5 \%$ & $15,5 \%$ & $9,5 \%$ & $4,0 \%$ & $4,5 \%$ & $5,5 \%$ & 200 \\
\hline & PROD8 & $1,5 \%$ & $26,5 \%$ & $22,1 \%$ & $22,1 \%$ & $7,4 \%$ & $13,2 \%$ & $0,0 \%$ & $7,4 \%$ & 68 \\
\hline \multirow{8}{*}{ 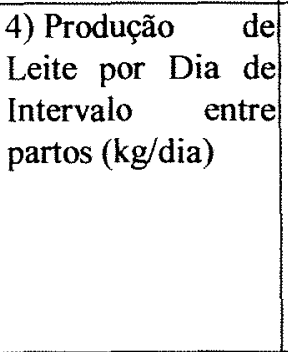 } & PDI1 & $7,7 \%$ & $34,6 \%$ & $19,2 \%$ & $11,5 \%$ & $7,7 \%$ & $0,0 \%$ & $3,8 \%$ & $15,4 \%$ & 26 \\
\hline & PDI2 & $0,7 \%$ & $12,9 \%$ & $8,6 \%$ & $10,7 \%$ & $18,6 \%$ & $10,0 \%$ & $17,1 \%$ & $21,4 \%$ & 140 \\
\hline & PDI3 & $2,6 \%$ & $12,8 \%$ & $14,0 \%$ & $11,4 \%$ & $16,0 \%$ & $16,3 \%$ & $16,6 \%$ & $10,2 \%$ & 343 \\
\hline & PDI4 & $6,7 \%$ & $27,9 \%$ & $24,8 \%$ & $19,4 \%$ & $12,5 \%$ & $5,6 \%$ & $1,9 \%$ & $1,1 \%$ & 463 \\
\hline & PDI5 & $10,0 \%$ & $44,0 \%$ & $30,6 \%$ & $10,9 \%$ & $2,7 \%$ & $1,9 \%$ & $0,0 \%$ & $0,0 \%$ & 589 \\
\hline & PDI6 & $10,8 \%$ & $62,1 \%$ & $21,8 \%$ & $5,1 \%$ & $0,3 \%$ & $0,0 \%$ & $0,0 \%$ & $0,0 \%$ & 372 \\
\hline & PDI7 & $14,1 \%$ & $67,4 \%$ & $15,6 \%$ & $3,0 \%$ & $0,0 \%$ & $0,0 \%$ & $0,0 \%$ & $0,0 \%$ & 135 \\
\hline & PDI8 & $41,2 \%$ & $58,8 \%$ & $0,0 \%$ & $0,0 \%$ & $0,0 \%$ & $0,0 \%$ & $0,0 \%$ & $0,0 \%$ & 34 \\
\hline \multirow{8}{*}{$\begin{array}{l}\text { 5) Idade ao Parto } \\
\text { anterior }\end{array}$} & IDPI & $8,6 \%$ & $40,0 \%$ & $21,6 \%$ & $10,3 \%$ & $6,6 \%$ & $4,9 \%$ & $5,2 \%$ & $2,9 \%$ & 653 \\
\hline & IDP2 & $10,3 \%$ & $42,3 \%$ & $17,9 \%$ & $9,4 \%$ & $8,2 \%$ & $3,8 \%$ & $3,8 \%$ & $4,4 \%$ & 319 \\
\hline & IDP3 & $7,7 \%$ & $38,2 \%$ & $23,4 \%$ & $10,2 \%$ & $6,5 \%$ & $6,3 \%$ & $3,8 \%$ & $4,0 \%$ & 479 \\
\hline & IDP4 & $8,0 \%$ & $37,1 \%$ & $21,2 \%$ & $12,5 \%$ & $10,2 \%$ & $3,4 \%$ & $4,2 \%$ & $3,4 \%$ & 264 \\
\hline & IDP5 & $9,0 \%$ & $31,6 \%$ & $22,0 \%$ & $15,3 \%$ & $7,9 \%$ & $9,0 \%$ & $4,0 \%$ & $1,1 \%$ & 177 \\
\hline & IDP6 & $4,3 \%$ & $30,2 \%$ & $31,0 \%$ & $14,7 \%$ & $6,9 \%$ & $4,3 \%$ & $5,2 \%$ & $3,4 \%$ & 116 \\
\hline & IDP7 & $9,8 \%$ & $37,3 \%$ & $23,5 \%$ & $9,8 \%$ & $11,8 \%$ & $2,0 \%$ & $3,9 \%$ & $2,0 \%$ & 51 \\
\hline & IDP8 & $4,7 \%$ & $32,6 \%$ & $20,9 \%$ & $14,0 \%$ & $7,0 \%$ & $4,7 \%$ & $2,3 \%$ & $14,0 \%$ & 43 \\
\hline
\end{tabular}




\begin{tabular}{|c|c|c|c|c|c|c|c|c|c|c|}
\hline \multirow{2}{*}{ Variáveis Ativas } & \multirow{2}{*}{ Classes } & \multicolumn{8}{|c|}{ IEP: Intervalo entre Partos } & \multirow{2}{*}{ Total } \\
\hline & & IEP1 & IEP2 & IEP3 & IEP4 & IEP5 & IEP6 & [EP7 & IEP8 & \\
\hline 6) Ordem & L1 & $9,0 \%$ & $40,9 \%$ & $20,0 \%$ & $10,1 \%$ & $7,1 \%$ & $4,5 \%$ & $4,8 \%$ & $3,7 \%$ & 947 \\
\hline \multirow[t]{4}{*}{ Lactação } & L2 & $7,7 \%$ & $36,5 \%$ & $23,8 \%$ & $10,8 \%$ & $7,8 \%$ & $5,7 \%$ & $3,6 \%$ & $4,1 \%$ & 665 \\
\hline & L3 & $8,3 \%$ & $36,2 \%$ & $21,2 \%$ & $13,2 \%$ & $8,6 \%$ & $6,1 \%$ & $4,9 \%$ & $1,5 \%$ & 326 \\
\hline & L4 & $6,6 \%$ & $31,1 \%$ & $32,8 \%$ & $12,3 \%$ & $6,6 \%$ & $3,3 \%$ & $4,1 \%$ & $3,3 \%$ & 122 \\
\hline & $\mathrm{L} 5$ & $9,5 \%$ & $35,7 \%$ & $14,3 \%$ & $19,0 \%$ & $7,1 \%$ & $4,8 \%$ & $2,4 \%$ & $7,1 \%$ & 42 \\
\hline 7) Número & NI1 & $22,0 \%$ & $64,8 \%$ & $10,7 \%$ & $2,1 \%$ & $0,1 \%$ & $0,1 \%$ & $0,0 \%$ & $0,1 \%$ & 722 \\
\hline \multirow[t]{7}{*}{ Inseminações } & NI2 & $2,4 \%$ & $52,2 \%$ & $34,3 \%$ & $7,1 \%$ & $3,3 \%$ & $0,2 \%$ & $0,2 \%$ & $0,2 \%$ & 452 \\
\hline & NI3 & $1,0 \%$ & $25,2 \%$ & $45,6 \%$ & $17,4 \%$ & $5,9 \%$ & $1,3 \%$ & $2,3 \%$ & $1,3 \%$ & 305 \\
\hline & NI4 & $0,0 \%$ & $8,2 \%$ & $33,3 \%$ & $27,7 \%$ & $16,9 \%$ & $7,2 \%$ & $4,1 \%$ & $2,6 \%$ & 195 \\
\hline & NI5 & $1,5 \%$ & $2,9 \%$ & $13,2 \%$ & $32,4 \%$ & $26,5 \%$ & $11,0 \%$ & $8,1 \%$ & $4,4 \%$ & 136 \\
\hline & NI6 & $0,0 \%$ & $0,0 \%$ & $7,0 \%$ & $19,0 \%$ & $27,0 \%$ & $26,0 \%$ & $15,0 \%$ & $6,0 \%$ & 100 \\
\hline & NI7 & $0,0 \%$ & $0,0 \%$ & $1,7 \%$ & $20,3 \%$ & $22,0 \%$ & $25,4 \%$ & $16,9 \%$ & $13,6 \%$ & 59 \\
\hline & NI8 & $0,0 \%$ & $0,0 \%$ & $0,0 \%$ & $3,8 \%$ & $11,3 \%$ & $23,3 \%$ & $29,3 \%$ & $32,3 \%$ & 133 \\
\hline \multirow{5}{*}{$\begin{array}{l}\text { 8) Ano ao } \\
\text { anterior }\end{array}$} & ANO94 & $5,5 \%$ & $33,9 \%$ & $21,4 \%$ & $14,4 \%$ & $10,0 \%$ & $4,8 \%$ & $5,2 \%$ & $4,8 \%$ & 271 \\
\hline & ANO95 & $7,4 \%$ & $35,4 \%$ & $20,9 \%$ & $11,9 \%$ & $10,8 \%$ & $4,1 \%$ & $5,4 \%$ & $4,1 \%$ & 444 \\
\hline & ANO96 & $10,0 \%$ & $37,7 \%$ & $24,1 \%$ & $10,1 \%$ & $5,6 \%$ & $4,2 \%$ & $4,0 \%$ & $4,3 \%$ & 552 \\
\hline & ANO97| & $8,0 \%$ & $36,6 \%$ & $16,5 \%$ & $12,5 \%$ & $8,3 \%$ & $9,1 \%$ & $5,6 \%$ & $3,4 \%$ & 552 \\
\hline & ANO98 & $9,9 \%$ & $50,2 \%$ & $30,7 \%$ & $6,0 \%$ & $2,1 \%$ & $1,1 \%$ & $0,0 \%$ & $0,0 \%$ & 283 \\
\hline \multirow{4}{*}{$\begin{array}{l}\text { 9) Estação do Ano } \\
\text { ao Parto anterior }\end{array}$} & INV & $9,7 \%$ & $41,9 \%$ & $18,4 \%$ & $6,4 \%$ & $6,4 \%$ & $7,6 \%$ & $6,5 \%$ & $3,1 \%$ & 642 \\
\hline & OUT & $9,7 \%$ & $43,6 \%$ & $22,8 \%$ & $7,9 \%$ & $4,1 \%$ & $3,2 \%$ & $3,8 \%$ & $4,9 \%$ & 711 \\
\hline & PRI & $7,3 \%$ & $28,7 \%$ & $18,2 \%$ & $17,0 \%$ & $15,8 \%$ & $7,0 \%$ & $4,4 \%$ & $1,5 \%$ & 341 \\
\hline & VER & $4,7 \%$ & $30,4 \%$ & $29,4 \%$ & $19,4 \%$ & $8,3 \%$ & $2,7 \%$ & $1,7 \%$ & $3,4 \%$ & 408 \\
\hline \multirow[t]{4}{*}{ 10) Rebanho } & $\mathrm{COL}$ & $7,8 \%$ & $38,8 \%$ & $21,3 \%$ & $12,2 \%$ & $6,8 \%$ & $5,7 \%$ & $4,3 \%$ & $3,1 \%$ & 863 \\
\hline & NAM & $11,4 \%$ & $38,4 \%$ & $19,5 \%$ & $10,5 \%$ & $8,0 \%$ & $4,4 \%$ & $3,7 \%$ & $4,1 \%$ & 589 \\
\hline & $\mathrm{SM}$ & $7,6 \%$ & $34,8 \%$ & $19,3 \%$ & $11,1 \%$ & $9,2 \%$ & $5,7 \%$ & $7,0 \%$ & $5,4 \%$ & 316 \\
\hline & SMP & $5,1 \%$ & $38,9 \%$ & $30,5 \%$ & $9,6 \%$ & $6,9 \%$ & $4,2 \%$ & $3,0 \%$ & $1,8 \%$ & 334 \\
\hline \multicolumn{2}{|l|}{ Total } & $8,3 \%$ & $38.1 \%$ & $22,0 \%$ & $11,1 \%$ & $7,5 \%$ & $5,1 \%$ & $4,3 \%$ & $3,5 \%$ & 21020 \\
\hline
\end{tabular}


Anexo E. Freqüências observadas de Intervalos entre Partos versus variável suplementar (Reprodutor) para a $1 .^{\text {a }}$ forma de categorizar.

\begin{tabular}{|c|c|c|c|c|c|c|c|c|c|}
\hline \multirow{2}{*}{ Reprodutores } & \multicolumn{8}{|c|}{ IEP: Intervalo entre Partos } & \multirow{2}{*}{ Total } \\
\hline & IEPI & IEP2 & IEP3 & IEP4 & IEP5 & IEP6 & IEP7 & IEP8 & \\
\hline 1 & 1 & 4 & 2 & 5 & 3 & 2 & 0 & 1 & 18 \\
\hline 2 & 9 & 12 & 9 & 5 & 1 & 2 & 1 & 0 & 39 \\
\hline 3 & 2 & 11 & 5 & 1 & 3 & 4 & 1 & 0 & 27 \\
\hline 4 & 2 & 11 & 5 & 2 & 0 & 0 & I & 0 & 21 \\
\hline 5 & 1 & 3 & 2 & 4 & 2 & 0 & 2 & 1 & 15 \\
\hline 6 & 2 & 12 & 0 & 0 & 0 & 0 & l & 0 & 15 \\
\hline 7 & 2 & 9 & 3 & 1 & 1 & 0 & 1 & 0 & 17 \\
\hline 8 & 5 & 30 & 14 & 7 & 12 & 2 & 8 & 8 & 86 \\
\hline 9 & 1 & 13 & 9 & 3 & 4 & 0 & 3 & 3 & 36 \\
\hline 10 & 1 & 6 & 8 & 4 & 2 & 2 & 1 & 0 & 24 \\
\hline 11 & 4 & 12 & 12 & 1 & I & 1 & 0 & 0 & 31 \\
\hline 12 & 1 & 6 & 5 & 3 & 1 & 1 & 0 & 0 & 17 \\
\hline 13 & 1 & 4 & 4 & 1 & 1 & 0 & 2 & 2 & 15 \\
\hline 14 & 3 & 20 & 13 & 9 & 4 & 3 & 5 & 1 & 58 \\
\hline 15 & 2 & 6 & 6 & I & 1 & 0 & 1 & 0 & 17 \\
\hline 16 & I & 4 & 8 & 2 & 5 & 3 & 3 & 3 & 29 \\
\hline 17 & I & 9 & 3 & 1 & 0 & 0 & 0 & 2 & 16 \\
\hline 18 & 2 & 5 & 4 & 3 & 1 & 3 & 0 & 0 & 18 \\
\hline 19 & 3 & 2 & 5 & 0 & 2 & 3 & 3 & 4 & 22 \\
\hline 20 & 1 & 6 & 2 & 4 & 3 & 0 & 1 & 0 & 17 \\
\hline 21 & 5 & 24 & 13 & 6 & 10 & 5 & 1 & 4 & 68 \\
\hline 22 & 1 & 12 & 6 & 1 & I & 0 & 0 & 0 & 21 \\
\hline 23 & 7 & 18 & 14 & 2 & 2 & 2 & 0 & 1 & 46 \\
\hline 24 & 4 & 9 & 12 & 4 & 5 & 4 & 1 & I & 40 \\
\hline 25 & 4 & 53 & 30 & 30 & 13 & 2 & 9 & 2 & 143 \\
\hline 26 & 7 & 17 & 7 & 5 & 6 & 3 & 0 & 4 & 49 \\
\hline 27 & 11 & 16 & 10 & 6 & 1 & 1 & 1 & 0 & 46 \\
\hline 28 & 7 & 18 & 11 & 9 & 0 & 4 & 1 & 3 & 53 \\
\hline 29 & 7 & 19 & 7 & 5 & 4 & 2 & 1 & 3 & 48 \\
\hline 30 & I & 13 & 7 & 4 & 3 & 2 & 2 & 1 & 33 \\
\hline 31 & 5 & 15 & 10 & 8 & 4 & I & 3 & 2 & 48 \\
\hline 32 & 4 & 10 & 7 & 0 & $i$ & 3 & 0 & 1 & 26 \\
\hline 33 & 8 & 35 & 23 & 16 & 8 & 4 & 4 & 3 & 101 \\
\hline 34 & 1 & 5 & 2 & 1 & 2 & 2 & 2 & 0 & 15 \\
\hline 35 & 4 & 8 & 5 & 4 & 0 & 1 & 0 & 0 & 22 \\
\hline 36 & 6 & 15 & 10 & 4 & I & 0 & 1 & 0 & 37 \\
\hline 37 & 0 & 16 & 7 & 3 & 2 & 2 & 1 & 1 & 32 \\
\hline 38 & 3 & 15 & 8 & 1 & 1 & 0 & 4 & 2 & 34 \\
\hline 39 & 2 & 6 & 5 & 0 & 1 & 2 & 0 & 1 & 17 \\
\hline 40 & 4 & 16 & 7 & 6 & 9 & 3 & 2 & 1 & 48 \\
\hline 41 & 0 & 10 & 9 & 4 & 1 & 1 & 3 & 0 & 28 \\
\hline 42 & 7 & 48 & 28 & 14 & 7 & 6 & 2 & 4 & 116 \\
\hline 43 & 2 & 5 & 9 & 1 & 1 & 1 & 0 & 0 & 19 \\
\hline 44 & 3 & 6 & 1 & 2 & 0 & 2 & 2 & 1 & 17 \\
\hline 45 & 3 & 15 & 5 & 3 & 0 & 0 & 0 & 0 & 26 \\
\hline 46 & 1 & 17 & 9 & 2 & 1 & 2 & 1 & 2 & 35 \\
\hline 47 & 2 & 13 & 4 & 1 & 2 & 1 & 0 & 0 & 23 \\
\hline 48 & 1 & 11 & 4 & 1 & 1 & 0 & 1 & 2 & 21 \\
\hline 49 & I & 13 & 7 & 3 & 1 & 2 & 0 & 2 & 29 \\
\hline 50 & $i$ & 10 & 5 & 4 & 2 & 3 & 2 & 0 & 27 \\
\hline 51 & 4 & 23 & 11 & 8 & 2 & 4 & 3 & 3 & 58 \\
\hline 52 & 0 & 7 & 7 & 0 & 1 & 1 & 1 & 0 & 17 \\
\hline 53 & 0 & 5 & 4 & 2 & 1 & 2 & 1 & 0 & 15 \\
\hline 54 & 3 & 14 & 5 & 2 & 1 & 2 & 0 & 0 & 27 \\
\hline 55 & 2 & 13 & 0 & 1 & 2 & 1 & 2 & 1 & 22 \\
\hline 56 & 1 & 8 & 6 & 1 & 4 & 1 & 3 & 0 & 24 \\
\hline 57 & 3 & 24 & 7 & 7 & 4 & 2 & 0 & 2 & 49 \\
\hline 58 & 2 & 9 & 6 & 4 & 0 & 1 & 2 & 0 & 24 \\
\hline 59 & 1 & 6 & 10 & 2 & 4 & 2 & 0 & 0 & 25 \\
\hline 60 & 1 & 12 & I & 0 & 0 & 2 & 1 & 0 & 17 \\
\hline 61 & 1 & 7 & 4 & 0 & 2 & 2 & 0 & 2 & 18 \\
\hline Total & 175 & 801 & 462 & 234 & 158 & 107 & 91 & 74 & 2102 \\
\hline
\end{tabular}


Anexo F. Perfis linha (em porcentagem) para a variável suplementar (Reprodutor) para a 1. ${ }^{a}$ forma de categorizar.

\begin{tabular}{|c|c|c|c|c|c|c|c|c|c|}
\hline \multirow{2}{*}{ Reprodutores } & \multicolumn{8}{|c|}{ IEP: Intervalo entre Partos } & \multirow{2}{*}{ Total } \\
\hline & IEPI & IEP2 & IEP3 & IEP4 & IEP5 & IEP6 & IEP7 & IEP8 & \\
\hline 1 & $5,6 \%$ & $22,2 \%$ & $11,1 \%$ & $27,8 \%$ & $16,7 \%$ & $11,1 \%$ & $0,0 \%$ & $5,6 \%$ & 18 \\
\hline 2 & $23,1 \%$ & $30,8 \%$ & $23,1 \%$ & $12,8 \%$ & $2,6 \%$ & $5,1 \%$ & $2,6 \%$ & $0,0 \%$ & 39 \\
\hline 3 & $7,4 \%$ & $40,7 \%$ & $18,5 \%$ & $3,7 \%$ & $11,1 \%$ & $14,8 \%$ & $3,7 \%$ & $0,0 \%$ & 27 \\
\hline 4 & $9,5 \%$ & $52,4 \%$ & $23,8 \%$ & $9,5 \%$ & $0,0 \%$ & $0,0 \%$ & $4,8 \%$ & $0,0 \%$ & 21 \\
\hline 5 & $6,7 \%$ & $20,0 \%$ & $13,3 \%$ & $26.7 \%$ & $13,3 \%$ & $0,0 \%$ & $13,3 \%$ & $6,7 \%$ & 15 \\
\hline 6 & $13,3 \%$ & $80,0 \%$ & $0,0 \%$ & $0,0 \%$ & $0,0 \%$ & $0,0 \%$ & $6,7 \%$ & $0,0 \%$ & 15 \\
\hline 7 & $11,8 \%$ & $52,9 \%$ & $17,6 \%$ & $5,9 \%$ & $5,9 \%$ & $0,0 \%$ & $5,9 \%$ & $0,0 \%$ & 17 \\
\hline 8 & $5,8 \%$ & $34,9 \%$ & $16,3 \%$ & $8,1 \%$ & $14,0 \%$ & $2,3 \%$ & $9,3 \%$ & $9,3 \%$ & 86 \\
\hline 9 & $2,8 \%$ & $36,1 \%$ & $25,0 \%$ & $8,3 \%$ & $11,1 \%$ & $0,0 \%$ & $8,3 \%$ & $8,3 \%$ & 36 \\
\hline 10 & $4,2 \%$ & $25,0 \%$ & $33,3 \%$ & $16,7 \%$ & $8,3 \%$ & $8,3 \%$ & $4,2 \%$ & $0,0 \%$ & 24 \\
\hline 11 & $12,9 \%$ & $38,7 \%$ & $38,7 \%$ & $3,2 \%$ & $3,2 \%$ & $3,2 \%$ & $0,0 \%$ & $0,0 \%$ & 31 \\
\hline 12 & $5,9 \%$ & $35,3 \%$ & $29,4 \%$ & $17,6 \%$ & $5,9 \%$ & $5,9 \%$ & $0,0 \%$ & $0,0 \%$ & 17 \\
\hline 13 & $6,7 \%$ & $26,7 \%$ & $26,7 \%$ & $6,7 \%$ & $6,7 \%$ & $0,0 \%$ & $13,3 \%$ & $13,3 \%$ & 15 \\
\hline 14 & $5,2 \%$ & $34,5 \%$ & $22,4 \%$ & $15,5 \%$ & $6,9 \%$ & $5,2 \%$ & $8,6 \%$ & $1,7 \%$ & 58 \\
\hline 15 & $11,8 \%$ & $35,3 \%$ & $35,3 \%$ & $5,9 \%$ & $5,9 \%$ & $0,0 \%$ & $5,9 \%$ & $0,0 \%$ & 17 \\
\hline 16 & $3,4 \%$ & $13,8 \%$ & $27.6 \%$ & $6,9 \%$ & $17,2 \%$ & $10,3 \%$ & $10,3 \%$ & $10,3 \%$ & 29 \\
\hline 17 & $6,3 \%$ & $56,3 \%$ & $18,8 \%$ & $6,3 \%$ & $0,0 \%$ & $0,0 \%$ & $0,0 \%$ & $12,5 \%$ & 16 \\
\hline 18 & $11,1 \%$ & $27,8 \%$ & $22.2 \%$ & $16,7 \%$ & $5,6 \%$ & $16,7 \%$ & $0,0 \%$ & $0,0 \%$ & 18 \\
\hline 19 & $13,6 \%$ & $9,1 \%$ & $22,7 \%$ & $0,0 \%$ & $9,1 \%$ & $13,6 \%$ & $13,6 \%$ & $18,2 \%$ & 22 \\
\hline 20 & $5,9 \%$ & $35,3 \%$ & $11,8 \%$ & $23,5 \%$ & $17,6 \%$ & $0,0 \%$ & $5,9 \%$ & $0,0 \%$ & 17 \\
\hline 21 & $7,4 \%$ & $35,3 \%$ & $19,1 \%$ & $8,8 \%$ & $14,7 \%$ & $7,4 \%$ & $1,5 \%$ & $5,9 \%$ & 68 \\
\hline 22 & $4,8 \%$ & $57,1 \%$ & $28,6 \%$ & $4,8 \%$ & $4,8 \%$ & $0,0 \%$ & $0,0 \%$ & $0,0 \%$ & 21 \\
\hline 23 & $15,2 \%$ & $39,1 \%$ & $30,4 \%$ & $4,3 \%$ & $4,3 \%$ & $4,3 \%$ & $0,0 \%$ & $2,2 \%$ & 46 \\
\hline 24 & $10,0 \%$ & $22,5 \%$ & $30,0 \%$ & $10,0 \%$ & $12,5 \%$ & $10,0 \%$ & $2,5 \%$ & $2,5 \%$ & 40 \\
\hline 25 & $2,8 \%$ & $37,1 \%$ & $21,0 \%$ & $21,0 \%$ & $9,1 \%$ & $1,4 \%$ & $6,3 \%$ & $1,4 \%$ & 143 \\
\hline 26 & $14,3 \%$ & $34,7 \%$ & $14,3 \%$ & $10,2 \%$ & $12,2 \%$ & $6,1 \%$ & $0,0 \%$ & $8,2 \%$ & 49 \\
\hline 27 & $23,9 \%$ & $34,8 \%$ & $21,7 \%$ & $13,0 \%$ & $2,2 \%$ & $2,2 \%$ & $2,2 \%$ & $0,0 \%$ & 46 \\
\hline 28 & $13,2 \%$ & $34,0 \%$ & $20,8 \%$ & $17,0 \%$ & $0,0 \%$ & $7,5 \%$ & $1,9 \%$ & $5,7 \%$ & 53 \\
\hline 29 & $14,6 \%$ & $39,6 \%$ & $14,6 \%$ & $10,4 \%$ & $8,3 \%$ & $4,2 \%$ & $2,1 \%$ & $6,3 \%$ & 48 \\
\hline 30 & $3,0 \%$ & $39,4 \%$ & $21,2 \%$ & $12,1 \%$ & $9,1 \%$ & $6,1 \%$ & $6,1 \%$ & $3,0 \%$ & 33 \\
\hline 31 & $10,4 \%$ & $31,3 \%$ & $20,8 \%$ & $16,7 \%$ & $8,3 \%$ & $2,1 \%$ & $6,3 \%$ & $4,2 \%$ & 48 \\
\hline 32 & $15,4 \%$ & $38,5 \%$ & $26,9 \%$ & $0,0 \%$ & $3,8 \%$ & $11,5 \%$ & $0,0 \%$ & $3,8 \%$ & 26 \\
\hline 33 & $7,9 \%$ & $34,7 \%$ & $22.8 \%$ & $15,8 \%$ & $7,9 \%$ & $4,0 \%$ & $4,0 \%$ & $3,0 \%$ & 101 \\
\hline 34 & $6,7 \%$ & $33,3 \%$ & $13,3 \%$ & $6,7 \%$ & $13,3 \%$ & $13,3 \%$ & $13,3 \%$ & $0,0 \%$ & 15 \\
\hline 35 & $18,2 \%$ & $36,4 \%$ & $22,7 \%$ & $18,2 \%$ & $0,0 \%$ & $4,5 \%$ & $0,0 \%$ & $0,0 \%$ & 22 \\
\hline 36 & $16,2 \%$ & $40,5 \%$ & $27,0 \%$ & $10,8 \%$ & $2,7 \%$ & $0,0 \%$ & $2,7 \%$ & $0,0 \%$ & 37 \\
\hline 37 & $0,0 \%$ & $50.0 \%$ & $21.9 \%$ & $9,4 \%$ & $6,3 \%$ & $6,3 \%$ & $3,1 \%$ & $3,1 \%$ & 32 \\
\hline 38 & $8,8 \%$ & $44,1 \%$ & $23.5 \%$ & $2,9 \%$ & $2,9 \%$ & $0,0 \%$ & $11,8 \%$ & $5,9 \%$ & 34 \\
\hline 39 & $11,8 \%$ & $35,3 \%$ & $29,4 \%$ & $0,0 \%$ & $5,9 \%$ & $11,8 \%$ & $0,0 \%$ & $5,9 \%$ & 17 \\
\hline 40 & $8,3 \%$ & $33,3 \%$ & $14,6 \%$ & $12,5 \%$ & $18,8 \%$ & $6,3 \%$ & $4,2 \%$ & $2,1 \%$ & 48 \\
\hline 41 & $0,0 \%$ & $35,7 \%$ & $32,1 \%$ & $14,3 \%$ & $3,6 \%$ & $3,6 \%$ & $10,7 \%$ & $0,0 \%$ & 28 \\
\hline 42 & $6,0 \%$ & $41,4 \%$ & $24,1 \%$ & $12,1 \%$ & $6,0 \%$ & $5,2 \%$ & $1,7 \%$ & $3,4 \%$ & 116 \\
\hline 43 & $10,5 \%$ & $26,3 \%$ & $47,4 \%$ & $5,3 \%$ & $5,3 \%$ & $5,3 \%$ & $0,0 \%$ & $0,0 \%$ & 19 \\
\hline 44 & $17,6 \%$ & $35,3 \%$ & $5,9 \%$ & $11,8 \%$ & $0,0 \%$ & $11,8 \%$ & $11,8 \%$ & $5,9 \%$ & 17 \\
\hline 45 & $11,5 \%$ & $57,7 \%$ & $19,2 \%$ & $11,5 \%$ & $0,0 \%$ & $0,0 \%$ & $0,0 \%$ & $0,0 \%$ & 26 \\
\hline 46 & $2,9 \%$ & $48,6 \%$ & $25,7 \%$ & $5,7 \%$ & $2,9 \%$ & $5,7 \%$ & $2,9 \%$ & $5,7 \%$ & 35 \\
\hline 47 & $8,7 \%$ & $56,5 \%$ & $17,4 \%$ & $4,3 \%$ & $8,7 \%$ & $4,3 \%$ & $0,0 \%$ & $0,0 \%$ & 23 \\
\hline 48 & $4,8 \%$ & $52.4 \%$ & $19.0 \%$ & $4,8 \%$ & $4,8 \%$ & $0,0 \%$ & $4,8 \%$ & $9,5 \%$ & 21 \\
\hline 49 & $3,4 \%$ & $44,8 \%$ & $24,1 \%$ & $10,3 \%$ & $3,4 \%$ & $6,9 \%$ & $0,0 \%$ & $6,9 \%$ & 29 \\
\hline 50 & $3,7 \%$ & $37,0 \%$ & $18.5 \%$ & $14,8 \%$ & $7,4 \%$ & $11,1 \%$ & $7,4 \%$ & $0,0 \%$ & 27 \\
\hline 51 & $6,9 \%$ & $39,7 \%$ & $19,0 \%$ & $13,8 \%$ & $3,4 \%$ & $6,9 \%$ & $5,2 \%$ & $5,2 \%$ & 58 \\
\hline 52 & $0,0 \%$ & $41,2 \%$ & $41,2 \%$ & $0,0 \%$ & $5,9 \%$ & $5,9 \%$ & $5,9 \%$ & $0,0 \%$ & 17 \\
\hline 53 & $0,0 \%$ & $33,3 \%$ & $26,7 \%$ & $13,3 \%$ & $6,7 \%$ & $13,3 \%$ & $6,7 \%$ & $0,0 \%$ & 15 \\
\hline 54 & $11,1 \%$ & $51,9 \%$ & $18.5 \%$ & $7,4 \%$ & $3,7 \%$ & $7,4 \%$ & $0,0 \%$ & $0,0 \%$ & 27 \\
\hline 55 & $9,1 \%$ & $59,1 \%$ & $0,0 \%$ & $4,5 \%$ & $9,1 \%$ & $4,5 \%$ & $9,1 \%$ & $4,5 \%$ & 22 \\
\hline 56 & $4,2 \%$ & $33,3 \%$ & $25,0 \%$ & $4,2 \%$ & $16,7 \%$ & $4,2 \%$ & $12,5 \%$ & $0,0 \%$ & 24 \\
\hline 57 & $6,1 \%$ & $49,0 \%$ & $14,3 \%$ & $14,3 \%$ & $8,2 \%$ & $4,1 \%$ & $0,0 \%$ & $4,1 \%$ & 49 \\
\hline 58 & $8,3 \%$ & $37,5 \%$ & $25,0 \%$ & $16,7 \%$ & $0,0 \%$ & $4,2 \%$ & $8,3 \%$ & $0,0 \%$ & 24 \\
\hline 59 & $4,0 \%$ & $24,0 \%$ & $40,0 \%$ & $8,0 \%$ & $16,0 \%$ & $8,0 \%$ & $0,0 \%$ & $0,0 \%$ & 25 \\
\hline 60 & $5,9 \%$ & $70,6 \%$ & $5,9 \%$ & $0,0 \%$ & $0,0 \%$ & $11,8 \%$ & $5,9 \%$ & $0,0 \%$ & 17 \\
\hline 61 & $5,6 \%$ & $38,9 \%$ & $22.2 \%$ & $0.0 \%$ & $11,1 \%$ & $11,1 \%$ & $0,0 \%$ & $11,1 \%$ & 18 \\
\hline Total & $8,3 \%$ & $38,1 \%$ & $22.0 \%$ & $11,1 \%$ & $7,5 \%$ & $5,1 \%$ & $4,3 \%$ & $3,5 \%$ & 2102 \\
\hline
\end{tabular}


Anexo G. Freqüências observadas para o cruzamento da variável Intervalo entre Partos com as variáveis ativas para a $2 .^{a}$ forma de categorizar.

\begin{tabular}{|c|c|c|c|c|c|c|}
\hline \multirow{2}{*}{ Variáveis ativas } & \multirow{2}{*}{ Categorias } & \multicolumn{4}{|c|}{ IEP: Intervalo entre Partos } & \multirow{2}{*}{ Total } \\
\hline & & IEP1 & IEP2 & IEP3 & IEP4 & \\
\hline \multirow[t]{4}{*}{ 1) Dias em Lactação } & DL1 & 410 & 79 & 31 & 24 & 544 \\
\hline & DL2 & 92 & 358 & 42 & 19 & 511 \\
\hline & DL3 & 10 & 95 & 354 & 65 & 524 \\
\hline & DLA & 0 & 1 & 107 & 415 & 523 \\
\hline \multirow{4}{*}{$\begin{array}{l}\text { 2) Pico de Lactação } \\
\text { (kg de leite) }\end{array}$} & $\mathrm{PCl}$ & 144 & 154 & 128 & 105 & 531 \\
\hline & $\mathrm{PC} 2$ & 122 & 122 & 143 & 139 & 526 \\
\hline & PC3 & 134 & 137 & 132 & 123 & 526 \\
\hline & PC4 & 112 & 120 & 131 & 156 & 519 \\
\hline \multirow{4}{*}{$\begin{array}{l}\text { 3) Produção de leite } \\
\text { por lactação }(\mathrm{kg})\end{array}$} & PROD1 & 172 & 132 & 104 & 119 & 527 \\
\hline & PROD2 & 149 & 132 & 121 & 123 & 525 \\
\hline & PROD3 & 114 & 142 & 138 & 130 & 524 \\
\hline & PROD4 & 77 & 127 & 171 & 151 & 526 \\
\hline \multirow{4}{*}{$\begin{array}{llr}\text { 4) Produção } & \text { de } \\
\text { Leite por } & \text { Dia } & \text { de } \\
\text { Intervalo } & \text { entre } \\
\text { partos }(\mathrm{kg} / \text { dia) } & \end{array}$} & PDII & 38 & 54 & 95 & 338 & 525 \\
\hline & PDI2 & 93 & 112 & 177 & 144 & 526 \\
\hline & PDI3 & 158 & 172 & 164 & 34 & 528 \\
\hline & PDI4 & 223 & 195 & 98 & 7 & 523 \\
\hline \multirow{4}{*}{$\begin{array}{l}\text { 5) Idade ao Parto } \\
\text { anterior }\end{array}$} & IDPI & 136 & 136 & 120 & 129 & 521 \\
\hline & IDP2 & 138 & 142 & 126 & 121 & 527 \\
\hline & IDP3 & 122 & 133 & 148 & 125 & 528 \\
\hline & IDP4 & 116 & 122 & 140 & 148 & 526 \\
\hline \multirow{5}{*}{$\begin{array}{l}\text { 6) Ordem } \\
\text { Lactação }\end{array}$} & Ll & 253 & 248 & 214 & 232 & 947 \\
\hline & L2 & 147 & 171 & 185 & 162 & 665 \\
\hline & L3 & 83 & 71 & 84 & 88 & 326 \\
\hline & L4 & 22 & 29 & 42 & 29 & 122 \\
\hline & L5 & 7 & 14 & 9 & 12 & 42 \\
\hline \multirow{5}{*}{$\begin{array}{ll}\text { 7) Número } & \mathrm{de} \\
\text { Inseminações }\end{array}$} & NII & 419 & 227 & 68 & 8 & 722 \\
\hline & NI2 & 71 & 200 & 154 & 27 & 452 \\
\hline & NI3 & 17 & 83 & 152 & 53 & 305 \\
\hline & NI4 & 3 & 19 & 94 & 79 & 195 \\
\hline & NI5 & 2 & 4 & 66 & 356 & 428 \\
\hline \multirow{5}{*}{$\begin{array}{l}\text { 8) Ano ao Parto } \\
\text { anterior }\end{array}$} & ANO94 & 52 & 64 & 72 & 83 & 271 \\
\hline & ANO95 & 88 & 113 & 115 & 128 & 444 \\
\hline & ANO96 & 144 & 140 & 146 & 122 & 552 \\
\hline & ANO97 & 146 & 110 & 119 & 177 & 552 \\
\hline & ANO98 & 82 & 106 & 82 & 13 & 283 \\
\hline \multirow{4}{*}{$\begin{array}{l}\text { 9) Estação do Ano } \\
\text { ao Parto anterior }\end{array}$} & INV & 173 & 175 & 121 & 173 & 642 \\
\hline & OUT & 203 & 203 & 174 & 131 & 711 \\
\hline & PRI & 75 & 56 & 89 & 121 & 341 \\
\hline & VER & 61 & 99 & 150 & 98 & 408 \\
\hline \multirow[t]{4}{*}{ 10) Rebanho } & COL & 206 & 230 & 217 & 210 & 863 \\
\hline & NAM & 171 & 135 & 141 & 142 & 589 \\
\hline & SM & 67 & 74 & 71 & 104 & 316 \\
\hline & SMP & 68 & 94 & 105 & 67 & 334 \\
\hline \multicolumn{2}{|l|}{ Total } & 5120 & 5330 & 5340 & 5230 & 21020 \\
\hline
\end{tabular}


Anexo H. Perfis linha (em porcentagem) das variáveis ativas para a $2 .^{a}$ forma de categorizar.

\begin{tabular}{|c|c|c|c|c|c|c|}
\hline \multirow{2}{*}{ Variáveis ativas } & \multirow{2}{*}{ Categorias } & \multicolumn{4}{|c|}{ IEP: Intervalo entre Partos } & \multirow{2}{*}{ Total } \\
\hline & & IEPI & IEP2 & IEP3 & IEP4 & \\
\hline \multirow[t]{4}{*}{ 1) Dias em Lactação } & DLI & $75,4 \%$ & $14,5 \%$ & $5,7 \%$ & $4,4 \%$ & 544 \\
\hline & DL2 & $18,0 \%$ & $70,1 \%$ & $8,2 \%$ & $3,7 \%$ & 511 \\
\hline & DL3 & $1,9 \%$ & $18,1 \%$ & $67,6 \%$ & $12,4 \%$ & 524 \\
\hline & DL4 & $0,0 \%$ & $0,2 \%$ & $20,5 \%$ & $79,3 \%$ & 523 \\
\hline \multirow{4}{*}{$\begin{array}{l}\text { 2) Pico de Lactação } \\
\text { (kg de leite) }\end{array}$} & $\mathrm{PCl}$ & $27,1 \%$ & $29,0 \%$ & $24,1 \%$ & $19,8 \%$ & 531 \\
\hline & $\mathrm{PC} 2$ & $23,2 \%$ & $23,2 \%$ & $27,2 \%$ & $26,4 \%$ & 526 \\
\hline & $\mathrm{PC} 3$ & $25,5 \%$ & $26,0 \%$ & $25,1 \%$ & $23,4 \%$ & 526 \\
\hline & PC4 & $21,6 \%$ & $23,1 \%$ & $25,2 \%$ & $30,1 \%$ & 519 \\
\hline \multirow{4}{*}{$\begin{array}{l}\text { 3) Produção de leite } \\
\text { por lactação (kg) }\end{array}$} & PROD1 & $32,6 \%$ & $25,0 \%$ & $19,7 \%$ & $22,6 \%$ & 527 \\
\hline & PROD2 & $28,4 \%$ & $25,1 \%$ & $23,0 \%$ & $23,4 \%$ & 525 \\
\hline & PROD3 & $21,8 \%$ & $27,1 \%$ & $26,3 \%$ & $24,8 \%$ & 524 \\
\hline & PROD4 & $14,6 \%$ & $24,1 \%$ & $32,5 \%$ & $28,7 \%$ & 526 \\
\hline \multirow{4}{*}{\begin{tabular}{lll|} 
4) Produção & de \\
Leite por Dia & de \\
Intervalo & entre \\
partos $(\mathrm{kg} / \mathrm{dia})$ & \\
\end{tabular}} & PDIl & $7,2 \%$ & $10,3 \%$ & $18,1 \%$ & $64,4 \%$ & 525 \\
\hline & PDI2 & $17,7 \%$ & $21,3 \%$ & $33,7 \%$ & $27,4 \%$ & 526 \\
\hline & PDI3 & $29,9 \%$ & $32,6 \%$ & $31,1 \%$ & $6,4 \%$ & 528 \\
\hline & PDI4 & $42,6 \%$ & $37,3 \%$ & $18,7 \%$ & $1,3 \%$ & 523 \\
\hline \multirow{4}{*}{\begin{tabular}{lll|} 
5) Idade & ao & Parto \\
anterior & & \\
\end{tabular}} & IDP1 & $26,1 \%$ & $26,1 \%$ & $23,0 \%$ & $24,8 \%$ & 521 \\
\hline & IDP2 & $26,2 \%$ & $26,9 \%$ & $23,9 \%$ & $23,0 \%$ & 527 \\
\hline & IDP3 & $23,1 \%$ & $25,2 \%$ & $28,0 \%$ & $23,7 \%$ & 528 \\
\hline & IDP4 & $22,1 \%$ & $23,2 \%$ & $26,6 \%$ & $28,1 \%$ & 526 \\
\hline \multirow{5}{*}{$\begin{array}{l}\text { 6) Ordem } \\
\text { Lactação }\end{array}$} & $\mathrm{LI}$ & $26,7 \%$ & $26,2 \%$ & $22,6 \%$ & $24,5 \%$ & 947 \\
\hline & $\mathrm{L} 2$ & $22,1 \%$ & $25,7 \%$ & $27,8 \%$ & $24,4 \%$ & 665 \\
\hline & L3 & $25,5 \%$ & $21,8 \%$ & $25,8 \%$ & $27,0 \%$ & 326 \\
\hline & L4 & $18,0 \%$ & $23,8 \%$ & $34,4 \%$ & $23,8 \%$ & 122 \\
\hline & L5 & $16,7 \%$ & $33,3 \%$ & $21,4 \%$ & $28,6 \%$ & 42 \\
\hline \multirow{5}{*}{$\begin{array}{ll}\text { 7) Número } & \text { de } \\
\text { Inseminações }\end{array}$} & NI1 & $58,0 \%$ & $31,4 \%$ & $9,4 \%$ & $1,1 \%$ & 722 \\
\hline & NI2 & $15,7 \%$ & $44,2 \%$ & $34,1 \%$ & $6,0 \%$ & 452 \\
\hline & NI3 & $5,6 \%$ & $27,2 \%$ & $49,8 \%$ & $17,4 \%$ & 305 \\
\hline & NI4 & $1,5 \%$ & $9,7 \%$ & $48,2 \%$ & $40,5 \%$ & 195 \\
\hline & NI5 & $0,5 \%$ & $0,9 \%$ & $15,4 \%$ & $83,2 \%$ & 428 \\
\hline \multirow{5}{*}{$\begin{array}{l}\text { 8) Ano ao Parto } \\
\text { anterior }\end{array}$} & ANO94 & $19,2 \%$ & $23,6 \%$ & $26,6 \%$ & $30,6 \%$ & 271 \\
\hline & ANO95 & $19,8 \%$ & $25,5 \%$ & $25,9 \%$ & $28,8 \%$ & 444 \\
\hline & ANO96 & $26,1 \%$ & $25,4 \%$ & $26,4 \%$ & $22,1 \%$ & 552 \\
\hline & ANO97 & $26,4 \%$ & $19,9 \%$ & $21,6 \%$ & $32,1 \%$ & 552 \\
\hline & ANO98 & $29,0 \%$ & $37,5 \%$ & $29,0 \%$ & $4,6 \%$ & 283 \\
\hline \multirow{4}{*}{$\begin{array}{l}\text { 9) Estação do Ano } \\
\text { ao Parto anterior }\end{array}$} & INV & $26,9 \%$ & $27,3 \%$ & $18,8 \%$ & $26,9 \%$ & 642 \\
\hline & OUT & $28,6 \%$ & $28,6 \%$ & $24,5 \%$ & $18,4 \%$ & 711 \\
\hline & PRI & $22,0 \%$ & $16,4 \%$ & $26,1 \%$ & $35,5 \%$ & 341 \\
\hline & VER & $15,0 \%$ & $24,3 \%$ & $36,8 \%$ & $24,0 \%$ & 408 \\
\hline \multirow[t]{4}{*}{ 10) Rebanho } & $\mathrm{COL}$ & $23,9 \%$ & $26,7 \%$ & $25,1 \%$ & $24,3 \%$ & 863 \\
\hline & NAM & $29,0 \%$ & $22,9 \%$ & $23,9 \%$ & $24,1 \%$ & 589 \\
\hline & $\mathrm{SM}$ & $21,2 \%$ & $23,4 \%$ & $22,5 \%$ & $32,9 \%$ & 316 \\
\hline & SMP & $20,4 \%$ & $28,1 \%$ & $31,4 \%$ & $20,1 \%$ & 334 \\
\hline \multicolumn{2}{|l|}{ Total } & $24.4 \%$ & $25,4 \%$ & $25,4 \%$ & $24,9 \%$ & 21020 \\
\hline
\end{tabular}


Anexo I. Freqüências observadas de Intervalos entre Partos versus variável suplementar (Reprodutor) para a 2. ${ }^{\text {a }}$ forma de categorizar.

\begin{tabular}{|c|c|c|c|c|c|}
\hline \multirow{2}{*}{ Reprodutores } & \multicolumn{4}{|c|}{ IEP: Intervalo entre Partos } & \multirow{2}{*}{ Total } \\
\hline & IEPI & IEP2 & IEP3 & IEP4 & \\
\hline 1 & 2 & 3 & 5 & 8 & 18 \\
\hline 2 & 14 & 8 & 10 & 7 & 39 \\
\hline 3 & 8 & 6 & 5 & 8 & 27 \\
\hline 4 & 6 & 8 & 6 & 1 & 21 \\
\hline 5 & 2 & 2 & 4 & 7 & 15 \\
\hline 6 & 8 & 6 & 0 & 1 & 15 \\
\hline 7 & 5 & 7 & 3 & 2 & 17 \\
\hline 8 & 19 & 17 & 17 & 33 & 86 \\
\hline 9 & 6 & 10 & 9 & 11 & 36 \\
\hline 10 & 3 & 5 & 10 & 6 & 24 \\
\hline 11 & 9 & 9 & 10 & 3 & 31 \\
\hline 12 & 5 & 3 & 6 & 3 & 17 \\
\hline 13 & 3 & 2 & 4 & 6 & 15 \\
\hline 14 & 5 & 18 & 16 & 19 & 58 \\
\hline 15 & 4 & 4 & 6 & 3 & 17 \\
\hline 16 & 3 & 5 & 5 & 16 & 29 \\
\hline 17 & 5 & 6 & 3 & 2 & 16 \\
\hline 18 & 6 & 1 & 5 & 6 & 18 \\
\hline 19 & 4 & 1 & 5 & 12 & 22 \\
\hline 20 & 5 & 3 & 1 & 8 & 17 \\
\hline 21 & 15 & 17 & 15 & 21 & 68 \\
\hline 22 & 7 & 7 & 6 & 1 & 21 \\
\hline 23 & 15 & 13 & 11 & 7 & 46 \\
\hline 24 & 5 & 9 & 13 & 13 & 40 \\
\hline 25 & 28 & 32 & 45 & 38 & 143 \\
\hline 26 & 11 & 14 & 9 & 15 & 49 \\
\hline 27 & 19 & 10 & 11 & 6 & 46 \\
\hline 28 & 15 & 11 & 14 & 13 & 53 \\
\hline 29 & 14 & 13 & 10 & 11 & 48 \\
\hline 30 & 8 & 6 & 10 & 9 & 33 \\
\hline 31 & 13 & 8 & 16 & 11 & 48 \\
\hline 32 & 6 & 9 & 6 & 5 & 26 \\
\hline 33 & 20 & 27 & 31 & 23 & 101 \\
\hline 34 & 4 & 2 & 3 & 6 & 15 \\
\hline 35 & 10 & 3 & 7 & 2 & 22 \\
\hline 36 & 15 & 8 & 11 & 3 & 37 \\
\hline 37 & 3 & 14 & 8 & 7 & 32 \\
\hline 38 & 10 & 8 & 9 & 7 & 34 \\
\hline 39 & 4 & 5 & 4 & 4 & 17 \\
\hline 40 & 12 & 9 & 10 & 17 & 48 \\
\hline 41 & 6 & 5 & 8 & 9 & 28 \\
\hline 42 & 26 & 34 & 31 & 25 & 116 \\
\hline 43 & 3 & 6 & 8 & 2 & 19 \\
\hline 44 & 5 & 5 & 1 & 6 & 17 \\
\hline 45 & 9 & 9 & 7 & 1 & 26 \\
\hline 46 & 8 & 12 & 9 & 6 & 35 \\
\hline 47 & 8 & 7 & 5 & 3 & 23 \\
\hline 48 & 4 & 9 & 4 & 4 & 21 \\
\hline 49 & 6 & 9 & 8 & 6 & 29 \\
\hline 50 & 5 & 6 & 6 & 10 & 27 \\
\hline 51 & 15 & 14 & 14 & 15 & 58 \\
\hline 52 & 4 & 5 & 5 & 3 & 17 \\
\hline 53 & 2 & 3 & 5 & 5 & 15 \\
\hline 54 & 9 & 10 & 5 & 3 & 27 \\
\hline 55 & 6 & 9 & 0 & 7 & 22 \\
\hline 56 & 2 & 8 & 6 & 8 & 24 \\
\hline 57 & 17 & 10 & 12 & 10 & 49 \\
\hline 58 & 6 & 5 & 9 & 4 & 24 \\
\hline 59 & 4 & 6 & 9 & 6 & 25 \\
\hline 60 & 9 & 5 & 0 & 3 & 17 \\
\hline 61 & 2 & 7 & 3 & 6 & 18 \\
\hline Total & 512 & 533 & 534 & 523 & 2102 \\
\hline
\end{tabular}


Anexo J. Perfis linha (em porcentagem) para a variável suplementar (Reprodutor) para a 2. ${ }^{a}$ forma de categorizar.

\begin{tabular}{|c|c|c|c|c|c|}
\hline \multirow{2}{*}{ Reprodutores } & \multicolumn{4}{|c|}{ IEP: Intervalo entre Partos } & \multirow{2}{*}{ Total } \\
\hline & IEPI & IEP2 & IEP3 & IEP4 & \\
\hline I & $11,1 \%$ & $16,7 \%$ & $27,8 \%$ & $44,4 \%$ & 18 \\
\hline 2 & $35,9 \%$ & $20,5 \%$ & $25,6 \%$ & $17,9 \%$ & 39 \\
\hline 3 & $29,6 \%$ & $22,2 \%$ & $18,5 \%$ & $29,6 \%$ & 27 \\
\hline 4 & $28,6 \%$ & $38,1 \%$ & $28,6 \%$ & $4,8 \%$ & 21 \\
\hline 5 & $13,3 \%$ & $13,3 \%$ & $26,7 \%$ & $46,7 \%$ & 15 \\
\hline 6 & $53,3 \%$ & $40,0 \%$ & $0,0 \%$ & $6,7 \%$ & 15 \\
\hline 7 & $29,4 \%$ & $41,2 \%$ & $17,6 \%$ & $11,8 \%$ & 17 \\
\hline 8 & $22,1 \%$ & $19,8 \%$ & $19,8 \%$ & $38,4 \%$ & 86 \\
\hline 9 & $16,7 \%$ & $27,8 \%$ & $25,0 \%$ & $30,6 \%$ & 36 \\
\hline 10 & $12,5 \%$ & $20,8 \%$ & $41,7 \%$ & $25,0 \%$ & 24 \\
\hline 11 & $29,0 \%$ & $29,0 \%$ & $32,3 \%$ & $9,7 \%$ & 31 \\
\hline 12 & $29,4 \%$ & $17,6 \%$ & $35,3 \%$ & $17,6 \%$ & 17 \\
\hline 13 & $20,0 \%$ & $13,3 \%$ & $26,7 \%$ & $40,0 \%$ & 15 \\
\hline 14 & $8,6 \%$ & $31,0 \%$ & $27,6 \%$ & $32,8 \%$ & 58 \\
\hline 15 & $23.5 \%$ & $23,5 \%$ & $35,3 \%$ & $17,6 \%$ & 17 \\
\hline 16 & $10,3 \%$ & $17,2 \%$ & $17,2 \%$ & $55,2 \%$ & 29 \\
\hline 17 & $31,3 \%$ & $37,5 \%$ & $18,8 \%$ & $12,5 \%$ & 16 \\
\hline 18 & $33,3 \%$ & $5,6 \%$ & $27,8 \%$ & $33,3 \%$ & 18 \\
\hline 19 & $18,2 \%$ & $4,5 \%$ & $22,7 \%$ & $54,5 \%$ & 22 \\
\hline 20 & $29.4 \%$ & $17,6 \%$ & $5,9 \%$ & $47,1 \%$ & 17 \\
\hline 21 & $22,1 \%$ & $25,0 \%$ & $22,1 \%$ & $30,9 \%$ & 68 \\
\hline 22 & $33,3 \%$ & $33,3 \%$ & $28,6 \%$ & $4,8 \%$ & 21 \\
\hline 23 & $32,6 \%$ & $28,3 \%$ & $23,9 \%$ & $15,2 \%$ & 46 \\
\hline 24 & $12,5 \%$ & $22,5 \%$ & $32,5 \%$ & $32,5 \%$ & 40 \\
\hline 25 & $19,6 \%$ & $22,4 \%$ & $31,5 \%$ & $26,6 \%$ & 143 \\
\hline 26 & $22.4 \%$ & $28,6 \%$ & $18,4 \%$ & $30,6 \%$ & 49 \\
\hline 27 & $41.3 \%$ & $21,7 \%$ & $23,9 \%$ & $13,0 \%$ & 46 \\
\hline 28 & $28,3 \%$ & $20,8 \%$ & $26,4 \%$ & $24,5 \%$ & 53 \\
\hline 29 & $29,2 \%$ & $27,1 \%$ & $20,8 \%$ & $22,9 \%$ & 48 \\
\hline 30 & $24,2 \%$ & $18,2 \%$ & $30,3 \%$ & $27,3 \%$ & 33 \\
\hline 31 & $27,1 \%$ & $16,7 \%$ & $33,3 \%$ & $22,9 \%$ & 48 \\
\hline 32 & $23,1 \%$ & $34,6 \%$ & $23,1 \%$ & $19,2 \%$ & 26 \\
\hline 33 & $19,8 \%$ & $26,7 \%$ & $30,7 \%$ & $22,8 \%$ & 101 \\
\hline 34 & $26,7 \%$ & $13,3 \%$ & $20,0 \%$ & $40,0 \%$ & 15 \\
\hline 35 & $45,5 \%$ & $13,6 \%$ & $31,8 \%$ & $9,1 \%$ & 22 \\
\hline 36 & $40,5 \%$ & $21,6 \%$ & $29,7 \%$ & $8,1 \%$ & 37 \\
\hline 37 & $9,4 \%$ & $43,8 \%$ & $25,0 \%$ & $21,9 \%$ & 32 \\
\hline 38 & $29,4 \%$ & $23,5 \%$ & $26,5 \%$ & $20,6 \%$ & 34 \\
\hline 39 & $23,5 \%$ & $29,4 \%$ & $23,5 \%$ & $23,5 \%$ & 17 \\
\hline 40 & $25,0 \%$ & $18,8 \%$ & $20,8 \%$ & $35,4 \%$ & 48 \\
\hline 41 & $21,4 \%$ & $17,9 \%$ & $28,6 \%$ & $32,1 \%$ & 28 \\
\hline 42 & $22,4 \%$ & $29,3 \%$ & $26,7 \%$ & $21,6 \%$ & 116 \\
\hline 43 & $15,8 \%$ & $31,6 \%$ & $42,1 \%$ & $10,5 \%$ & 19 \\
\hline 44 & $29,4 \%$ & $29,4 \%$ & $5,9 \%$ & $35,3 \%$ & 17 \\
\hline 45 & $34,6 \%$ & $34,6 \%$ & $26,9 \%$ & $3,8 \%$ & 26 \\
\hline 46 & $22,9 \%$ & $34,3 \%$ & $25,7 \%$ & $17,1 \%$ & 35 \\
\hline 47 & $34.8 \%$ & $30,4 \%$ & $21,7 \%$ & $13,0 \%$ & 23 \\
\hline 48 & $19,0 \%$ & $42,9 \%$ & $19,0 \%$ & $19,0 \%$ & 21 \\
\hline 49 & $20,7 \%$ & $31,0 \%$ & $27,6 \%$ & $20,7 \%$ & 29 \\
\hline 50 & $18.5 \%$ & $22,2 \%$ & $22,2 \%$ & $37,0 \%$ & 27 \\
\hline 51 & $25,9 \%$ & $24,1 \%$ & $24,1 \%$ & $25,9 \%$ & 58 \\
\hline 52 & $23,5 \%$ & $29,4 \%$ & $29,4 \%$ & $17,6 \%$ & 17 \\
\hline 53 & $13,3 \%$ & $20,0 \%$ & $33,3 \%$ & $33,3 \%$ & 15 \\
\hline 54 & $33,3 \%$ & $37,0 \%$ & $18,5 \%$ & $11,1 \%$ & 27 \\
\hline 55 & $27,3 \%$ & $40,9 \%$ & $0,0 \%$ & $31,8 \%$ & 22 \\
\hline 56 & $8,3 \%$ & $33,3 \%$ & $25,0 \%$ & $33,3 \%$ & 24 \\
\hline 57 & $34,7 \%$ & $20,4 \%$ & $24,5 \%$ & $20,4 \%$ & 49 \\
\hline 58 & $25,0 \%$ & $20,8 \%$ & $37,5 \%$ & $16,7 \%$ & 24 \\
\hline 59 & $16,0 \%$ & $24,0 \%$ & $36,0 \%$ & $24,0 \%$ & 25 \\
\hline 60 & $52,9 \%$ & $29,4 \%$ & $0,0 \%$ & $17,6 \%$ & 17 \\
\hline 61 & $11,1 \%$ & $38,9 \%$ & $16,7 \%$ & $33,3 \%$ & 18 \\
\hline Total & $24,4 \%$ & $25,4 \%$ & $25,4 \%$ & $24,9 \%$ & 2102 \\
\hline
\end{tabular}




\section{REFERÊNCIAS BIBLIOGRÁFICAS}

AGUAYO, M.T.V. Análise de correspondência e modelos log-lineares: um enfoque integrado para a análise exploratória de dados categóricos. Campinas, 1993. 147p. Dissertação de Mestrado - Instituto de Matemática, Estatística e Ciência da Computação - Universidade de Campinas.

BARIONI JUNIOR, W. Análise de Correspondência na Identificação dos Fatores de Risco Associados à Diarréia e à Performance de Leitões na Fase de Lactação. Piracicaba, 1995. 97p. Dissertação de Mestrado - Escola Superior de Agricultura "Luiz de Queiroz", Universidade de São Paulo.

BASILE, J.R.; RIBAS, N.P.; KOEHLER, H.S.; TAHIRA, J.K. Efeitos do Meio Ambiente na Duração do Período de Gestação e do Intervalo entre Partos de um Rebanho de Gado Holandês (Malhado de Preto e Malhado de Vermelho) Criado no Estado do Paraná. Revista Brasileira de Reprodução Animal, v.13, n.1, p.33-52, 1989.

CARDOSO, V.L.; FREITAS, M.A.R.; LOBO, R.B.; FILHO, E.B. O. Intervalo entre partos de vacas da raça Holandesa criadas no Estado de São Paulo. Boletim da Indústria Animal, v.44, n.1, p.49-57, 1987.

COSTA, C.N.; MILAGRES, J.C.; GARCIA, J.A.; CASTRO, A.C.G. Fatores Genético e de Meio na Eficiência Reprodutiva de um Rebanho Holandês. Revista da Sociedade Brasileira de Zootecnia, v.11, n.1, p.86-102, 1982. 
CRIVISQUI, E.M. Analisis Factorial de Correspondencias un Instrumento de Investigacion en Ciencias Sociales. Asunción - Paraguai: Centro de Publicaciones Universidad Católica "Nuestra Señora de la Asunción, 1993. 302p.

FREITAS, A.F.; MADALENA, F.E.; MARTINEZ, M.L. Idade ao primeiro parto e intervalo entre partos de vacas HPB e mestiças HPB:Gir. Pesquisa Agropecuária Brasileira, Brasília, v.15, n.1, p.101-105, 1980.

GREENACRE, M.J. Theory and applications of correspondence analysis. New York: Academic Press, 1984. 364p.

GREENACRE, M.J. Correspondence analysis in pratice. London: Academic Press, 1993. 193p.

GREENACRE, M.J. \& HASTIE, T. The geometric interpretation of correspondence analysis. Journal of de American Statistical Association, v.82, p.437-447, 1987.

HARVEY, W.R. Least-squares analysis of data with unequal subclass numbers. Ohio State University, 1975. 157p.

KRZANOWSKI, W.J. Attribute Selection in Correspondence Analysis of Incidence Matrices. Applied Statistics, v.42, n.3, p.529-541, 1993.

MADALENA, F.E.; VALENTE, J.; TEODORO, R.L.; MONTEIRO, J.B.N. Produção de leite e intervalo entre partos de vacas HPB e mestiças HPB:Gir num alto nível de manejo. Pesquisa Agropecuária Brasileira, v.18, n.2, p.195-200, 1983.

MANDEL, J. Use of the singular value decomposition in regression analysis. The American Statistician, v.36, n.1, p.15-23, 1982.

MCGOWAN, M.R.; VEERKAMP, R.F.; ANDERSON, L. Effects of genotype and feedings system on the reproductive performance of dairy cattle. Livestock Prodution Science, v.46, p.33-40, 1996. 
MEJ́A, N.A.; MILAGRES, J.C.; SILVA, M.A.; CASTRO, A.C.G. Efeitos de fatores genéticos e de meio sobre o intervalo entre partos de bovinos das raças Suíça Parda e Holandesa, na República de Honduras, América Central. Revista da Sociedade Brasileira de Zootecnia, v.11, n.2, p.307-319, 1982.

MILAGRES, J.C.; ALVES, A.J.R.; PEREIRA, J.C.; TEIXEIRA, N.M. Influência de fatores genéticos e de meio sobre a produção de leite de vacas mestiças das raças Holandesa, schwys, jersey e zebu. III - Intervalo entre partos. Revista da Sociedade Brasileira de Zootecnia, v.17, n.4, p.358-366, 1988.

NOBRE, P.R.C.; MILAGRES, J.C.; LUDWIG, A.; FONSECA, F.A. Fatores genéticos e de meio no intervalo de partos e na idade ao primeiro parto no rebanho leiteiro da Universidade Federal de Viçosa, Estado de Minas Gerais. Revista da Sociedade Brasileira de Zootecnia, v.13, n.3, p.347-359, 1984.

PIMPÃO, C.T.; RIBAS, N.P.; MONARDES, H.G.; ALMEIDA, R.; GIACOMAZZI, M.V. Estudo do intervalo entre partos e do período de serviço em rebanhos Holandeses da Bacia Leiteira de Arapoti, Estado do Paraná. Revista do Setor de Ciências Agrárias, v.14, n.1-2, p.63-69, 1995.

POLASTRE, R.; MILAGRES, J.C.; FILHO, J.L.; RAMOS, A.A. Fatores genéticos e de ambiente do desempenho de vacas mestiças Holandês-Zebu. II - Intervalo de partos. Revista da Sociedade Brasileira de Zootecnia, v.16, n.3, p.233-240, 1987.

QUEIROZ, S.A.; GIANNONI, M.A.; RAMOS, A.A. Efeito genéticos e de meio ambiente sobre a duração do intervalo de partos de bovinos mestiços holandês na região de São Carlos, Estado de São Paulo. Revista da Sociedade Brasileira de Zootecnia, v.15, n.6, p.468-474, 1986. 
RAMOS, A.A. Avaliação dos fatores genéticos e de ambiente sobre o intervalo entre partos de zebuínos leiteiros da raça Gir. Revista Brasileira de Reprodução Animal, v.10, n.4, p.221-234, 1986.

RIBAS, N.P.; KOEHLER, H.S.; RONGONI, E.G.; BASILE, J.R.; BAJALUK, S.A.B.; BATISTA, R.L.F. Fatores de meio que interferem na idade ao primeiro parto e no intervalo entre partos das vacas da raça Holandesa importadas do Canadá. Revista Brasileira de Reprodução Animal, v.12, n.4, p.181-189, 1988.

RIBAS, N.P.; MILAGRES, J.C.; SILVA, M.A.; CASTRO, A.C.G. Estudo de idade ao primeiro parto e intervalo entre partos em rebanhos Holandeses da bacia leiteira de Castrolanda, Estado do Paraná. Revista da Sociedade Brasileira de Zootecnia, v.12, n.4, p.756-770, 1983.

RIBAS, N.P.; MONARDES, H.G.; RICHTER, G.O.; HORST, J.A. Estudo do período de serviço e intervalo entre partos em vacas da raça holandesa, na região de Witmarsum, Paraná. Revista do Setor de Ciências Agrárias, v.15, n.1, p.109-116, 1996.

SLAMA, H.; WELLS, M.E.; ADAMS, G.D.; MORRISON, R.D. Factors Affecting Calving Interval in Dairy Herds. Journal of Dairy Science, v.59, n.7, p.1334-1339, 1976.

SOUZA, E.M. de; MILAGRES, J.C.; REGAZZI, A.J.; CASTRO, A.C.G.; MARTINEZ, M.L. Efeitos de fatores genéticos e de meio ambiente sobre o intervalo de partos em rebanhos Gir leiteiro. Revista da Sociedade Brasileira de Zootecnia, v.24, n.1, p.138-149, 1995. 
TEIXEIRA, N.M.; FREITAS, A.F.; RIBAS, N.P.; VALENTE, J. Tendências genéticas em rebanhos da raça Holandesa no Estado do Paraná II. Idade ao primeiro parto e primeiro intervalo de partos. Revista da Sociedade Brasileira de Zootecnia, v.23, n.6, p.992-1001, 1994.

VIANA, H.A.; GIRÃO, L.C.F.; NEIVA, R.S. Influência de alguns fatores de meio no intervalo entre partos de um rebanho da raça Gir, na região sudeste do Estado de Goiás. Ciência e Prática, v.4, n.1, p.21-30, 1980. 